INSTITUTO DE PESQUISAS ENERGÉTICAS E NUCLEARES

Autarquia Associada à Universidade de São Paulo

DESENVOLVIMENTO DE SISTEMA COMPUTACIONAL PARA PLANEJAMENTO E CONTROLE DA MANUTENÇÃO DO REATOR IEA-R1

MAURO ONOFRE MARTINS

Dissertação apresentada como parte dos requisitos para obtenção do grau de Mestre em Ciências na Área de Tecnologia Nuclear Aplicações.

Orientador:

Prof. Dr. Tufic Madi Filho

SÃO PAULO

2015 


\section{AGRADECIMENTOS}

Ao Instituto de Pesquisas Energéticas e Nucleares, que permitiu o desenvolvimento deste trabalho.

Ao Professor Dr. Tufic Madi Filho pela orientação, sugestões, paciência e apoio no desenvolvimento deste trabalho.

A Divisão de Desenvolvimento de Sistemas, através de seus analistas, pelo apoio durante a codificação e implantação do sistema.

As colegas do Grupo da Gestão da Qualidade pelo apoio e sugestões relativa aos requisitos regulamentares durante o desenvolvimento do trabalho.

Aos colegas do Grupo de Manutenção do Reator IEA-R1 pelo apoio e valiosas sugestões durante a elaboração dos planos de manutenção, validação e aplicação do sistema.

Aos colegas do grupo de Operação do Reator IEA-R1, pelo apoio durante a validação e aplicação do sistema.

A todos aqueles que contribuíram, direta e indiretamente, para a realização deste trabalho. 


\title{
DESENVOLVIMENTO DE SISTEMA COMPUTACIONAL PARA PLANEJAMENTO E CONTROLE DA MANUTENÇÃO DO REATOR IEA-R1
}

\author{
Mauro Onofre Martins
}

\section{RESUMO}

A manutenção é uma atividade essencial em reatores nucleares. Os componentes de sistemas de segurança de uma instalação industrial devem ter uma baixa probabilidade de falha, especialmente se houver um elevado risco de acidentes que podem causar danos ambientais. Em instalações nucleares, a presença de sistemas de segurança são uma especificação técnica e uma exigência para a sua licença de funcionamento. De forma a gerenciar todo o fluxo de informações provenientes das manutenções do Reator IEA-R1 foi desenvolvido um sistema computacional, que além de planejar e controlar toda a manutenção mantém atualizados documentos e registros para salvaguardar a qualidade e garantir a segurança na operação do Reator IEA-R1. O sistema computacional possui níveis de acesso e apresenta relatórios detalhados de todas as manutenções previstas e executadas, e também um histórico individual de cada equipamento durante sua vida útil na instalação. $O$ trabalho apresenta todas as etapas de desenvolvimento do sistema, sua descrição, compatibilidades, aplicação, vantagens e resultados obtidos experimentalmente. 


\title{
DEVELOPMENT OF A COMPUTATIONAL PROGRAM TO PLANNING AND CONTROL OF THE IEA-R1 REACTOR MAINTENANCE
}

\section{Mauro Onofre Martins}

\begin{abstract}
Maintenance is an essential activity in nuclear reactors. The safety systems components of an industrial plant should have a low failure probability, especially in case of high risk of accidents with potential for environment damage. In nuclear facilities, the security systems are a technical specification and a requirement for license operation. In order to manage the IEA-R1 maintenance information flow, a computational program (software) was developed, to plan and control all the maintenance, update the documents and records to quality safeguard and ensure the safe reactor operation. The software has access levels and share detailed maintenance planned and implemented reports, and equipment reports, during its facility lifetime. This work presents all the stages of the software development, description, compatibilities, application, advantages and experimental results.
\end{abstract}




\section{SUMÁRIO}

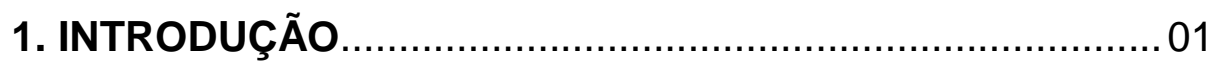

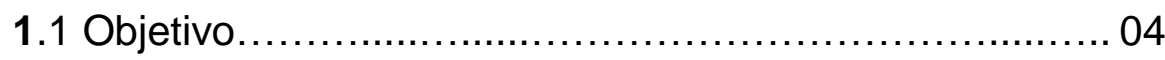

2. DESCRIÇÃO

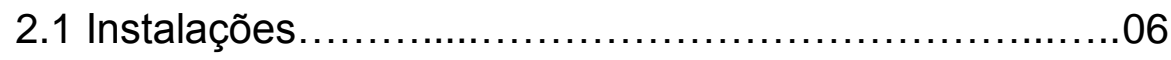

2.2 Dispositivos de irradiação.........................................

2.2.1 Instalado na placa matriz.............................. 08

2.2.2 Sistema pneumático de irradiação....................... 10

2.2.3 Tubos de irradiação horizontal........................... 11

2.3 Atividades do Reator

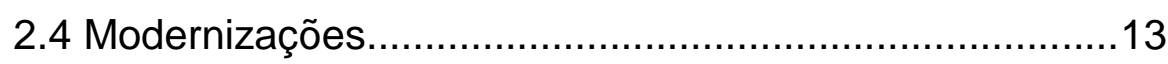

2.5 Organização funcional........................................ 14

2.5.1 Atividades de responsabilidade do grupo de

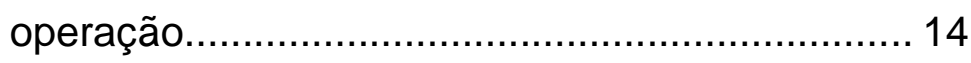

2.5.2 Atividades de responsabilidade do grupo de manutenção......................................................... 15

3. METODOLOGIA

3.1 Sistema operacional................................................... 17

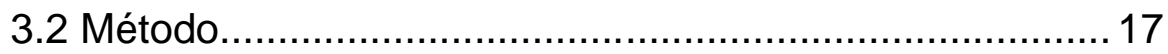

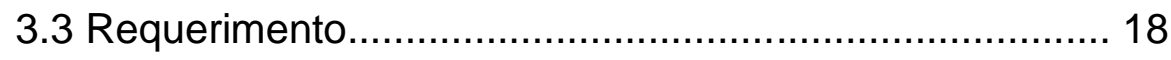

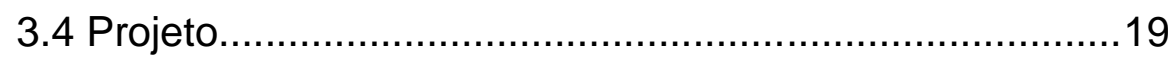

3.4.1 Entradas e saídas......................................... 19

3.4.2 Operacionalidade do sistema.............................19

3.4.3 Navegação...................................................... 19

3.4.4 Segurança do sistema.......................................20

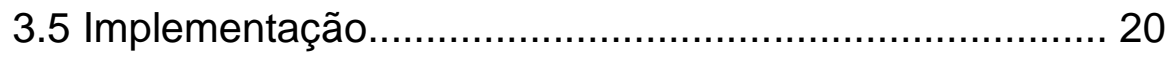

3.5.1 Identificação dos equipamentos.........................20

3.5.2 Cadastro........................................................ 22

3.5.2.1 Equipamentos...................................22

3.5.2.2 Pessoal e usuários.............................. 22 
3.5.2.3 Tarefas de manutenção 23

3.5.2.4 Formulários ........................................23

3.5.2.5 Critérios................................................ 23

3.5.2.6 Tipos de sistemas................................24

3.5.3 Manutenção preventiva e corretiva..................... 24

3.5.3.1 Classificação dos equipamentos.......... 24

3.5.3.2 Instruções de manutenção.................... 26

3.5.3.3 Plano de manutenção preventiva......... 26

3.5.3.4 Registro de manutenção preventiva.....26

3.5.4.5 Registro de manutenção corretiva........28

3.5.4 Calibração dos medidores...................................30

3.5.5 Histórico de manutenção e calibração................ 32

3.5.6 Relatórios....................................................... 32

3.6 Verificação (dos módulos do sistema)...............................33

3.6.1 Validação da manutenção preventiva.................. 34

3.6.2 Validação da manutenção corretiva..................... 35

3.6.3 Validação da calibração..................................... 37

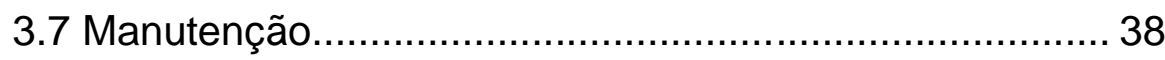

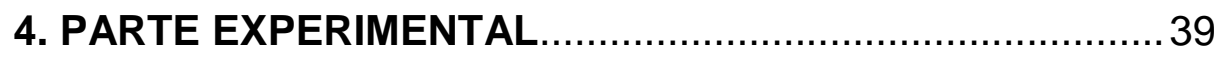

5. RESULTADOS

5.1 Módulo de manutenção preventiva.....................................4

5.1.1 Cadastro....................................................... 42

5.1.2 Atualização................................................... 48

5.1.2.1 Programação da manutenção preventiva........................................... 50

5.1.2.2 Gerar registro de manutenção...............50

5.1.2.3 Acompanhamentos do registro.............51

5.1.2.4 Histórico de equipamento......................54

5.1.2.5 Lista de planos .....................................54

5.1.2.6 Lista de equipamentos.........................54

5.2 Módulo de manutenção corretiva......................................60

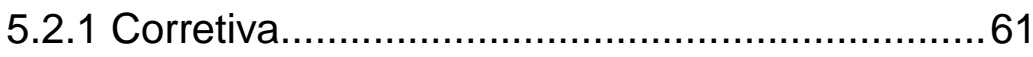




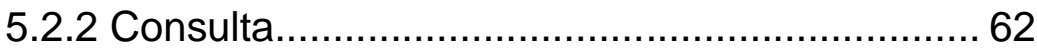

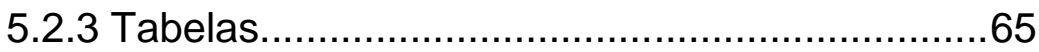

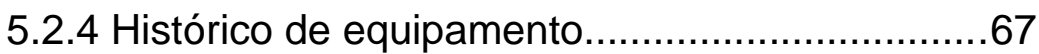

5.3 Módulo de calibração......................................................

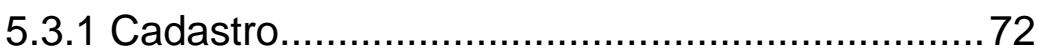

5.3.1.1 Atualização do plano........................... 72

5.3.1.2 Cadastro de medidor............................ 74

5.3.1.3 Histórico................................................ 74

5.3.2 Consulta......................................................... 76

5.4 Indicadores e índices de manutenção.............................. 79

5.4.1 Indicadores..................................................... 79

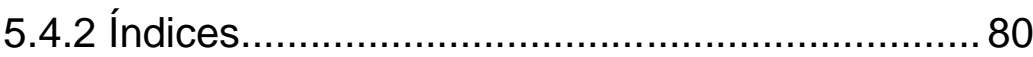

5.4.3 Relatórios gerenciais......................................... 83

5.4.3.1 Produção e disponibilidade....................83

5.4.3.2 Grupo de manutenção.......................... 84

5.4.3.3 Relatório mensal de aitividades............88

5.4.4 Resultados operacionais.................................... 91

5.4.4.1 Manutenção preventiva........................ 91

5.4.4.2 Manutenção corretiva............................ 91

5.4.4.3 Calibração...........................................92

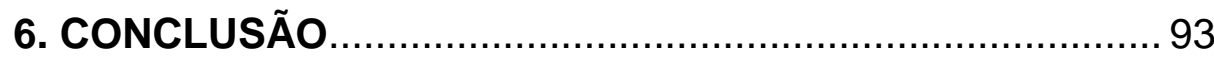

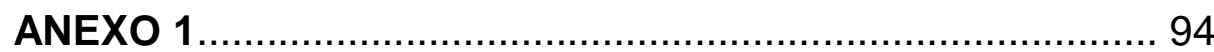

Tabela 1- Código e descrição dos sistemas............................94

Tabela 2 - Código e tipo de equipamento e medidores........ 95

REFERÊNCIAS BIBLIOGRÁFICAS....................................... 100 


\section{DEFINIÇÕES E ABREVIATURAS}

Neste trabalho são usadas as abreviaturas e definições seguintes:

5W1H: Ferramenta da Qualidade Total, onde os 5W significam "why" (porque), "where" (onde), "who" (quem), "what" (o que), "when" (quando) e o H significa "how" (como).

ABNT NBR ISO 9001:2008: Sistemas de Gestão da Qualidade.

ABNT: Associação Brasileira de Normas Técnicas.

ASP/SQL: Active Server Page/Structure Query Language.

CCM: Centro de Comando de Motores.

CNEN NN-1.04: Licenciamento de Instalações Nucleares.

CNEN NN-1.16: Garantia da Qualidade para Usinas Nucleares.

CNEN NN-1.21: Manutenção de Usinas Nucleoelétricas.

CNEN: Comissão Nacional de Energia Nuclear.

CP: Circuito Primário de Refrigeração.

CRO: Grupo de Gerência Adjunta para Operação e Manutenção do Reator IEA-R1.

CRPq: Centro do Reator de Pesquisas.

CTI: Computer Telefhony Integration.

Delphi: Linguagem de pesquisa declarativa para bancos de dados relacionais.

EC: Elemento Combustível.

EIBE: Elemento de Irradiação com Berílio.

EIBRA: Elemento de Irradiação com Berílio Refrigerado a Água.

EIRA: Elemento de Irradiação Refrigerado a Água.

FM: Formulário

FM-CRPq-1101-03: Entrada e Saída de Equipamentos.

FM-CRPq-1101-06: Registro de Manutenção Preventiva.

FM-CRPq-1101-07: Registro de Manutenção Corretiva.

GM: Grupo de Manutenção.

GO: Grupo de Operação.

GUI: Interface Gráfica com Usuário

HHE: Hora Homem Executado.

HHP: Hora Homem Previsto. 
IAEA: Agência Internacional de Energia Atômica.

IEA-R1: Instituto de Energia Atômica - Reator 1.

INMETRO: Instituto Nacional de Metrologia.

IPEN: Instituto de Pesquisas Energéticas e Nucleares.

IPT: Instituto de Pesquisas Tecnológicas.

ISO: Organização Internacional de Normalização.

Log-Book: Livro de Ocorrências.

Object Pascal: Linguagem de programação orientada a objetos.

Pascal: Linguagem de programação.

PCM: Planejamento e Controle de Manutenção.

PCMN: Plano de Controle de Material Nuclear.

PG: Procedimento Gerencial.

PG-CRPq-0101-05: Organização do Centro do Reator de Pesquisas.

PG-CRPq-1101-06: Controle de Equipamento.

PGQ: Programa da Garantia da Qualidade

QT: qualidade Total.

RAS: Relatório de Análise de Segurança.

RBC: Rede Brasileira de Calibração.

RM: Registro de Manutenção.

RMC: Registro de Manutenção Corretiva.

RMP: Registro de Manutenção Preventiva.

RP: Proteção Radiológica.

SGQ: Sistema de Gestão da Qualidade.

Skype: Linguagem de relacionamento social na web.

TAG: Etiqueta de identificação de equipamento.

TecEspec: Especificações Técnicas.

USP: Universidade de São Paulo

VIM: Vocabulário Internacional de Metrologia.

Web: Sistemas de documentos em hipermídia, que são executados na internet.

Windows: Ambiente de programação. 


\section{1. - INTRODUÇÃO}

A manutenção é uma atividade essencial em reatores nucleares, assim sendo vários autores $[1,23]$ propõem o estudo de um modelo conceitual de tarefas de manutenção para facilitar a identificação das causas dos erros humanos na realização de tais tarefas.

Os componentes dos sistemas de segurança de uma planta industrial devem ter uma baixa probabilidade de falha, especialmente, se houver um elevado risco de acidentes que podem causar danos ambientais. Em instalações nucleares, a presença de sistemas de segurança robustos aparece não só na especificação técnica, como também é uma exigência dos órgãos reguladores: IAEA e CNEN, para a obtenção da licença de operação e funcionamento [2]. A operação e a manutenção de plantas nucleares, como toda planta industrial, possuem particularidades técnicas que com o passar do tempo, podem apresentar uma série de falhas em seus componentes e para minimizá-las deve ser aplicado um programa de manutenção preventiva e preditiva.

A manutenção é uma tarefa que deve ser executada em todas as atividades, especialmente aquelas de ativos fixos (bens e direitos adquiridos pela instalação que são de caráter permanentes, duram um longo período e são utilizados em processos normais da instalação, como: equipamentos, medidores de processo, construções) sejam eles industriais ou não. A manutenção exige organização, planejamento, programação, alocação de recursos, treinamento e controle de qualidade [3].

Essas tarefas podem ser executadas de diversas maneiras, mas é sempre necessário que existam preparações e métodos para uma harmonia entre a execução, a expectativa do cliente e a minimização de custos.

Os melhores resultados, normalmente são obtidos com o uso de programas computacionais dedicados à manutenção [4]. Para a execução do $P C M$ é necessário que existam pessoas treinadas para esta tarefa. Se o PCM for manual, a pessoa deverá estar treinada para preencher os formulários em uso, arquivá-los de forma adequada e lidar com a documentação necessária para apuração de dados e de resultados. Isto pode ser otimizado usando um programa computacional que faça de forma simples as tarefas rotineiras e 
trabalhosas para processar a informação e, arquivá-las sempre da mesma forma, permitindo um acesso fácil e rápido da informação. Para isto torna-se necessário um programa computacional desenvolvido de forma específica para atender às finalidades de planejamento e controle das tarefas e rotinas de manutenção.

O PCM deve abranger todas as medidas administrativas e técnicas necessárias para a realização de atividades de manutenção, incluindo vistoria, reparo e substituição das peças, e quando apropriado, testes, calibração e inspeção, além de modificações em estruturas, sistemas e componentes [5].

As vantagens de um sistema informatizado são muitas, tais como:

- Facilidade e rapidez no acesso a informações: as informações são devidamente registradas e estarão disponíveis imediatamente, quer esteja o sistema ligado em rede quer esteja em um computador isolado. Qualquer usuário pode acessar a informação, desde que tenha a permissão para acessar o sistema;

- Redução do trabalho de planejamento: com o sistema, os registros de manutenções são emitidos diretamente, pelo computador, evitando que a equipe de manutenção tenha que preocupar-se com esta tarefa;

- Rapidez na emissão de relatórios: é de grande importância para qualquer nível gerencial, dispor de informações rápidas para corrigir possíveis desvios.

- Facilidade e rapidez em monitorar desempenho: informações como HHP e HHE, quantidades de intervenções de emergência e tempos despendidos, quantidades de RM programadas e não realizadas e seus motivos, são obtidos de imediato.

- Histórico de equipamentos: permite o levantamento de históricos de equipamentos de uma maneira predeterminada, rápida e segura;

- Análise de frequências de ocorrências de cada equipamento: com o histórico do equipamento pode-se realizar uma análise das ocorrências de cada equipamento, ou da mesma ocorrência em vários equipamentos;

- Análise de distribuição dos tipos de manutenção: com o banco de dados bem projetado, pode-se saber quais manutenções foram executadas e que tipo de tarefas cumpridas. 
Planejamento e Controle de Manutenção são requisitos básicos para licenciamento de uma instalação nuclear como indica a Norma CNEN NN 1.04, que estabelece o processo de "Licenciamento de Instalações Nucleares" aplicadas às atividades relacionadas com a localização, a construção e a operação de tais instalações. No Item 8.1.3 "O requerimento de autorização para operação permanente deve incluir um programa da garantia da qualidade do requerente para a fase de operação em caráter permanente" [6]. "A autorização para operação permanente será concedida após a comprovação de que a instalação possui o programa da garantia da qualidade e após o cumprimento, pelo requerente, das condições pertinentes exigidas na norma CNEN NN - 1.16" [7]. Essa norma determina os requisitos a serem adotados no estabelecimento e implementação do $P G Q$ para usinas nucleoelétricas, instalações nucleares e, conforme aplicável, para instalações radiativas. Determina também a forma segundo a qual os $P G Q$ devem ser preparados e submetidos à $C N E N$. Aplicase nas atividades que influem na qualidade de itens importantes à segurança, no gerenciamento do empreendimento e em cada um dos seus diversos estágios: escolha do local, projeto, construção, comissionamento, operação e descomissionamento, como descrito no item 4.9.1.1 [7] "Deve ser estabelecido e executado um programa de itens importantes à segurança e de atividades que influem na qualidade, pela ou para a organização responsável pela atividade a fim de verificar a conformidade com normas ou documentos" e no item 4.9.3.1[7] "Devem ser estabelecidas medidas para assegurar que as ferramentas, instrumentos e outros equipamentos e aparelhos de inspeção, medição e testes, usados para determinar as conformidades com os critérios de aceitação, tenham exatidão e precisão adequados" [7].

Para a comprovação dos itens da norma CNEN NN - 1.16, o PCM, quando aplicável, segue os procedimentos estabelecidos na norma CNEN NN - 1.21 [8]. Essa norma determina os requisitos administrativos e organizacionais aplicáveis ao estabelecimento e implementação de um PCM de usinas núcleoelétricas, instalações nucleares e, conforme aplicável, para instalações radiativas, sem especificar os detalhes técnicos dessa manutenção. Especifica a responsabilidade da Organização Operadora pelo estabelecimento e implementação de um programa de manutenção preventiva ou corretiva para manter o desempenho previsto no projeto durante a vida útil da instalação bem como pela organização, aquisição, recebimento e armazenagens de materiais, 
itens e componentes sobressalentes. Estabelece ainda os controles da estrutura organizacional e as responsabilidades, os critérios de seleção, treinamento do pessoal de manutenção bem como os controles administrativos, fornecendo um escopo dos procedimentos administrativos e técnicos dessa manutenção. Especifica também como devem ser as instalações onde serão realizadas as manutenções e os procedimentos para as substituições e reparos de itens defeituosos a serem realizados, como descrito no item 4.1.1 [8] "O PCM deve abranger todas as medidas administrativas e técnicas necessárias à realização de atividades de manutenção, incluindo vistoria, reparo e substituição de peças e, quando apropriado, testes, ensaios não destrutivos, calibração e inspeção, além de modificações em estruturas, sistemas e componentes" e do item 6.1.2 [8] "Os controles administrativos devem ser efetuados através de procedimentos, os quais incluirão requisitos administrativos necessários para a realização da manutenção" [8].

\section{1 - Objetivo}

O objetivo desse trabalho foi desenvolver e instalar um Sistema Computacional para Planejamento e Controle da Manutenção do Reator IEAR1. O sistema computacional além de planejar e controlar a manutenção deveria manter atualizados os documentos e registros para salvaguardar a qualidade e garantir a segurança da operação do Reator IEA-R1. 


\section{2. - DESCRIÇÃO}

O sistema computacional de que se trata este trabalho para Planejamento e Controle da Manutenção deverá ser instalado no Reator de pesquisa IEA-R1 do IPEN-CNEN/SP. Também está previsto o armazenamento dos históricos destes componentes. O sistema deverá processar as informações de modo a disponibilizar ao usuário relatórios diversos [10].

O Reator nuclear de pesquisas IEA-R1 do IPEN-CNEN/SP está localizado no campus da USP Figura 1. O Reator é do tipo piscina, foi projetado pela empresa "Babcok \& Wilcox Company", tendo atingido sua primeira criticalidade em 16 de setembro de 1957 [21].

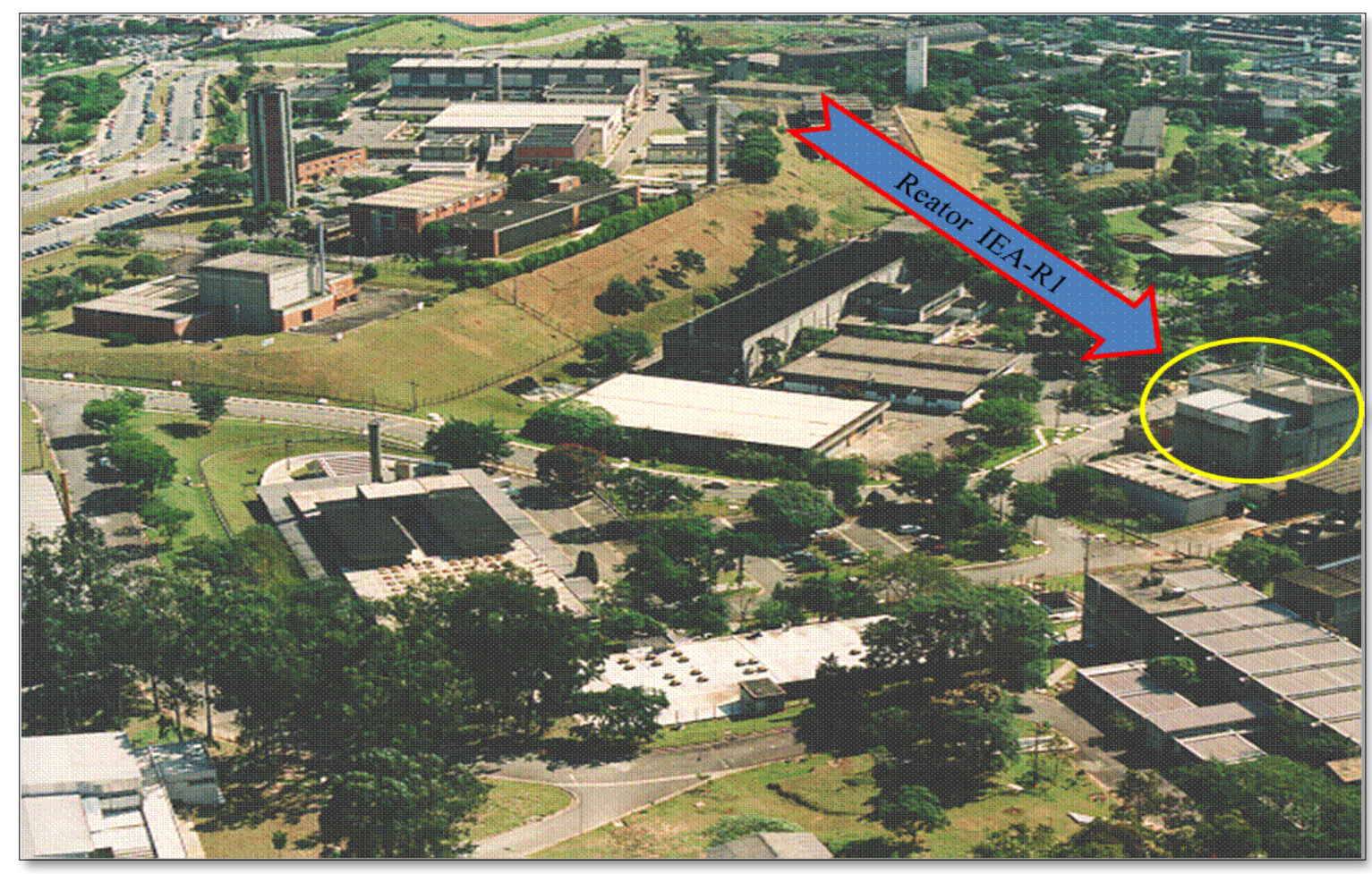

Figura 1 - Foto da localização do prédio do Reator no IPEN.

As finalidades do Reator são: produção de radioisótopos para aplicações na medicina, indústria, agricultura e para pesquisas, servindo como uma fonte intensa de nêutrons em experimentos científicos de física nuclear, química, engenharia e biologia, treinamento do corpo científico do IPENCNEN/SP em física de reatores, projetos, desenvolvimento de instrumentação nuclear e segurança de reatores, treinamento e formação de operadores e supervisores de Reator e análise radioquímica de amostras através do método de análise por ativação. 
Durante os três primeiros anos de operação, a potência do Reator foi de até 1 MW. De 1960 a 1995, o regime de operação do Reator foi de 40h semanais a uma potência de 2 MW. A partir de 1995, o Reator teve seu regime de operação modificado para $64 \mathrm{~h}$ ininterruptas visando a produção de ${ }^{153} \mathrm{Sm}$ e o atendimento ao corpo científico do IPEN-CNEN/SP.

Com a crescente demanda e o surgimento de novas aplicações de radioisótopos para o uso em medicina, tais como ${ }^{153} \mathrm{Sm},{ }^{125} \mathrm{I}$ e o ${ }^{99} \mathrm{Mo}$, foi necessária a alteração do regime de operação e o aumento da potência para 5 MW. Visando este novo ritmo de trabalho e adequação da instalação para este aumento de potência, foi iniciado um projeto de modernização contínua do Reator. Como um dos resultados desse esforço, o Reator passou a ser o único Reator com certificação ABNT NBR ISO 9001:2008 [10], sendo submetido a inspeções rotineiras da própria CNEN, AIEA e ABNT.

A Figura 2 apresenta a foto do núcleo do Reator IEA-R1 quando em operação.

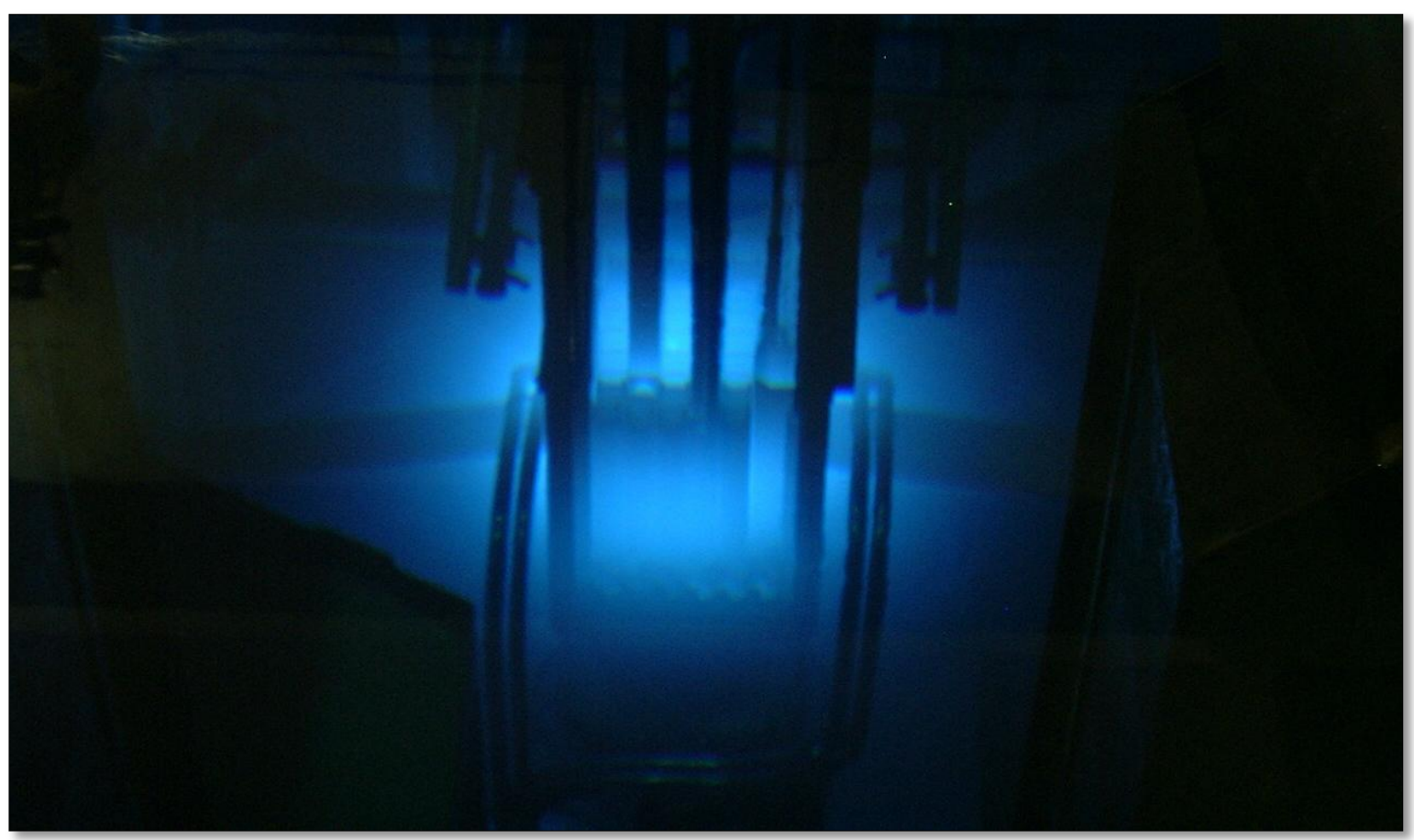

Figura 2 - Foto do núcleo do Reator em operação.

\section{1 - Instalações}

O prédio do Reator possui 5 pavimentos:

- Subsolo: encontra-se a casa de máquinas que acomoda os sistemas de resfriamento e retratamento de água da piscina; 
- Primeiro pavimento: encontram-se os tubos de irradiação horizontais, canais que disponibilizam os feixes de nêutrons para os experimentos de física nuclear, física da matéria condensada e aplicações comerciais de neutrongrafia;

- Segundo pavimento: acomoda a casa de máquinas do sistema de ventilação e ar condicionado, almoxarifados e sala de apoio da proteção radiológica;

- Terceiro pavimento: encontram-se a sala de controle, o saguão da piscina e a oficina mecânica. No interior da piscina localiza-se a placa matriz que acomoda os elementos combustíveis, elementos combustíveis de controle, refletores, dispositivos para irradiação de amostras e os canais para medição da potência do Reator;

- Quarto pavimento: localiza-se o sistema de exaustão normal e de emergência do prédio do Reator. A Figura 3 apresenta um corte lateral do prédio do Reator.

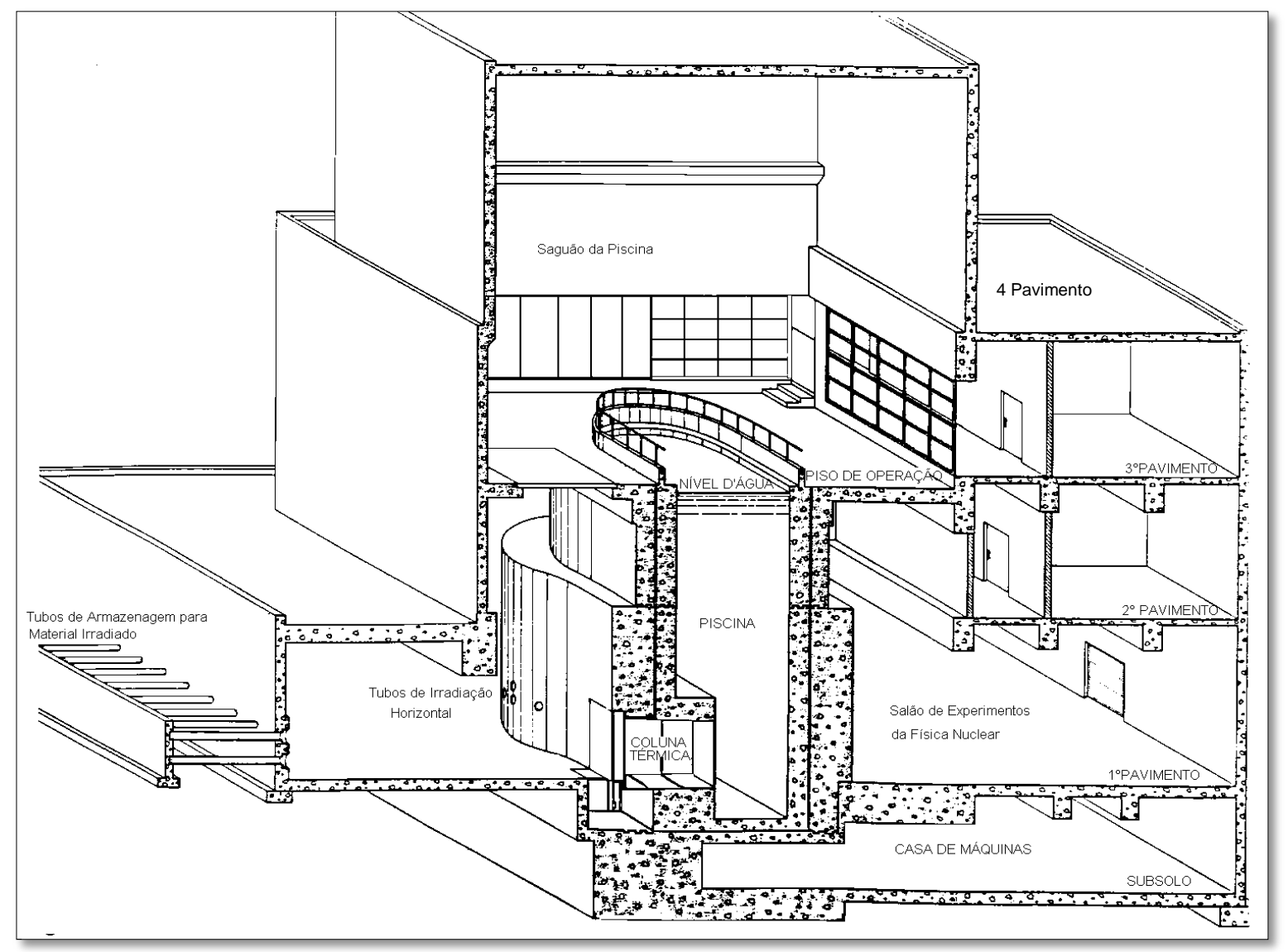

Figura 3 - Corte lateral do Reator com os pavimentos. 
O IEA-R1 é um Reator de pesquisa imerso em uma piscina contendo $273 \mathrm{~m}^{3}$ de água deionizada. A piscina possui 9 metros de profundidade por 3 metros de largura e 10 metros de comprimento.

A piscina está divida em dois compartimentos, o da esquerda, utilizado para operação do Reator e o da direita, utilizado para o armazenamento do combustível queimado e manuseio de amostras.

O núcleo do Reator está situado a 7 metros da superfície da piscina, tem a forma de um paralelepípedo composto por 20 elementos combustíveis padrões, 4 elementos combustíveis de controle, 25 elementos refletores de grafite e berílio, 7 posições para irradiação de amostras e tampões encaixados verticalmente em uma placa matriz de alumínio. Esta placa é sustentada por uma treliça conectada a uma plataforma móvel que permite o seu deslocamento ao longo da piscina.

O Reator IEA-R1 possui um núcleo aberto que permite:

- Flexibilidade para colocação e retirada de amostras mesmo com o Reator em operação;

- Colocação de dispositivos especiais;

- Montagem de experimentos;

- Obtenção de parâmetros operacionais.

\section{2. - Dispositivos de irradiação.}

O Reator dispõe ainda de vários dispositivos que permitem realizar irradiação da ordem de segundos até dias, que são os seguintes : instalado na placa matriz, sistema pneumático de irradiação e tubos de irradiação horizontal.

\subsection{1 - Instalado na placa matriz.}

Cápsulas de alumínio contendo as amostras de material a ser irradiado são colocadas em dispositivos padrões ou especiais para irradiações com durações acima de 1 hora.

No Reator IEA-R1 tem-se os seguintes dispositivos de irradiação:

- EIRA (elemento de irradiação refrigerado a água): permite a colocação de 8 cápsulas dispostas verticalmente no interior de um tubo de seção circular; 
- EIBRA (elemento de irradiação com berílio refrigerado a água): permite a irradiação simultânea de 24 cápsulas dispostas horizontalmente no interior de um tubo de seção retangular. Por apresentar uma barra de grafite na sua posição posterior em relação ao núcleo, neste dispositivo, o fluxo de nêutrons é superior ao anterior;

- EIF (elemento de irraiação de fio): elemento de irradiação com movimento rotacional;

- EIBE (elemento de irradiação de berílio): especialmente projetado para produção de ${ }^{99}$ Mo por captura radioativa.

No Reator podem ser utilizados de forma simultânea 6 EIRAs, 2 EIBRAs, 2 EIFs e 2 EIBEs.

A Figura 4 apresenta uma foto do saguão da piscina do Reator onde estão os dispositivos de irradiação.

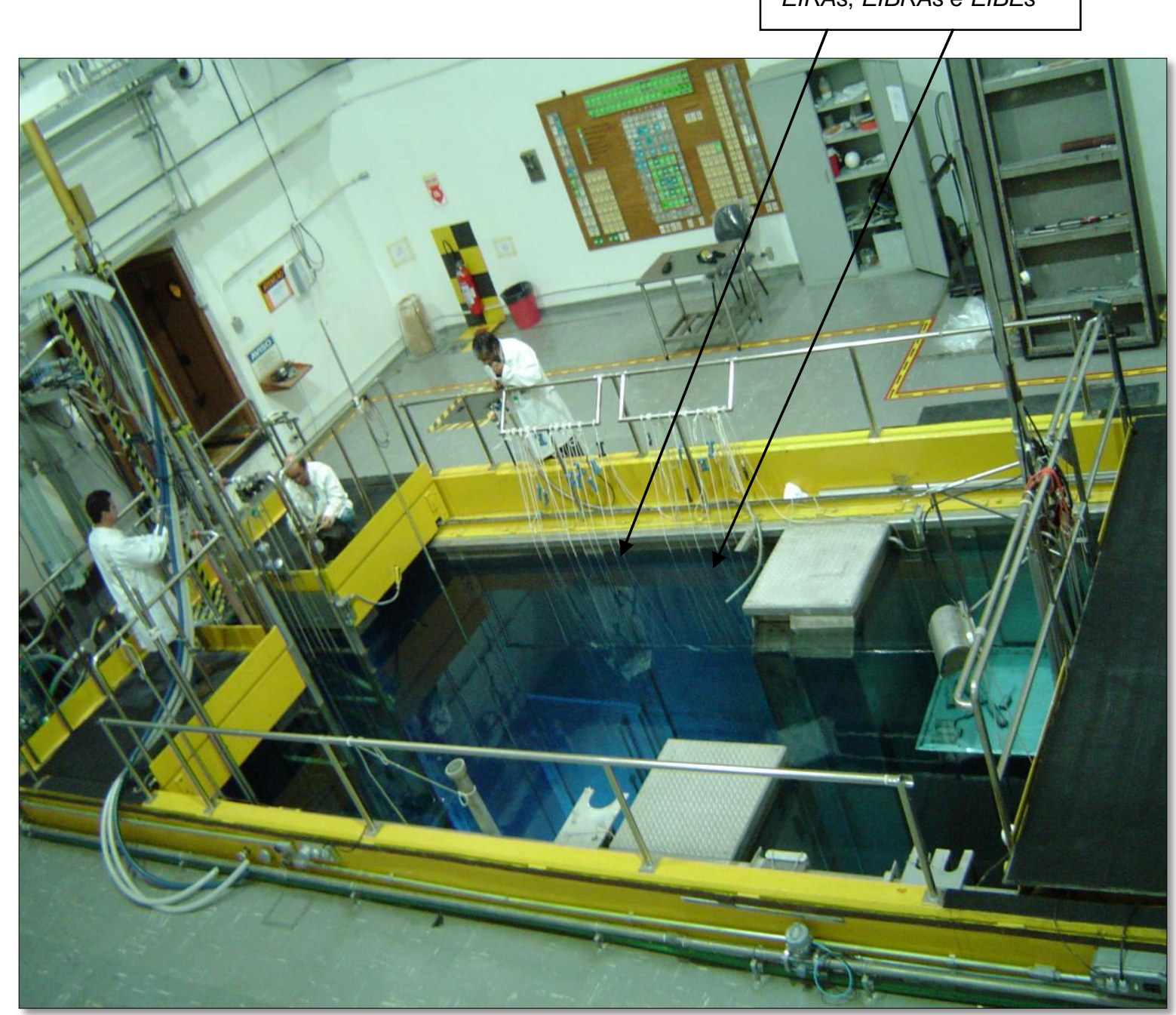

Figura 4 - Foto do saguão da piscina do Reator. 
A Figura 5 apresenta um esquema dos elementos combustível e de irradiação que podem ser instalados na placa matriz.

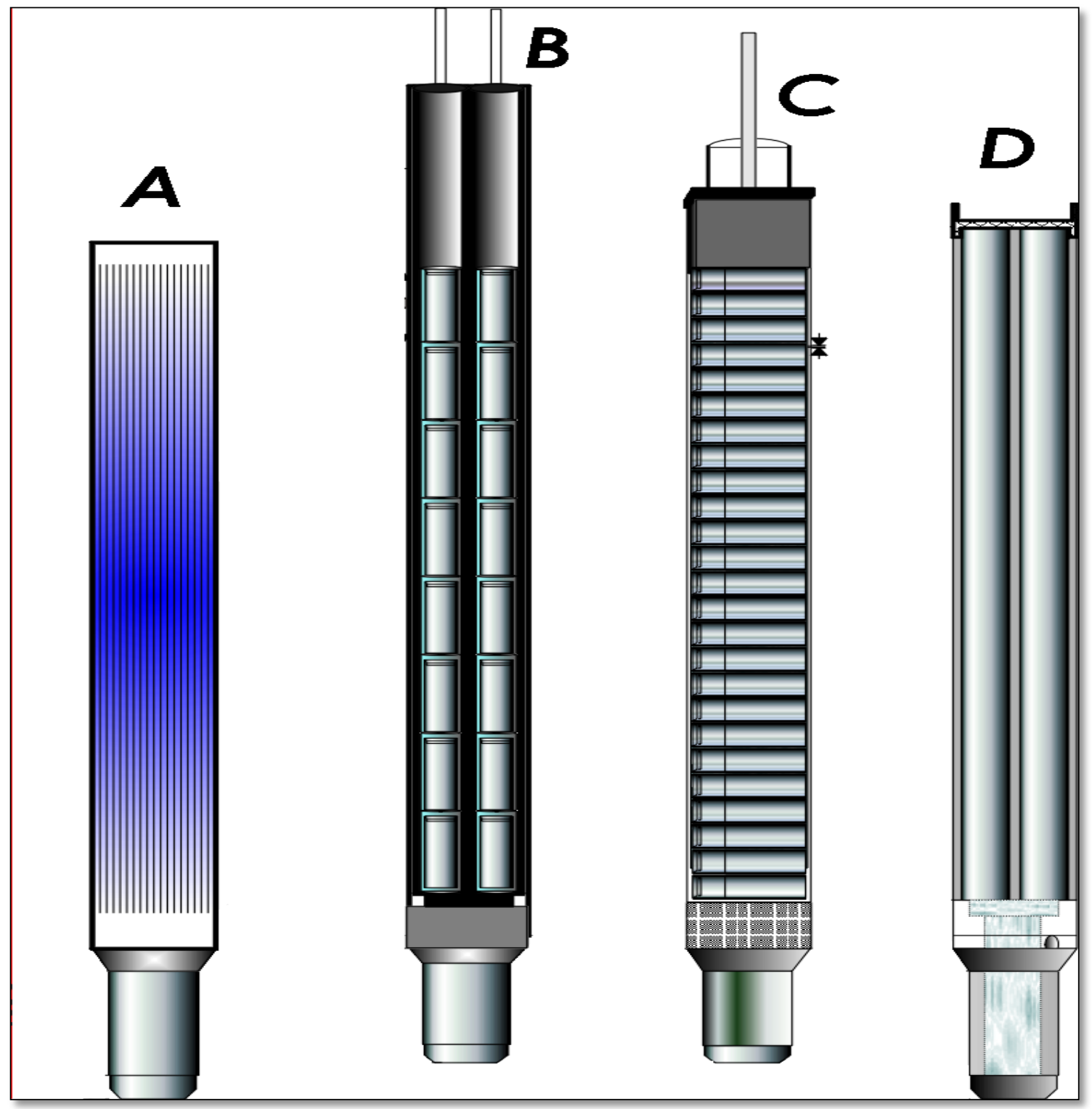

Figura 5 - Elemento combustível e elementos de irradiação:

A - Elemento combustível (EC);

B - Elemento de irradiação refrigerado a água (EIRA);

C - Elemento de Irradiação com berílio refrigerado a água (EIBRA);

D - Elemento de irradiação com berílio (EIBE).

\subsection{2 - Sistema pneumático de irradiação}

Utilizado para irradiações de até 5 minutos, amostras com no máximo 70 gramas são introduzidas em cápsulas de polietileno e enviadas até as proximidades do núcleo através de um sistema pneumático. A estação de envio e recebimento destas cápsulas está situada em um laboratório localizado 
na parte externa do prédio do Reator. A Figura 6 apresenta uma foto da estação pneumática de irradiação.

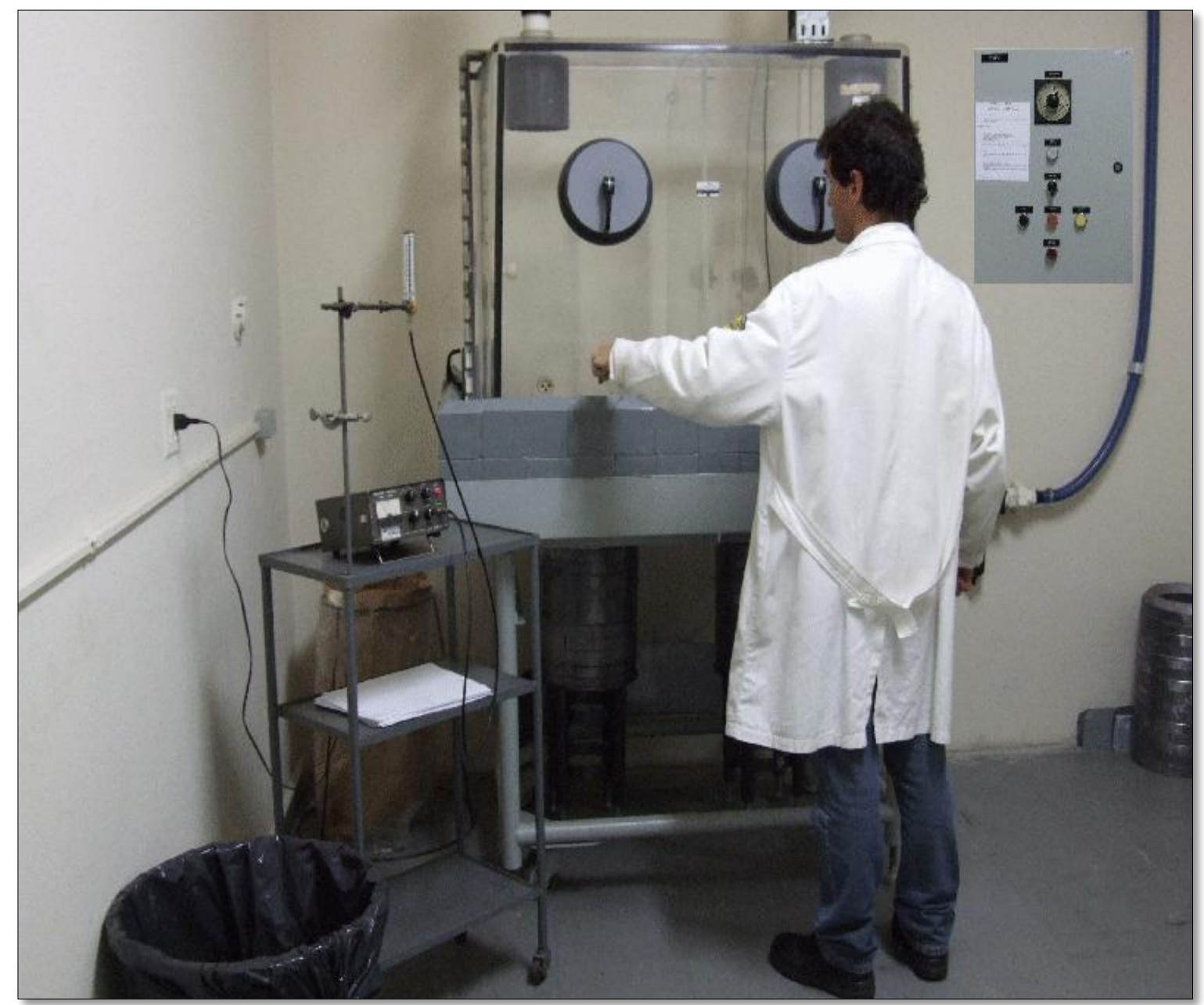

Figura 6 - Foto da estação pneumática.

\subsection{3 - Tubos de irradiação horizontal}

Os tubos de irradiação horizontal permitem a realização de experimentos de física nuclear, física do estado sólido e neutrongrafia. A Figura 7 apresenta uma foto do núcleo do Reator com os tubos de irradiação horizontal.Os tubos de irradiação existentes no Reator estão dispostos da seguinte maneira:

- 10 tubos com diâmetros entre 6 e 8 pol que se prolongam até a face externa da parede do Reator sendo:

- 8 tubos radiais;

- 1 tubo tangencial ao núcleo do Reator;

- 2 tubos encontram-se fora da posição principal de operação do Reator onde a potência não pode ser superior a 100 KW [22]. 


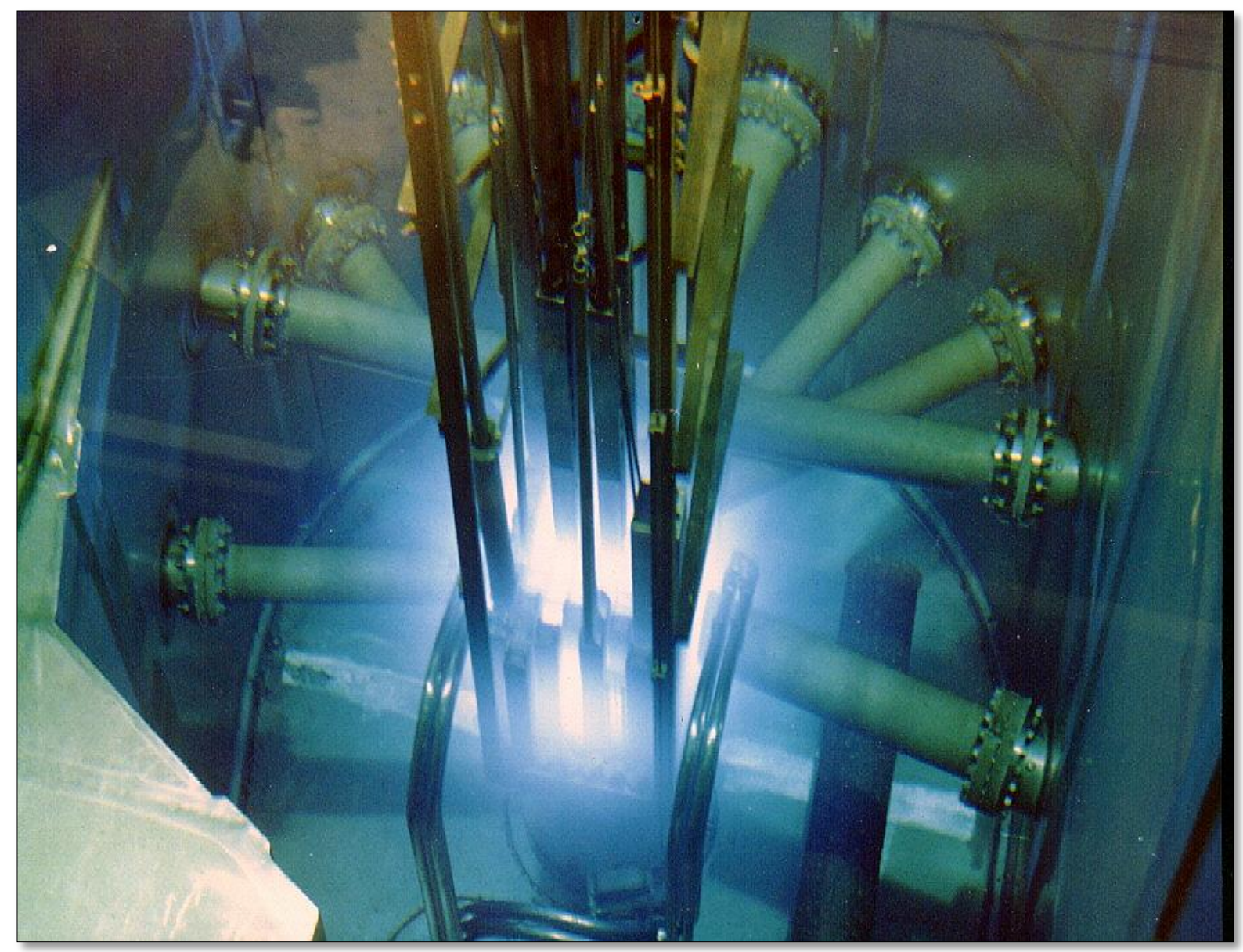

Figura 7 - Foto do núcleo e tubos de irradiação horizontais.

\section{3 - Atividades do Reator}

O Reator IEA-R1 é utilizado, para os seguintes fins:

- Produção de radioisótopos para aplicações na medicina, indústria e agricultura e prestação de serviços como análise por ativação e neutrongrafia;

- Pesquisas em física, química nuclear e testes de materiais;

- Realização de experimentos visando a obtenção de dados nucleares;

- Produção de fontes de ${ }^{60} \mathrm{Co},{ }^{72} \mathrm{Ga}$ e traçadores $\mathrm{KBr}$;

- Produção de ${ }^{131}$ I para para aplicações médicas;

- Produção de ${ }^{203} \mathrm{Hg}$ para serviços de medição de vazões em efluentes industriais;

- Irradiação de fios de ${ }^{192} \mathrm{Ir}$, para tratamentos em braquiterapia;

- Irradiações de "sementes" de ${ }^{198}$ Au para tratamentos de próstata; 
- Irradiação de Ar-Kr-Xe para aplicações em refinarias de petróleo;

- Irradiações de cabelos, unhas entre outros tecidos para análise multielementar por ativação com nêutrons;

- Irradiações de cristais minerais para utilização em datação geológica.

\section{4 - Modernizações}

- 1971 - Alterações no sistema de ventilação do prédio;

- 1978 - Novo revestimento na piscina, nova mesa de controle e instrumentação, novos detectores nucleares de radiação e novos CCM;

- 1985 - Programa de nacionalização componentes eletrônicos;

- 1988 - Separação de câmaras quente e fria e nova torre de resfriamento;

- 1991 - Construção de blindagem no sistema de retratamento de água;

- 1995 - Implantação da instrumentação digital e industrial, troca da tubulação circuito secundário;

- 2000 - Novas barras absorvedoras de nêutrons;

- 2004 - Novo sistema de tratamento e retratamento de água;

- 2007 - Novo sistema pneumático de irradiação de amostras;

- 2007 - Novo trocador de calor do sistema de resfriamento;

- 2009 - Troca dos racks da sala de controle;

- 2010 - Reforma do piso do saguão da piscina e da sala de máquinas;

- 2010 - Novas bombas do circuito secundário de resfriamento;

- 2012- Reforma das canaletas do sistema de drenagem de efluentes líquidos;

- 2013 - Nova torre de resfriamento do circuito secundário;

- 2014 - Troca da tubulaçao do circuito primário;

- 2014 - Reforma das galerias do circuito primario e blindagens. 


\section{5 - Organização funcional}

O Reator IEA-R1 está localizado no Centro do Reator de Pesquisas, $C R P q$. O corpo gerencial do $C R P q$ é formado por um gerente e três gerentes adjuntos, que atuam nas seguintes áreas:

- Pesquisa, Desenvolvimento, Ensino e Inovação;

- Aplicações, Serviços e Infraestrutura;

- Operação e Manutenção do Reator IEA-R1.

A base da organização funcional do CRPq é constituída por grupos de trabalho e laboratórios, que são formados por profissionais que se alternam em diferentes processos, sem níveis hierárquicos, para alcançar uma meta préestabelecida.

No Reator o GM e o GO estão no Gerência Adjunta para Operação e Manutenção do Reator IEA-R1, o CRO.

Estes grupos são responsáveis pelas atribuições descritas a seguir, conforme procedimento gerencial PG-CRPq-0101-05, "Organização do Centro do Reator de Pesquisas" do Sistema de Gestão da Qualidade.

\subsubsection{Atividades de responsabilidade do grupo de operação}

- Manter a área destinada à operação do Reator quanto à limpeza, materiais necessários, equipamentos e outros;

- Operar o Reator de acordo com o RAS da instalação e os documentos operacionais;

- Aprovar as Fichas de Informação para Irradiação de Amostras e os Pedidos de Irradiação no Reator IEA-R1;

- Receber as cápsulas de irradiação devidamente lacradas, testadas e documentadas, colocar no núcleo, retirar e enviar para Área de Aplicações e Serviços com os Pedidos de Irradiação preenchidos;

- Realizar a mudança de configuração do núcleo conforme a Escala de Operação do Reator IEA-R1;

- Providenciar o mapeamento de fluxo de nêutrons nas posições de irradiação da placa matriz, após cada mudança de configuração do Reator IEA$\mathrm{R} 1$; 
- Realizar a calibração das barras absorvedoras de nêutrons sempre que houver mudança de configuração do núcleo;

- Realizar os testes dos sistemas de segurança do Reator conforme periodicidade exigida na TecEspec do RAS;

- Assistir a gerência na decisão sobre a disposição de produto não conforme, ação corretiva e preventiva na sua competência;

- Manter o inventário de todo material nuclear manuseado no CRO, incluindo documentos de remessa e recebimento;

- Elaborar planilhas de queima dos combustíveis utilizados no Reator IEA-R1;

- Elaborar o Plano de Controle de Material Nuclear do Reator IEA$\mathrm{R} 1$;

- Participar das inspeções nacionais CNEN e ABNT e internacionais IAEA;

- Realizar e implementar o Programa de Treinamento e Retreinamento de Operadores do Reator IEA-R1;

- Organizar seminários, reuniões, aulas e avaliação dos treinandos;

- Manter contato com o órgão licenciador CNEN sobre documentos, datas de avaliação e verificação do atendimento ao programa de retreinamento.

\subsection{2 - Atividades de responsabilidade do grupo de manutenção}

- Elaborar e fazer cumprir o Programa de Manutenção Preventiva e Corretiva dos equipamentos da instalação;

- Elaborar e fazer cumprir o Plano de Calibração dos medidores e instrumentos da instalação;

- Participar da realização dos editais e especificações técnicas para contratação de firmas terceirizadas;

- Assegurar o cumprimento das manutenções terceirizadas;

- Manter controle sobre os documentos de manutenção;

- Adquirir e manter as ferramentas de manutenção organizadas;

- Especificar e selecionar novos equipamentos e medidores;

- Instalação de equipamentos e medidores novos; 
- Acompanhar as construções e montagens de novos equipamentos e medidores;

- Modificar os equipamentos existentes;

- Efetuar inspeções regulares sobre o funcionamento dos equipamentos e medidores como o TecEspec;

- Inspeção técnica no recebimento de sobressalentes;

- Previsão de consumo de sobressalentes;

- Manutenção e conservação de sobressalentes armazenados em almoxarifado;

- Estudo de novos métodos de manutenção;

- Descrever e documentar as instruções de manutenção e as tarefas;

- Acompanhamento e melhoria de métodos de trabalho na segurança do trabalho;

- Assistir a Gerência na decisão sobre as manutenções corretivas e preventivas e contratos de firmas terceirizadas que venham a fazer manutenções no $\mathrm{CRO}$;

- Providenciar as autorizações necessárias (radioproteção e operação do Reator) para entrada de técnicos para realização da manutenção e calibração. 


\section{3. - METODOLOGIA}

\section{1 - Sistema operacional}

O programa foi projetado com a capacidade de ser instalado numa rede interna de computadores (Intranet-servidor/cliente), operando num ambiente "Windows", para que possa ser acessado por vários usuários simultaneamente. Deste modo, todos terão acesso a um único banco de dados central, em um computador designado como servidor [14]. Além disso, cada usuário deverá estar cadastrado neste sistema, para que possa receber um nível de acesso à base de dados, dependendo das tarefas que the serão permitidas executar como: consultar os registros de manutenções preventivas, corretivas, calibrações e emitir relatórios; gerar os registros de manutenções preventivas, corretivas e calibrações, acrescentar, atualizar, modificar e eliminar registros de manutenções preventivas, corretivas ou calibrações da base de dados; e controlar o cadastro e nível de acesso dos usuários [15].

\section{2 - Método}

O modelo usado no sistema computacional do Reator foi 0 desenvolvimento em cascata. A metodologia de desenvolvimento em cascata foi elaborada pela marinha norte-americana para aplicação em softwares militares complexos. No modelo em cascata, o projeto segue uma série de passos ordenados. Ao final de cada etapa, foi realizada uma revisão, ou seja, o projeto só avança para a etapa seguinte, se o "cliente" estiver satisfeito com os resultados obtidos.

O modelo em cascata funciona bem em ambientes rígidos e fortemente controlados. São especialmente indicados em projetos que possuem componentes de alto risco, tais como projetos para a área médica, nuclear ou segurança pública.

O modelo em cascata é baseado numa enorme quantidade de relatórios e saídas que nada mais são do que documentos. O modelo em cascata funciona bem quando os requisitos dos usuários são rígidos (normas, procedimentos) e podem ser conhecidos com antecedência, como é o caso do Reator [11].

O sistema computacional é como um processo de "software", ou processo de engenharia de "software", que é uma sequência coerente de 
etapas que objetiva o desenvolvimento ou evolução de sistemas de "software" Figura 8. No sistema computacional estas etapas englobam as seguintes atividades: Requerimento, Projeto, Implementação, Verificação e Manutenção. Caracterizam-se pela interação de ferramentas, pessoas e métodos $[17,18]$.

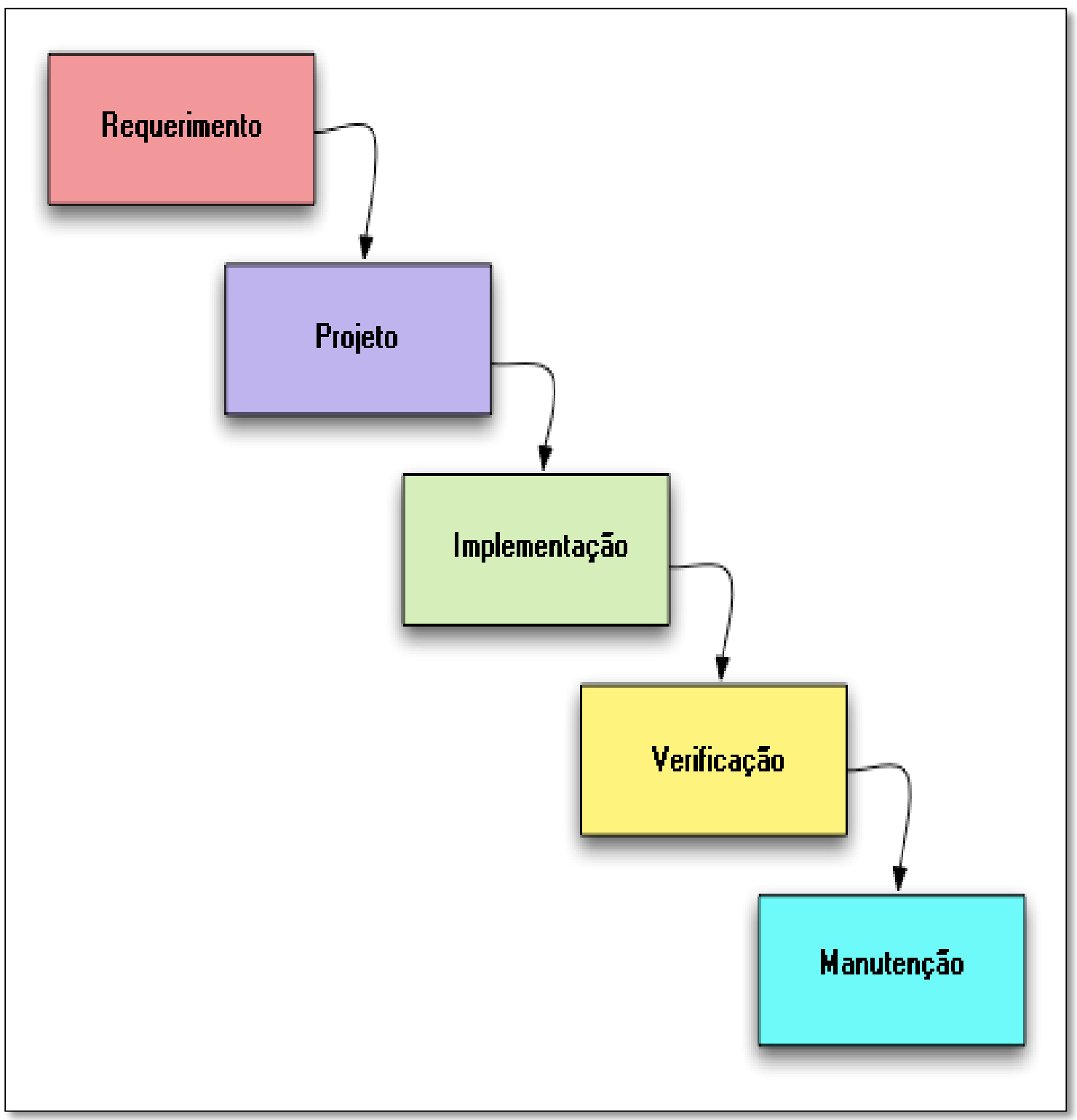

Figura 8 - Modelo de desenvolvimento em cascata.

\section{3 - Requerimento}

Nesta etapa foram levantados todos os aspectos relacionados ás necessidades do Reator, que são os aspectos legais (normas) que deverão ser atendidos pelo sistema. Foi também realizado um estudo de viabilidade do sistema computacional para determinar: as vantagens e desvantagens, a escolha da linguagem (ou plataforma) de programação, escolha do "hardware", 
a adequação do "hardware" disponível, as informações gerenciais disponíveis e o custo para o Reator $[19,20]$.

\section{4 - Projeto}

Para o desenvolvimento do Projeto foi detalhada uma sequência de passos para a execução do sistema computacional:

\subsection{1 - Entradas e saídas}

Foram definidas quais seriam as entradas (tarefas e planos) e as saídas (registros de manutenção e calibração, históricos, listas, relatórios, estatística) do sistema. Foram definidos os principais módulos de programação como o cadastro do banco de dados, os registros de manutenções preventivas e corretivas, calibrações e históricos de manutenções e calibrações.

\subsection{2 - Operacionalidade do sistema}

Foram levantados os elencos de facilidades que o sistema irá propiciar em tempo real.

\subsection{3 - Navegação}

Foi definido como os módulos do sistema devem orientar o usuário, de forma simples e clara a "navegar" pelas telas, também foi concebido de modo que, as sequencias das telas sejam ordenados segundo o fluxo normal das tarefas, permitindo ao usuário "saltar" telas indesejadas, quando necessário.

Uma das maiores vantagens da interface gráfica é que o usuário pode interagir com um conjunto padronizado de objetos, tais como janelas, botões e barras de deslocamento. Aplicativos que usam esses objetos comportam-se de forma padrão, simplificando o aprendizado do aplicativo. Uma parte do trabalho é selecionar o estilo de interação mais apropriado para a situação e escrever os programas de forma que o usuário ache-o intuitivamente.

Em um ambiente GUI, o usuário interage com os objetos apresentados na tela para dar início a eventos como abrir uma janela, dar um clique em um ícone, escolher um item de tela, e, por meio disto, controlar o 
aplicativo. O aplicativo transforma eventos iniciados pelo usuário em atividade programada, chamando o procedimento associado ao evento $[16,19]$.

\subsection{4 - Segurança do sistema}

Foi definido como o sistema irá permitir que somente o usuário autorizado a executar determinadas tarefas possa fazê-lo. Foi definido que apenas os administradores do sistema devam poder cadastrar equipamentos, códigos de acesso e senhas, acessar a tela de Cadastro. Os demais usuários somente poderão utilizar as telas de consultas.

\section{5 - Implementação}

$\mathrm{Na}$ Implementação foi realizada a sequencia de implantação e a programação (codificação) do sistema computacional.

Foi definida a sequencia de eventos para montar o sistema de planejamento e controle de manutenção: identificação dos equipamentos, manutenção preventiva, manutenção corretiva, calibração, histórico de manutenção e calibração e, finalmente, os relatórios.

\subsection{1. - Identificação dos equipamentos}

A identificação dos equipamentos é parte fundamental da montagem do sistema de planejamento e controle de manutenção, seja ele manual ou informatizado em qualquer grau, para que o sistema reconheça sobre o que está sendo trabalhado.

O sistema informatizado de planejamento e controle da manutenção obriga o uso de uma codificação que relacione de modo biunívoco o equipamento e o seu código para que o executante possa saber, sem erros, se está trabalhando no equipamento correto e o administrador possa indicar de maneira inequívoca em qual equipamento está planejando as tarefas e a parada para manutenção. A codificação, sempre que necessário, deve indicar o tipo de equipamento, a localização, o sistema ao qual o equipamento pertence, a sequência numérica, entre outras informações. Para tanto foram estabelecidos alguns critérios para esta identificação.

Apesar de existir no Reator uma identificação dos equipamentos, foi criado um novo sistema de codificação para facilitar a identificação e atender 
as necessidades normativas e do sistema informatizado. Os sistemas de códigos podem ser criados de maneiras diferentes, como códigos numéricos, códigos alfabéticos e códigos alfanuméricos.

- Código numérico: são códigos construídos apenas com números. São fáceis de serem montados, possuem um alcance fácil de ser visualizado e são facilmente memorizáveis. Existe uma dificuldade em interligar um sistema de códigos com os equipamentos se o sistema for apenas numérico.

- Código alfabético: são códigos construídos apenas com letras do alfabeto. Nem sempre são fáceis de memorizar, mas são mais fáceis de serem correlacionados com os equipamentos. É difícil visualizar a amplitude do código, mas para uma mesma quantidade de dígitos possui maior amplitude que o código numérico.

- Código alfanumérico: são códigos mais fáceis de serem construídos e memorizados, possuem maior amplitude e são mais facilmente relacionados com os equipamentos (parte alfabética) e memorizados pelos executores das oficinas, e laboratórios (parte numérica).

Para o sistema computacional do Reator foi adotado o código alfanumérico, conforme descrito no procedimento gerencial PG-CRPq-1101-06 "Controle de Equipamento" do Sistema da Gestão da Qualidade do Reator, ABNT NBR ISO 9001:2008.

Os equipamentos são identificados por um Tag. O código de Identificação dos equipamentos tem a seguinte estrutura:

Sistema Tipo Sequência

CP-BOM- 01

Onde:

Sistema: Campo com dois caracteres alfanuméricos identificando o sistema ao qual pertence o equipamento. No exemplo, Circuito Primário de Resfriamento $C P$.

Tipo: Campo com três caracteres alfanuméricos identificando o tipo de equipamento. No exemplo bomba de recirculação BOM.

Sequencial: Campo com dois dígitos, indicando a numeração sequencial para um mesmo tipo de equipamento, pertencente a um mesmo sistema. No exemplo 01. 
Foi criada uma tabela de equivalência entre o Tag existente e o Tag que foi criado e um campo no registro de cadastro do equipamento com essa equivalência.

\subsection{2 - Cadastro}

Cadastro por definição é um censo, um recenseamento de forma organizada e metódica convenientemente registrada, catalogada e arquivada. Foram relacionadas todas as variáveis necessárias para podermos trabalhar bem e organizadamente no sistema informatizado. Foi montado um cadastro de equipamentos, usuários e tarefas a serem executadas.

\subsubsection{1 - Equipamentos}

Cadastro de equipamentos é o registro do maior número de dados dos equipamentos, através de formulários padronizados que, arquivados, possibilitem o acesso rápido a qualquer informação necessária para manter, comparar e analisar condições operativas, sem que seja necessário recorrer a fontes diversificadas de consulta.

Um levantamento foi realizado com todos os equipamentos ou medidores de cada sistema do Reator e de todas as informações possíveis de cada equipamento ou medidores, ou seja, os dados que necessitamos durante a operação do Reator e que eventualmente serão necessários para o uso no sistema computacional. Foram definidas as informações relevantes para 0 sistema computacional e também o formato do banco de dados.

\subsubsection{2 - Pessoal e usuários}

Cadastro de usuários é o registro de todos os dados necessários sobre as pessoas que trabalham na manutenção, como sua especialidade (mecânica, elétrica, eletrônica) e das pessoas que terão acesso ao sistema informatizado como administrador ou usuário.

\subsubsection{3 - Tarefas de manutenção}

Cadastro de tarefas de manutenção é um banco de dados, ou um conjunto de folhas onde estão descritas as tarefas que a manutenção deve 
executar durante o cumprimento do RMP e RMC, sem que seja necessário recorrer aos manuais na maior parte dos trabalhos de rotinas.

\subsubsection{4 - Formulários}

Existem dois tipos de formulários para cadastramento, o específico e o genérico:

- Formulários específicos: são aqueles utilizados para cada tipo de equipamento, ou seja, nos casos em que é necessário que se utilize um tipo de formulário diferente para cada tipo de equipamento. São de preenchimento mais simples, normalmente mais completos e podem ser preenchidos por pessoa sem treinamento. Porém quando o tipo de equipamento for muito grande, (com vários componentes) pode tornar o sistema informatizado mais complicado, pois seriam necessárias mais telas de cadastro.

- Formulários genéricos: são aqueles utilizados para todos os tipos de equipamentos. Exigem muita atenção para que os dados sejam dispostos em sequência (para facilitar a busca futura da informação), são de implantação simples, porém necessitam de mão de obra especializada para o preenchimento.

Para o sistema computacional do Reator foi adotado o formulário genérico.

\subsubsection{5 - Critérios}

Os dados de equipamentos cadastrados podem ser reunidos de diversas maneiras. Os arquivos de cadastros podem ser agrupados por linhas de produção, tipos de equipamentos, famílias de equipamentos, unidades de produção, importância funcional, área geográfica (localização), unidade móvel, sistema operacional, entre outros, de acordo com a necessidade da instalação.

No sistema computacional temos somente um arquivo de banco de dados, onde foram definidos campos para a procura de informações pelas variáveis que foram necessárias e previamente estabelecidas. Foi definido que o cadastro do sistema informatizado seria realizado pelos sistemas existentes no Reator e definidos em lista no programa do Sistema de Gestão da Qualidade, que segue o estabelecido no Relatório de Análise de Segurança da instalação. No ANEXO 1 é apresentadas a Tabela1, com a descrição dos 
sistemas do Reator, e a Tabela 2, com a descrição dos equipamentos e medidores ou instrumentos existentes no Reator.

\subsubsection{6 - Tipos de sistemas}

Neste tipo de cadastro os dados (informações) serão agrupados ao sistema ao qual o equipamento pertença, independente de qual tipo ou família de equipamento pertença. Por exemplo:

No caso do Circuito Primário de Refrigeração, todos os equipamentos e medidores pertencentes a este sistema estarão agrupados primeiro por:

- Sistema (CP - Circuito Primário);

- Tipo de equipamento (BOM - bomba de recirculação);

- Número sequencial (01).

\subsection{3 - Manutenção preventiva e corretiva}

Para a implantação dos módulos de manutenção foi necessário primeiro classificar os equipamentos, criar os planos de manutenção preventiva, as instruções de manutenção e definir como será a forma do RMP e $R M C$.

\subsubsection{1 - Classificação dos equipamentos}

Os equipamentos foram classificados de acordo com sua importância operacional, onde foi usado o critério de prioridade na implantação para os equipamentos mais importantes no processo, ou seja, aqueles que não podem falhar ou onde a falha ou a indisponibilidade causará maiores problemas, e em seguida estendido o estudo para os demais que existirem, usando o critério de importância da função que ele desempenha.

Como exemplo o Circuito Primário de Refrigeração. A função do Circuito Primário é prover o resfriamento adequado do núcleo do Reator assegurando que os critérios de projeto do combustível, não sejam excedidos durante qualquer condição normal de operação da planta. A Figura 9 apresenta o fluxograma do Circuito Primário de refrigeração com os seus equipamentos e medidores. 


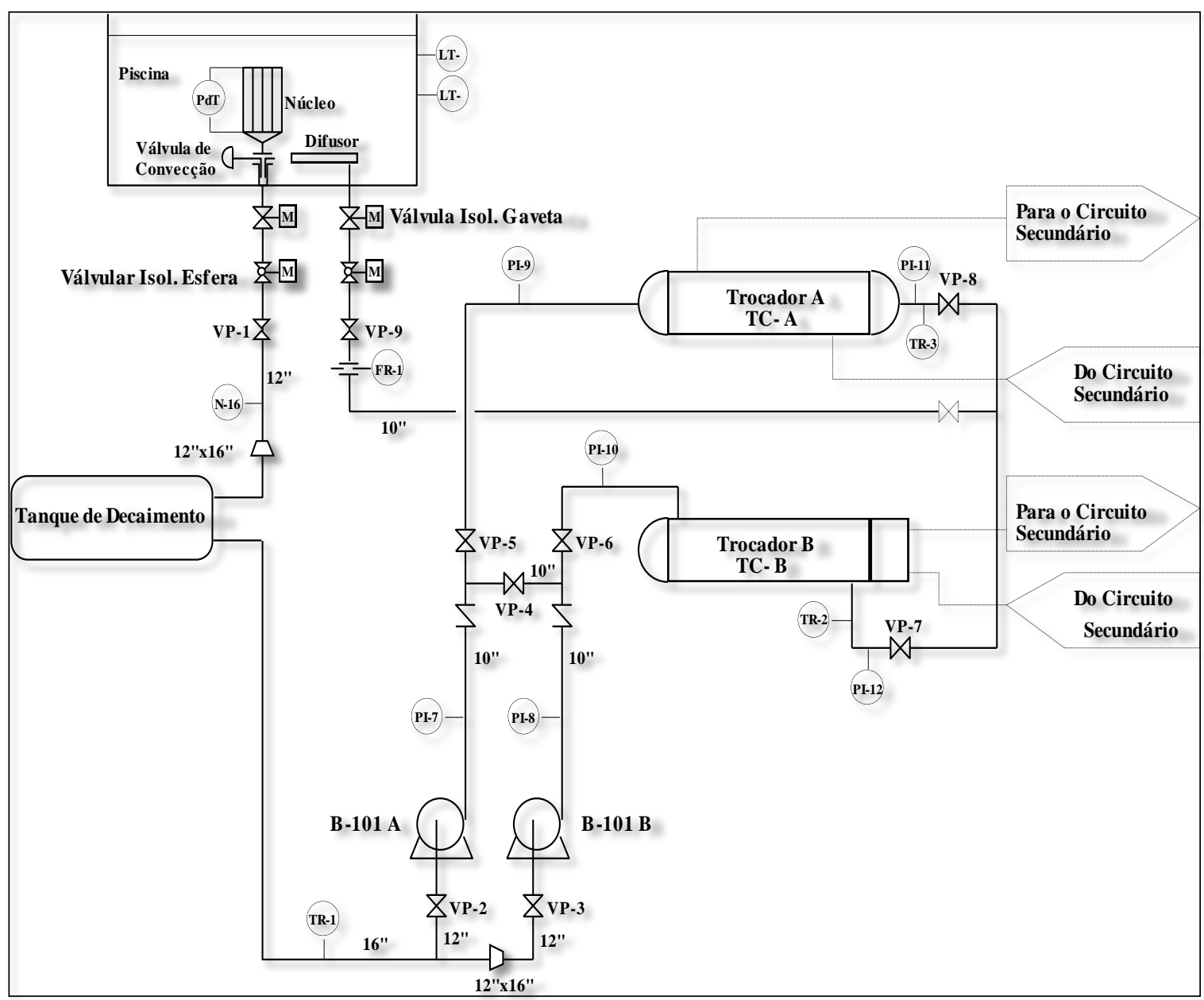

Figura 9 - Esquema do Circuito Primário de Refrigeração do núcleo.

A massa de água na piscina assegura a remoção de calor residual do núcleo quando da falta de energia elétrica, atuando como uma fonte de acúmulo e dissipação de calor. A água da piscina também tem a função de blindagem da radiação emitida pelo núcleo.

Os equipamentos deste circuito foram classificados conforme descrito no procedimento gerencial PG-CRPq-1101-06 "Controle de Equipamento" do Sistema de gestão da Gestão da Qualidade, ABNT NBR ISO 9001:2008.

Classificação quanto à importância para a instalação e ou processo:

- Vital: São equipamentos ou medidores cujo mau funcionamento ou não operacionalidade obrigam a interrupção da operação da instalação ou do processo. Devido à sua importância para o processo, geralmente, possuem redundância. 
- Essencial: São equipamentos ou medidores cujo mau funcionamento ou não operacionalidade não obrigam a interrupção da operação da instalação ou do processo, mas comprometem seu desempenho.

- Normal: São equipamentos ou medidores que não têm influência direta sobre a operação da instalação ou do processo.

Para um maior controle do plano de manutenção os equipamentos são classificados quanto à sua disponibilidade:

- Redundante: Existe um ou mais equipamentos reserva.

- Não Redundante: Não existe equipamento reserva.

Este procedimento foi estendido a todos os sistemas e seus equipamentos ou medidores existentes na instalação.

\subsubsection{2 - Instruções de manutenção}

As instruções de manutenção foram elaboradas de maneira a indicar ao executante da manutenção como fazer a tarefa que está descrita no RMP. Além de lembrar valores e padrões de qualidade existentes dentro do $P G Q$.

As tarefas que envolvem riscos de acidentes de trabalho estão mencionadas na $R M P$, bem como aquelas que podem causar danos às pessoas, ao meio ambiente ou que exigem medidas específicas para serem iniciadas.

Juntamente com as instruções de trabalho, foi definida a periodicidade recomendada para cada tarefa, através de manuais e da experiência dos profissionais que executam as manutenções.

\subsubsection{3 - Plano de manutenção preventiva}

Os planos de manutenção foram criados segundo os critérios de prioridade definidos anteriormente, nesta ordem: equipamentos vitais, que devem ter seus planos rigorosamente cumpridos, equipamentos essenciais, que devem ter seus planos cumpridos dentro de uma faixa determinada de tempo, e normais que não necessitam de manutenções.

\subsubsection{4 - Registro de manutenção preventiva}

O registro de manutenção preventiva $R M P$, é o formulário (documento) básico para a execução da manutenção do equipamento. 
Nenhuma manutenção em condições normais deve ser executada sem uma RMP previamente emitida e aprovada.

O registro de manutenção preventiva $R M P$ é onde se descrevem as tarefas que devem ser executadas pelo pessoal de manutenção, oriundas do plano de manutenção preventiva.

O registro de manutenção preventiva $R M P$, do sistema informatizado foi elaborado dentro das normas de Qualidade Total [23], usando a ferramenta chamada $5 W 1 H$, onde os $5 W$ significam: "why "(porque), "where" (onde), "who "(quem), "what" (o que), "when" (quando) e o "H" significa "how" (como).

Deste modo, para cumprir o que foi escrito acima, o registro de manutenção preventiva deve explicitar, sempre:

- Porque foi executado (why): No registro de manutenção preventiva consta porque deve ser realizado o serviço.

- O que foi executado (what): No registro de manutenção preventiva consta o que deve ser feito. Existe uma indicação clara de qual área (Produção, Serviços, Oficina Mecânica, Proteção Radiológica) ou laboratório (Absorção Atômica, Metrologia Nuclear) o equipamento pertença e qual o tipo de manutenção a ser executado.

- Como foi executado (how): No registro de manutenção existe a descrição de como executar o trabalho, quais parâmetros são importantes, toda a sequencia de trabalhos, ou quando a manutenção for muito grande a rotina ou o plano de manutenção que deve ser seguido.

- Onde foi executado (where): O RMP indica claramente em qual sistema (por exemplo: o Circuito Primário de Refrigeração) a manutenção deve ser executada. Para isto foi definido um código para o equipamento, um nome ou Tag pelo qual o equipamento é conhecido na instalação, junto com a sua descrição.

- Quem executou (who): No registro de manutenção preventiva é obrigatória indicação de quem executou a manutenção. Esta indicação de retorno é fornecida através do código do empregado (no caso do Reator é o crachá). Existe a indicação do tempo previsto para a execução da tarefa, e o tempo real de execução da tarefa, que será usado para controle da mão de obra. 
- Quando foi executado (when): Com a indicação de quando foi executada a manutenção, o sistema computacional está fazendo um controle entre o planejamento prévio e a execução da manutenção. Este controle é muito importante, porque existem manutenções que afetam outras áreas, ou que exigem cuidados especiais com mobilização de muitos recursos.

O registro de manutenção preventiva $R M P$, foi criado $\mathrm{e}$ personalizado para atender os requisitos regulamentares da instalação. Foi analisado cuidadosamente que tipo de informação deve ser fornecido ao executante e que tipo de informação o executante deve fornecer de retorno ao sistema computacional para que as metas e a missão da manutenção sejam cumpridas. O RMP possui cabeçalho com o logotipo da instituição, identificação do centro, identificação do registro, setor ou área e o número de controle do registro, os itens descritos no $5 \mathrm{~W} 1 \mathrm{H}$ e para atender o requisito regulamentar o RMP foi numerado como formulário do Sistema de Gestão da Qualidade.

\subsubsection{5 - Registro de manutenção corretiva}

Foram estabelecidos os procedimentos que serão usados para os registros de pedidos de manutenções corretivas e outros serviços que não estejam dentro do plano de manutenção preventiva que está no sistema computacional, mas que tratam sobre os equipamentos e medidores que estão cadastrados e codificados.

O registro de manutenção corretiva $R M C$, do sistema informatizado foi elaborado a partir do mesmo princípio usado na elaboração do registro de manutenção preventiva RMP, ou seja, dentro das normas de Qualidade Total, usando a ferramenta chamada $5 \mathrm{~W} 1 \mathrm{H}$.

O registro de manutenção preventiva $R M C$, foi criado $\mathrm{e}$ personalizado para atender os requisitos regulamentares da instalação. Foi analisado cuidadosamente que tipo de informação deve ser fornecido ao executante e que tipo de informação o executante deve fornecer de retorno ao sistema computacional para que as metas e a missão da manutenção sejam cumpridas. O RMC possui cabeçalho com o logotipo da instituição, identificação do centro, identificação do registro, setor ou área e o número de controle do registro, os itens do descritos no $5 \mathrm{~W} 1 \mathrm{H}$ e para atender o requisito 
regulamentar o $R M C$ foi numerado como formulário do Sistema de Gestão da Qualidade.

No caso do registro de manutenção corretiva, foi necessário definir a prioridade para 0 atendimento da manutenção indicando qual manutenção corretiva deve ser executada antes e qual o motivo do atendimento.

Foram definidos os seguintes códigos de prioridade em escala de importância para a instalação: imediato, urgente, normal e outros.

- Imediato: Esta prioridade é usada pelo sistema computacional para definir que a não execução da manutenção poderá ocasionar riscos de acidentes ou colocará em risco o patrimônio da instalação. São manutenções que devem ser feitas imediatamente, em equipamento classificado como vital para a instalação.

- Urgente: Esta prioridade é usada pelo sistema computacional para definir que a não execução da manutenção não trará riscos de acidentes, ou colocará em risco o patrimônio da instalação. São manutenções que devem ser feitas em um prazo máximo estabelecido de 1 dia para o seu atendimento, em equipamento classificado como essencial para a instalação.

- Normal: Esta prioridade é usada pelo sistema computacional para definir que a não execução da manutenção não trará riscos de acidentes, ou colocará em risco o patrimônio da instalação, mas se não for executada, a médio ou longo prazo originarão uma falha, que irá comprometer a operação da instalação. São manutenções que devem ser feitas em um prazo máximo estabelecido de 4 dias, em equipamento classificado como normal para a instalação.

- Outros: Esta prioridade é usada pelo sistema computacional para definir que a não execução da manutenção não trará riscos de acidentes, ou colocará em risco o patrimônio da instalação, mas não estão nas prioridades maiores anteriores. São manutenções que devem ser feitas sem um prazo máximo estabelecido, em equipamento classificado como normal para a instalação.

No registro de manutenção corretiva, foi elaborada uma pesquisa de satisfação do solicitante, a respeito da qualidade do serviço, o prazo de entrega e o atendimento da equipe de manutenção ou do executor do trabalho, conforme requisito regulamentar do Sistema de Gestão da Qualidade. 


\subsection{4 - Calibração dos medidores}

Calibração é o nome dado ao conjunto de operações que estabelecem, sob condições especificadas, a relação entre os valores indicados por um instrumento calibrado ou sistema de medição e os valores representados por uma medida materializada ou um material de referência, ou os correspondentes das grandezas estabelecidas por padrões [27].

As operações de calibração são baseadas na comparação dos instrumentos padrão de modo a determinar sua exatidão e verificar se essa exatidão continua de acordo com a especificação de fabricante.

Em termos práticos, a calibração é uma ferramenta básica que visa a assegurar a confiabilidade de um instrumento de medição, por meio da comparação do valor medido com um padrão rastreado à $R B C$. A calibração de instrumentos pode ser feita por um laboratório, sem necessariamente estar acreditado. Como argumentos, encontram-se na página do Inmetro [28], a citação que a acreditação é voluntária e tem-se também, a definição do VIM [25], que contém as definições sobre metrologia, que descreve a calibração como operação que estabelece, numa primeira etapa e sob condições especificadas, uma relação entre os valores indicados e as incertezas de medição, fornecidos por padrões e as indicações correspondentes com as incertezas associadas; numa segunda etapa, utiliza-se esta informação para estabelecer uma relação visando a obtenção de um resultado de medição a partir de uma indicação.

De acordo com o Vocabulário Internacional de Termos Fundamentais e Gerais de Metrologia (aprovado pela Portaria INMETRO № 029/95) [26], calibração representa o conjunto de operações que estabelecem, sob condições específica, a relação entre os valores indicados por um instrumento de medição, sistema de medição ou valores representados por uma medida materializada ou material de referência, e os valores correspondentes às grandezas estabelecidas por padrões. Calibrar significa colocar um instrumento de medição em condições de utilização, por meio da comparação dos valores das medições fornecidos pelo instrumento, com os valores padrão, aplicando-se quando necessário, o ajuste ou regulagem.

A calibração deve ser realizada em todos os instrumentos de medição que tiverem influência na exatidão ou validade dos processos ou 
ensaios. Nem todo instrumento de medição necessita de calibração. No Reator todo o instrumento ou medidor classificado como vital ou essencial estão no Plano de Calibração. Os instrumentos ou medidores classificados como normais não estão no plano de calibração.

Os resultados da calibração do instrumento de medição, expressos em um certificado de calibração, são importantes, pois fornecem informações válidas e úteis que podem auxiliar na tomada de decisões gerenciais, como por exemplo, para correções a serem realizadas no processo de medição. Permitem ainda, o estabelecimento da correspondência entre a indicação do instrumento de medição e o valor padrão. Também podem determinar outras propriedades metrológicas, tais como os efeitos das grandezas de influência sobre a indicação, ou o comportamento metrológico de sistemas de medição em condições adversas de utilização (em temperaturas elevadas ou muito baixas, na ausência de gravidade, radiação nuclear).

Vale ressaltar, também, outro fator fundamental que influencia nas medições: o cuidado com a preservação da identidade e integridade do instrumento. Isto se constitui em uma das mais importantes responsabilidades do grupo de manutenção. Sem este cuidado, qualquer resultado obtido, por mais reprodutível e preciso que seja não poderá ser associado exclusivamente às características do instrumento calibrado.

No Reator foi estabelecido um programa de calibração dos instrumentos de medição que contempla os critérios para calibração, incluindo os parâmetros a serem calibrados; as metodologias; as frequências e, quando procedente, o laboratório ou organismo responsável pelas calibrações [27]. Este programa foi concebido de maneira tal que, sempre que aplicável, as medições feitas em laboratório possam ser rastreáveis aos padrões de medidas estabelecidos.

A frequência da calibração (periodicidade) deve ser estabelecida em um procedimento, sendo o critério escolhido por meio de uma série de fatores, tais como: tipo de equipamento e periodicidade estabelecida pelo fabricante; análise da tendência conforme os dados das calibrações anteriores; histórico de uso e manutenção; comparações com periodicidade de equipamentos similares; e precisão da medida. 


\subsection{5 - Histórico de manutenção e calibração}

Durante as atividades de manutenção preventiva, corretiva e calibração são executadas atividades em equipamentos ou medidores que devem ser lembradas para uso posterior. Podem ser trabalhadas para estudo de confiabilidade, para estimativa de custos, tempo de parada, requisição de material entre outros. Estas informações constituem um arquivo de banco de dados chamado de histórico.

Na definição do dicionário Aurélio, histórico é "relativo à história" ou "exposição cronológica de fatos", então histórico de equipamento ou medidor é um arquivo onde são armazenadas as informações e registros das calibrações, avarias, reparações, intervenções em geral que dizem respeito ao equipamento ou medidor.

O arquivo de histórico do sistema computacional é atualizado pelos registros de manutenção preventiva $R M P$, o registro de manutenção corretiva $R M C$ e o plano de calibração.

Para atender aos requisitos regulamentares o registro de manutenção preventiva ou corretiva e o histórico de calibração impressos, tem uma validade definida sendo após o seu vencimento descartados (retirados do programa da qualidade), mas o arquivo digital é preservado por tempo indeterminado. Alguns documentos impressos como o livro de ocorrências durante a operação do Reator (Log-Book), Folhas de Operação com os parâmetros operacionais, Lista de Verificação Inicial e Final, também são preservados por tempo indeterminado ou durante a vida útil da instalação.

\subsection{6 - Relatórios}

Relatórios de manutenção e calibração, de maneira geral, são documentos escritos, baseados em fatos contendo informações relevantes para avaliação e possíveis tomadas de decisão. Todo relatório de manutenção e calibração é praticamente um relatório gerencial.

Um relatório gerencial é um relatório baseado em análises de dados passados e atuais, projeções futuras e sugestões de como melhorar os índices de manutenção, sobre possíveis efeitos de falhas de equipamentos, compra de equipamentos novos, mudança de periodicidade da calibração, etc. 
Relatórios gerenciais de boa qualidade são de extrema importância para o Sistema de Gestão da Qualidade. É possível elaborar e utilizar os Relatórios Gerenciais de forma simples, objetiva e eficaz.

Para que seja feito um relatório, é necessário ter dados e índices a serem analisados. O relatório deve sempre ter qualidade gráfica, informações, confiabilidade, clareza de texto e impressão, acabamento e papel adequado, para quando um gerente ou responsável venha analisar possa interpretar as informações exatamente como devem ser. Caso o gerente ou responsável não entenda, ou ache meio complicado, provavelmente o relatório será arquivado sem ter atingido o seu propósito.

No sistema computacional os relatórios foram criados em uma linguagem simples e curta, de parágrafos breves e fáceis de ler. Foram definidos e desenhados dentro da implantação de cada módulo do sistema.

\section{6 - Verificação (dos módulos do sistema)}

$\mathrm{Na}$ Verificação foram realizados os testes operacionais de cada módulo e a validação do novo software.

A validação de software é um processo de engenharia de requisito. Este processo trata, tal como o seu nome indica, da validação quanto à consistência, precisão, contextualização de requisitos levantados no processo de identificação, descoberta, análise e negociação de requisitos. Este processo envolve uma revisão de todos os requisitos levantados e negociados, assim como da validação de modelos e testes de requisitos.

Este processo é um dos mais importantes. Isto porque tal como um documento de requisitos bem definido permite a correção de incoerências e inconformidades no desenvolvimento de um produto de software, a validação permite minimizar o tempo gasto na deteção dessas incoerências e inconformidades devido à sua alta eficiência na sua descoberta. Também porque como é este processo que permite a identificação destas mesmas incoerências na fase anterior à versão final do relatório de requisitos, minimiza grandemente o risco de encontrarem estas incoerências numa fase tardia, ou até mesmo no final do desenvolvimento do sistema. É fácil entender que um erro encontrado numa fase tardia do desenvolvimento do projeto pode ser 
desastroso, pois a sua alteração poderá ser bastante onerosa e incompatível, em termos de prazos a serem cumpridos.

Os seguintes atributos de qualidade foram tomados em conta na formulação do teste de validação: compreensibilidade, redundância, completude, ambiguidade, consistência, organização, conformidade com as normas e rastreabilidade. Na Tabela 3 é apresentado o modelo de questões para formulação dos atributos de qualidade do teste de validação do sistema computacional.

Tabela 3 - Teste de validação dos atributos do sistema

\begin{tabular}{|l|l||}
\hline Questões & Atributo de Qualidade \\
\hline \hline As questões são atributos da qualidade? & Rastreabilidade, Conformidade \\
\hline Os termos especializados aparecem no plano? & Compreensibilidade \\
\hline \hline Os requisitos dependem de outro para se & Compreensibilidade, \\
\hline compreender o seu significado? & Completude \\
\hline \hline $\begin{array}{l}\text { Existem requisitos que usam o mesmo termo com } \\
\text { sentidos diferentes? }\end{array}$ & Ambiguidade \\
\hline \hline O mesmo serviço é solicitado em vários requisitos? & Consistência, Redundância \\
\hline \hline Existe contradição nesta solicitação? & \\
\hline Isto está descrito no documento? & Organização, Rastreabilidade \\
\hline \hline $\begin{array}{l}\text { Os requisitos relacionados estão agrupados? } \\
\text { Se não estão, como se referenciam mutuamente? }\end{array}$ & \\
\hline
\end{tabular}

Para cada módulo do sistema computacional foi elaborado um roteiro e uma sequência para validação dos requisitos.

\subsection{1 - Validação da manutenção preventiva}

Para validar a manutenção preventiva se faz necessário:

- Alterar dados do plano de manutenção preventiva;

- Gerar o RMP;

- Consultar e Imprimir o RMP. 


\title{
Validação
}

Identificação:

Tag:

\author{
EE-CCM-01
}

Alterar Dados de Manutenção:

Previsão da Data Próxima realização:

19/12/2013

Frequência:

Semestral

Aplicabilidade (Sim ou Não):

SIM

Registrar a Execução da Manutenção:

Identificação do Equipamento:

EE-CCM-01

Descrição do Equipamento:

Centro de comando de motores

Manutenção Programada para:

19/06/2013

Empresa:

IPEN-CNEN/SP

Técnico Responsável:

Gílson

Identificação da Empresa (CNPJ):

00.402.552/0005-50

Ocorrências Verificadas:

Nenhuma

Executor e Data:

27/06/2013

Funcionário e Data:

27/06/2013

Tarefas:

Parecer do Técnico

Limpar os contatos elétricos das chaves

OK

seccionadoras;

Verificar o funcionamento das lâmpadas OK

de sinalização.

Imprimir o RMP:

Número de Controle:

11995

\subsection{2 - Validação da manutenção corretiva}

Para validar a manutenção corretiva se faz necessário:

- Criar um usuário;

- Solicitar serviço de manutenção corretiva e emitir RMC;

- Atualizar dados referentes a execução do RMC;

- Gerar um novo RMC;

- Avaliar o serviço executado; 
- Imprimir o RMC.

\section{Validação}

Identificação:

Tag:

\section{$X N-V G C-05$}

Solicitar um Serviço de Manutenção Corretiva:

Modalidade:

Natureza do Serviço:

Atendimento até:

Descrição do Problema:

Contato - Nome:

Contato - Setor:

Contato - Ramal:

Contato - Data:

Contato - Hora:

Solicitante - Crachá:

Registrar a Execução da Manutenção:

Descrição dos Componentes:

Descrição do Serviço:

Observação:

Executor - Crachá:

Avaliação do Solicitante:

Qualidade do Serviço:

Prazo de Entrega:

Atendimento ao Cliente:

Tempo de Execução (horas):

Horas Homem Previsto:

Horas Homem Executado:

Imprimir o RMC:

Número de Controle
Equipamento

Mecânica

Normal

Ventilador inoperante

$B I S P O$

CRO

8855

$28 / 02 / 2013$

08:20:00

106 - Alberto

Correias A30

Troca

Nenhuma

Emanoel Bispo - 496

Ótimo

Ótímo

Ótimo

1 hora

1 hora

1057

\subsection{3 - Validação da calibração}

Para validar a calibração se faz necessário:

- Cadastrar um instrumento ou medidor; 
- Incluir uma programação de calibração para o instrumento ou medidor;

- Imprimir o histórico de calibração para o referido instrumento ou medidor;

- Imprimir relatório de calibração;

- Colocar data de execução, executor e empresa;

- Gerar uma nova programação;

- Imprimir o histórico de calibração;

- Imprimir relatórios de calibração de pendentes no mês/ano da nova data de programação;

- Imprimir relatórios de calibração concluídos no mês/ano de execução.

\section{Validação}

Identificação:

Tag:

IC-ELM-03

Registrar um Novo Medidor ou Instrumento:

Numero de Patrimônio:

28829

Localização:

Laboratório de eletrônica

Área responsável:

CRO

Descrição do Medidor:

Eletrômetro digital

Fabricante:

KEITHLEY

Modelo:

617

Serie:

0577694

Aplicação:

IC - Instrumentação e controle

Situação:

Em uso

Observações:

Nenhuma

Parâmetros de Calibração: $\quad$ Faixa de Operação: 10 a 100 nA; 1 uA a 10 uA; 100 uA a 1 mA.

Erro máximo admissível: $5 \%$ do valor medido em cada faixa de operação

Incluir uma Programação de Calibração: 
Tarefa (Calibrar ou Validar): Calibrar

Periodicidade: Bi-anual

Programar Calibração Para: 28/06/2013

Situação do Equipamento: $\quad$ Em uso

Registrar a Execução da Calibração:

Data da Realização

28/06/2013

Técnico Responsável

Patrício

Situação do Equipamento

Em uso

Certificado 125167-101

Empresa Responsável

IPT

\section{7 - Manutenção}

Foram realizadas as correções necessárias de falhas ou erros durante a etapa de Verificação do software do sistema computacional.

Foi finalizada a documentação do projeto interno do sistema computacional, o manual do usuário, para propósitos de futuras correções e aprimoramentos. 


\section{4. - PARTE EXPERIMENTAL}

O sistema computacional foi desenvolvido em "Delphi" que é uma linguagem de pesquisa declarativa para bancos de dados relacionais. $O$ "Delphi" é largamente utilizado no desenvolvimento de aplicações desktop, aplicações multicamadas e "Cliente/Servidor", além de ser compatível com os bancos de dados mais conhecidos do mercado.

Como uma ferramenta de desenvolvimento genérica, o Delphi pode ser utilizado para diversos tipos de desenvolvimento de projeto, abrangendo desde serviços a aplicações Web e CTI. Pode ser usado para desenvolver aplicações que exijam tanto uma linguagem de alto nível ou baixo nível. Um exemplo de software conhecido que foi desenvolvido em "Delphi" é o "Skype" $[12,13]$.

O nome "Delphi" é inspirado na cidade de Delfos, o único local na Grécia antiga em que era possível consultar o Oráculo de Delfos. O nome deve-se ao fato de que os desenvolvedores do compilador buscavam uma ferramenta capaz de acessar o banco de dados Oracle - daí o trocadilho:

A única maneira de acessar o oráculo é usando "Delphi".

Vantagens do Delphi como linguagem de programação:

- Melhor Ferramenta para se começar a desenvolver um software;

- Permite programar, virtualmente, qualquer tipo de aplicação para qualquer ambiente de programação;

- Existem muitas assistências on-line, componentes gratuitos ou de custo reduzido disponíveis na Internet e uma infinidade de listas de discussão;

- O Delphi possui características que possibilitam a reusabilidade do código-fonte;

- O Delphi é oriundo do "Object Pascal", que é uma ferramenta de desenvolvimento poderosa, abrangente e totalmente orientada a objetos;

- Compilador rápido que gera instruções binárias nativas (código de máquina), dispensando a necessidade de se usar "run time's" e tendo a grande vantagem de ser impossível de ser descompilado;

- Acesso a bases de dados "Cliente/Servidor" como: "Oracle", "Informix", "Interbase", "Access", "Paradox", "DBase" e outras; 
- Possibilidade de se desenvolver objetos do início ou usar como base algum já disponível. Esta característica economiza muito tempo na hora do desenvolvimento de objetos, e minimiza a ocorrência de erros;

- Desenvolvimento de aplicações para Internet;

- Ambiente de desenvolvimento com compilador extremamente rápido, com tecnologia que possibilita que após a primeira compilação só seja compilado o código modificado.

A linguagem de programação "Delphi” foi utilizada na elaboração de aplicativos que permitirão ao usuário realizar tarefas tais como: entrada, atualização de dados, emissão de relatórios, controle das manutenções e calibrações realizadas.

Outra opção para o sistema computacional seria o desenvolvimento em ambiente $A S P / S Q L$, onde o $A S P$ é uma estrutura de bibliotecas básicas para processamento de linguagens de script servidor para geração de conteúdo na Web, e o SQL, é uma linguagem de pesquisa declarativa para bancos de dados relacionais [29] [30]. 


\section{5. - RESULTADOS}

O Sistema Computacional Para Planejamento e Controle da Manutenção do Reator IEA-R1 é constituído dos seguintes módulos: Manutenção Preventiva, Manutenção Corretiva e Calibração.

\section{1 - Módulo de manutenção preventiva}

Para acessar o módulo de Manutenção Preventiva, é necessário informar o crachá e a senha. O usuário pode efetuar o seu cadastramento selecionando a opção "Cadastramento", ao entrar com as informações será criado um usuário com direitos apenas de consulta e impressão de relatórios. Para criar usuários com direitos de atualização somente por intermédio do administrador do sistema. A Figura 10 apresenta a tela de acesso do módulo de manutenção preventiva.

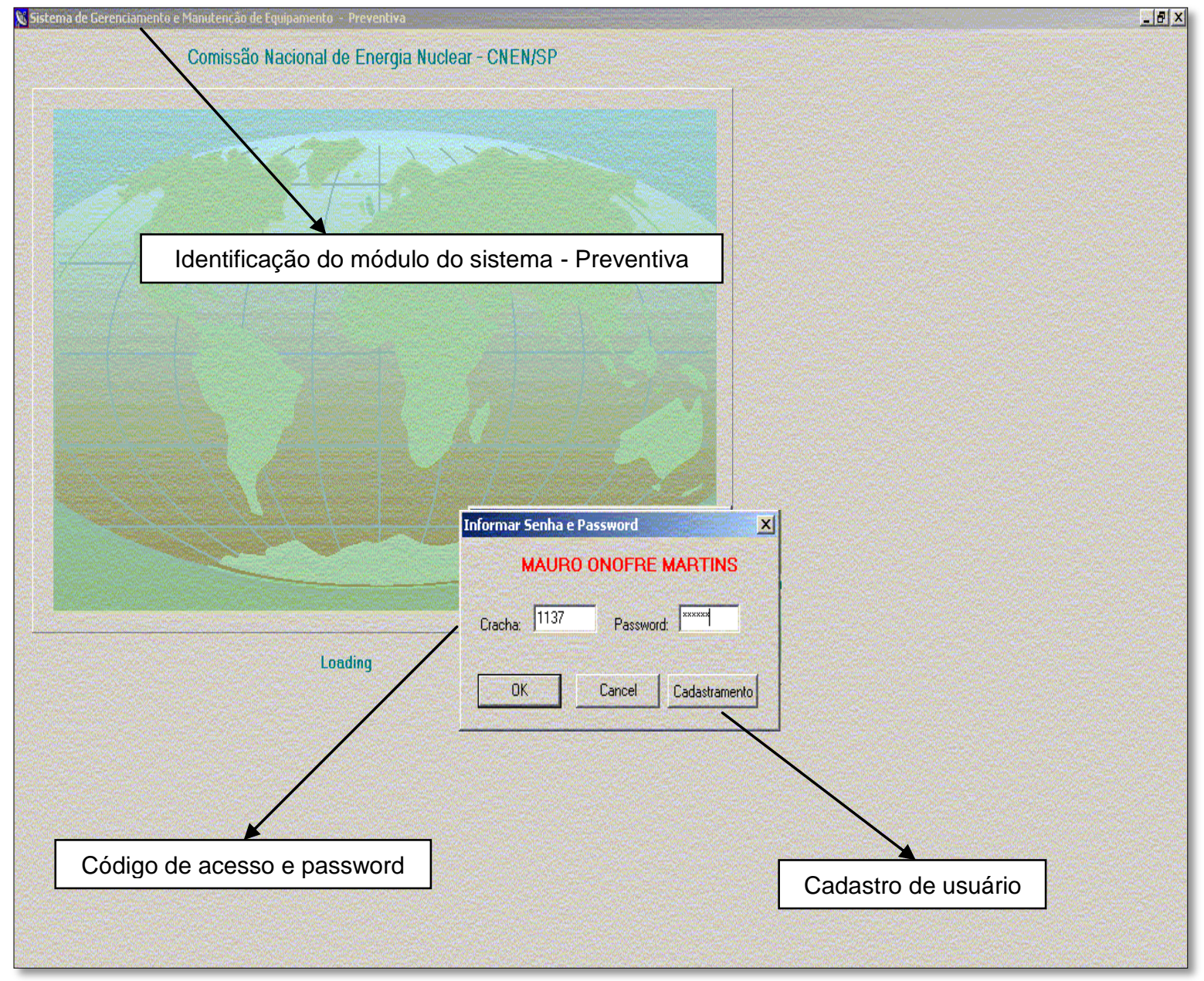

Figura 10 - Tela de acesso do módulo de manutenção preventiva.

O módulo de Manutenção Preventiva é dividido em: Cadastro, Atualização e Relatórios. 


\subsection{1 - Cadastro}

O Cadastro é o responsável pelo armazenamento das informações nos bancos de dados dos equipamentos da instalação, dos planos de manutenção e das tarefas a serem executadas durante as manutenções preventivas. Todo equipamento cadastrado recebe uma identificação Tag, que permite identificar o sistema a que pertence o tipo de equipamento e a quantidade existente.

No plano de manutenção estão armazenadas todas as instruções técnicas referentes ao plano de manutenção do Reator, bem como a periodicidade em que estas deve ser executadas. As informações armazenadas se referem tanto a um equipamento individual como a um sistema composto de vários equipamentos. A Figura 11 apresenta a tela principal da manutenção preventiva.

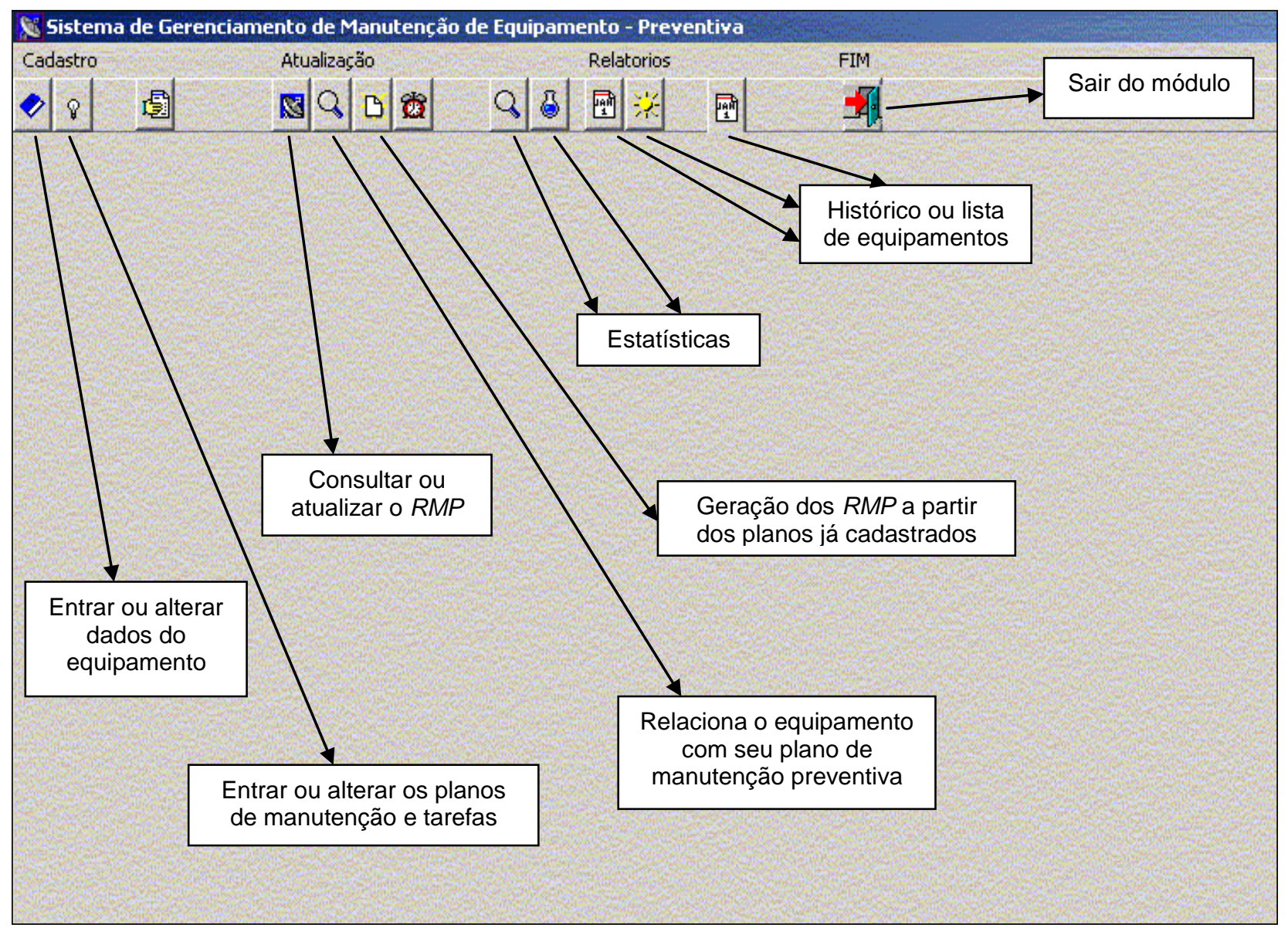

Figura 11 - Tela principal do módulo de manutenção preventiva.

O Cadastro permite a inclusão, alteração e exclusão de registros, bem como elaboração de relatórios para simples conferência. 
As Figuras 12, 13, 14, 15, 16, 17, 18, 19 apresentam telas descritas acima e a Figura 20 o relatório impresso.

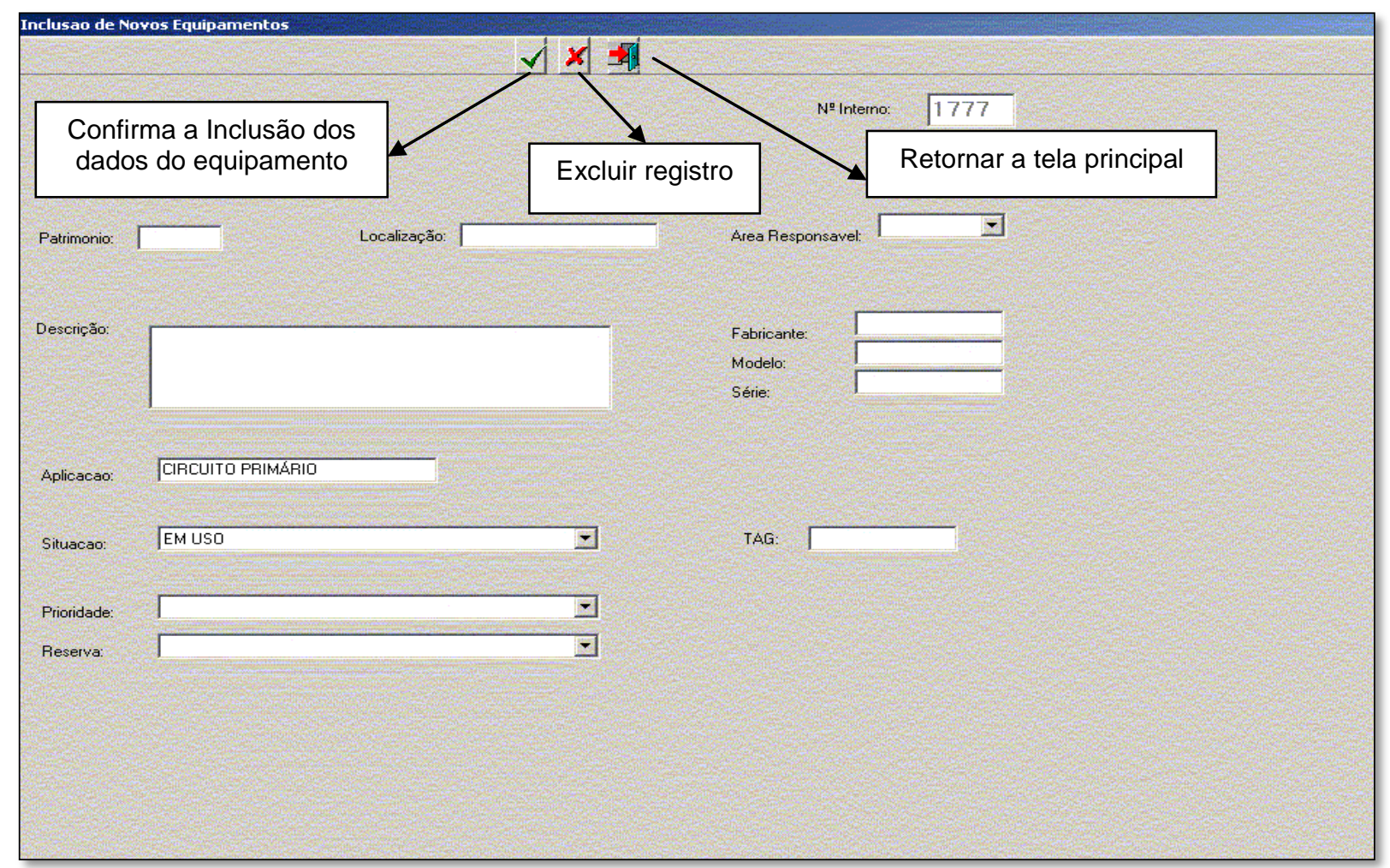

Figura 12 - Inclusão de dados de equipamento.

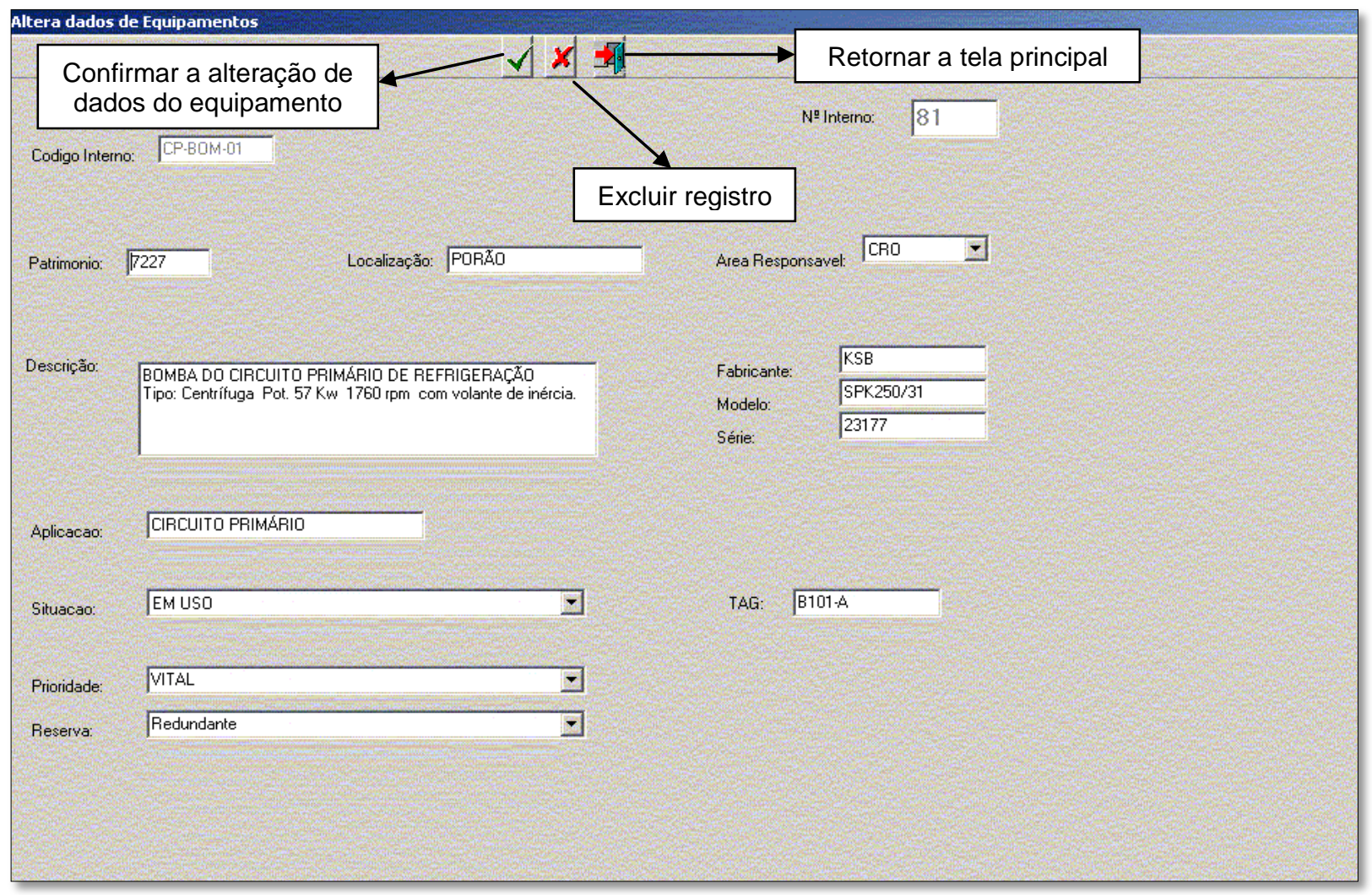

Figura 13 - Alteração de dados de equipamento. 


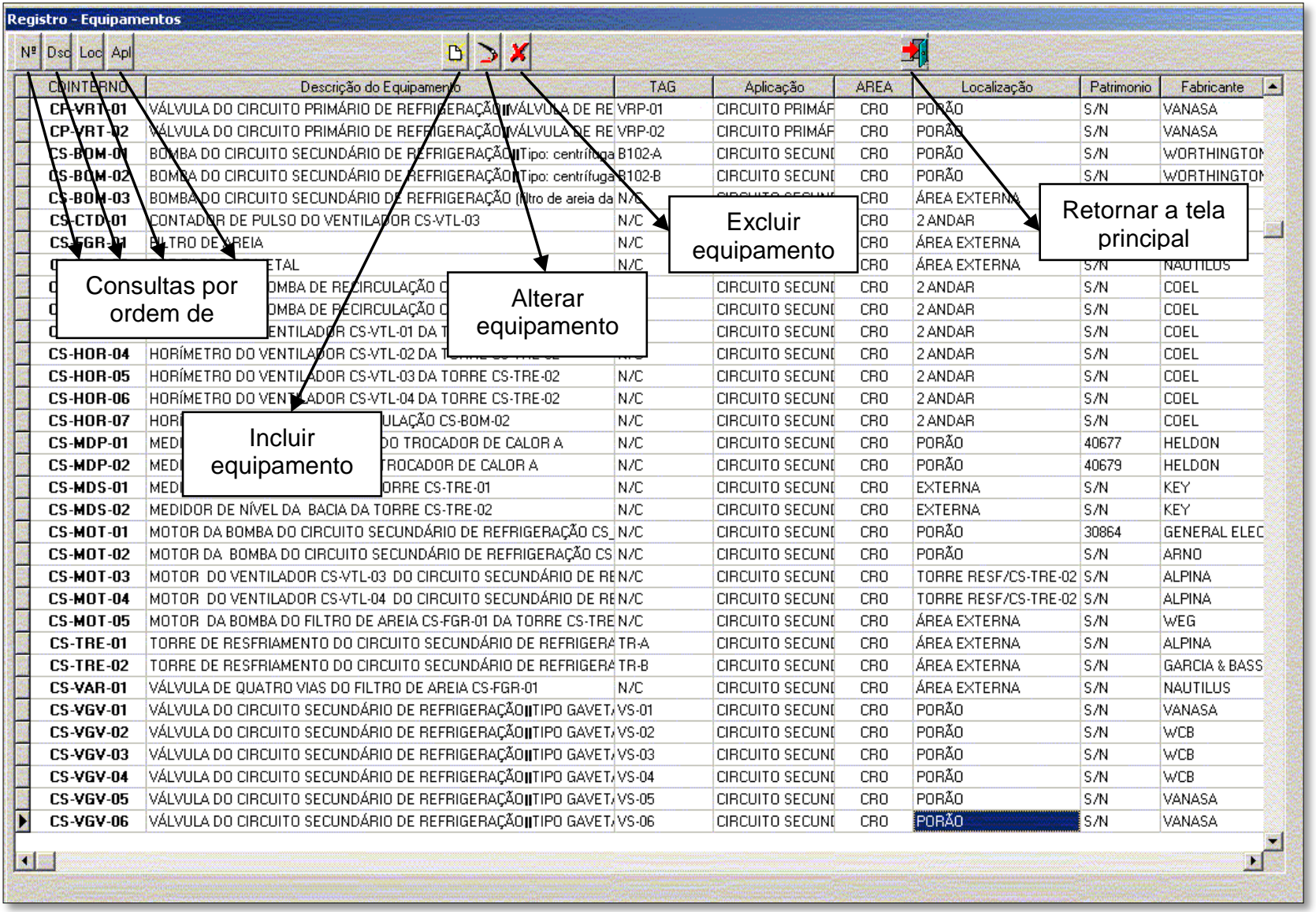

Figura 14 - Cadastro de equipamento completo.

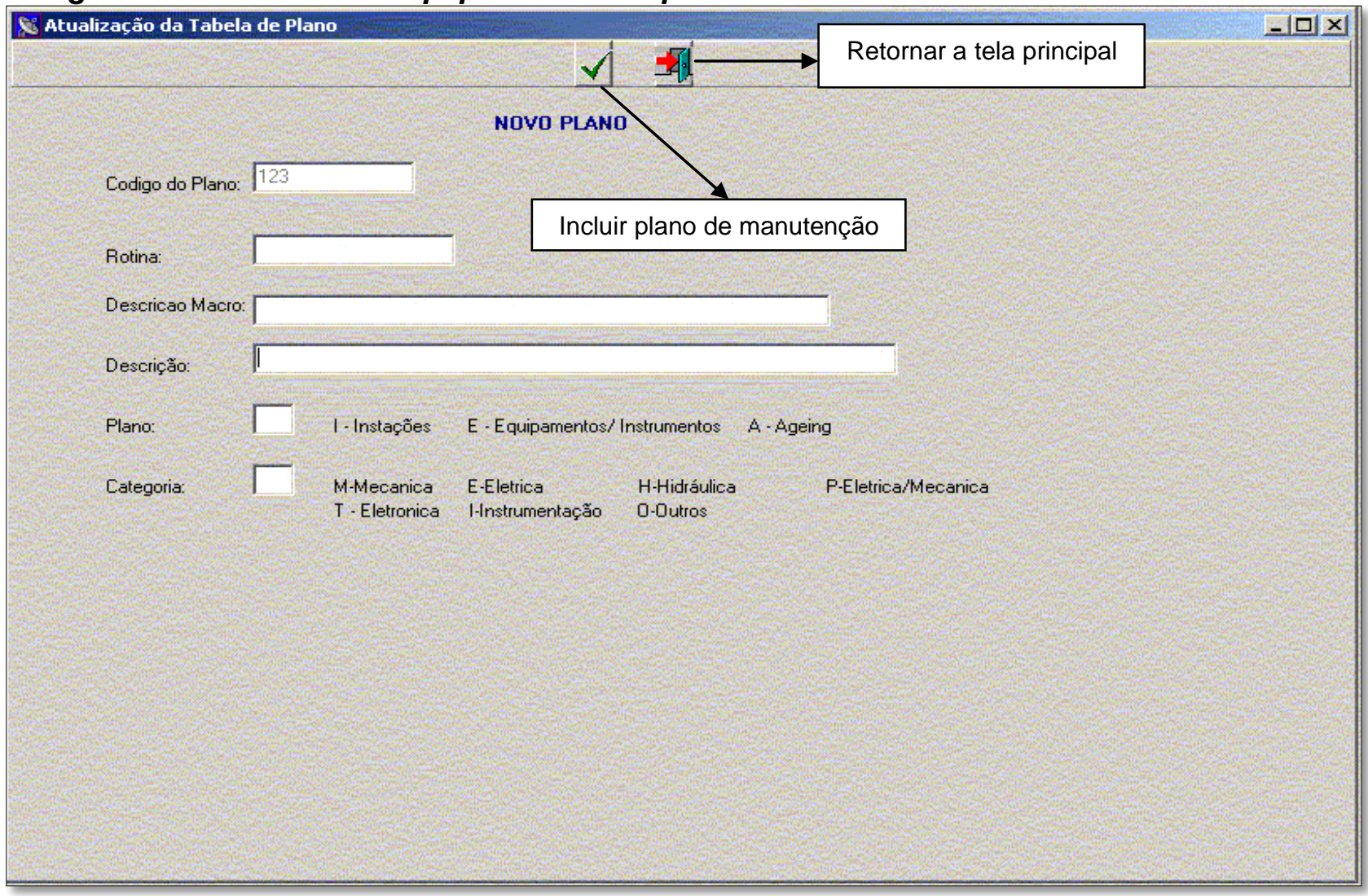

Figura 15 - Inclusão de plano de manutenção preventiva. 


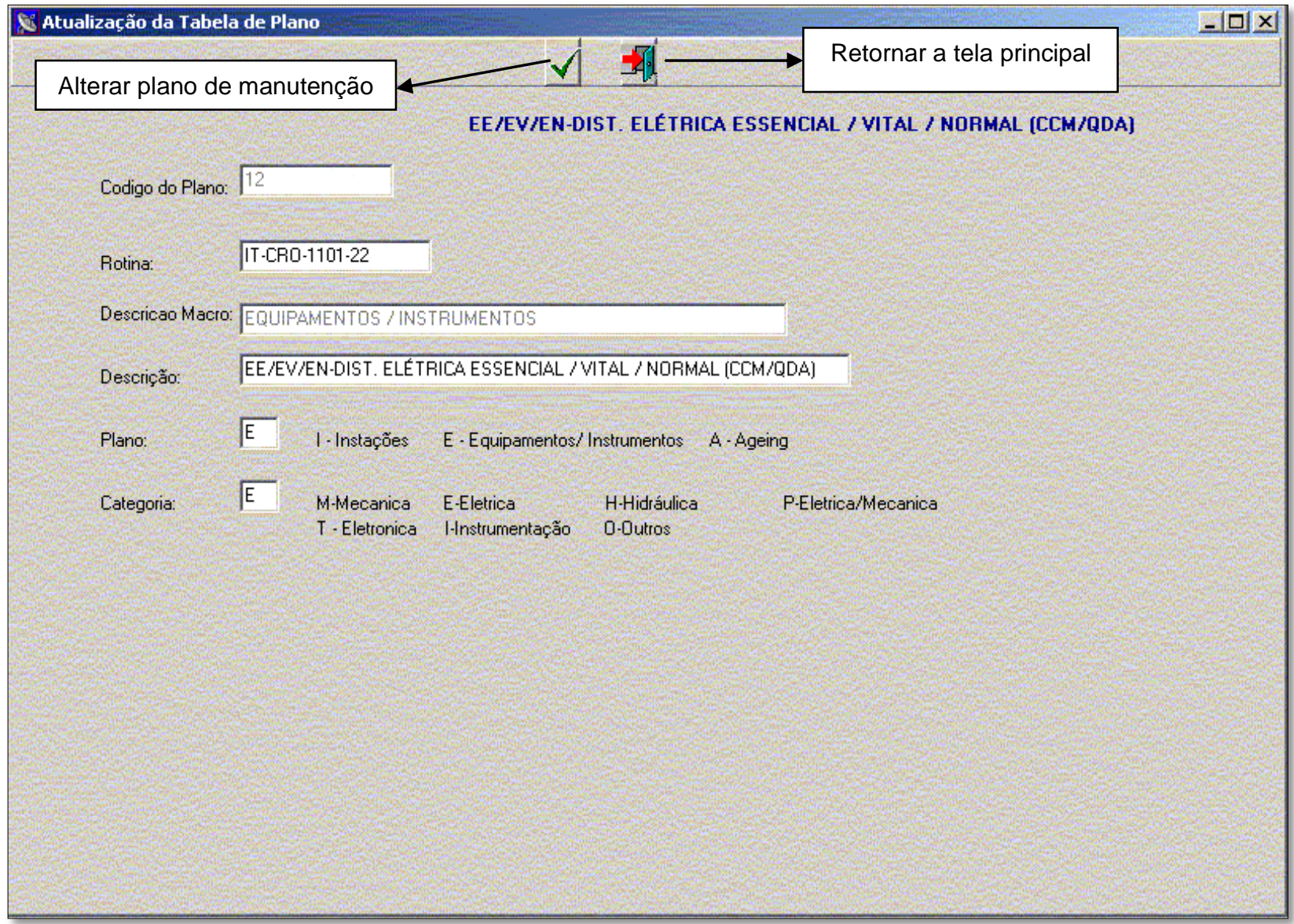

Figura 16 - Alteração do plano de manutenção preventiva.

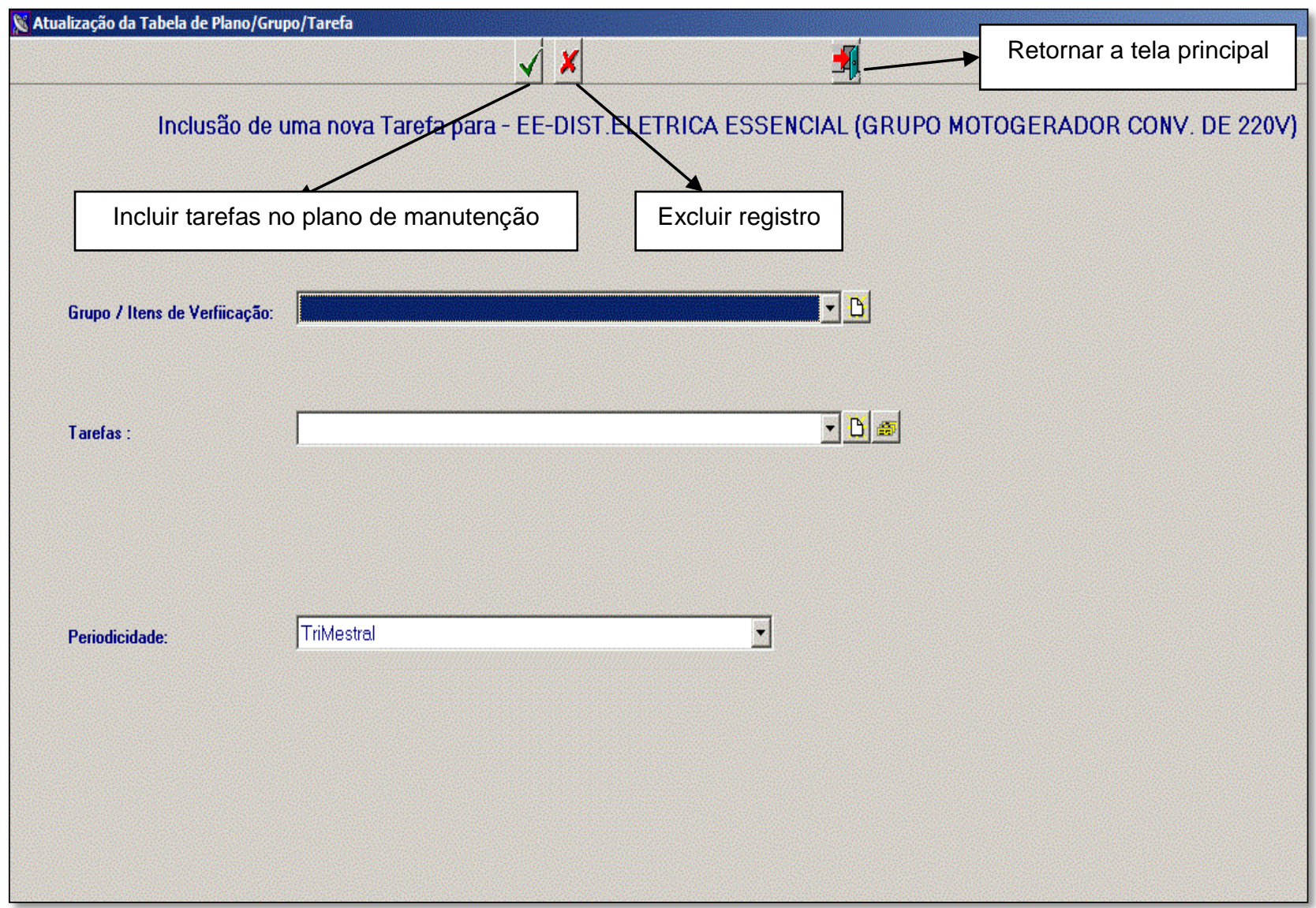

Figura 17 - Inclusão de tarefas no plano de manutenção preventiva. 


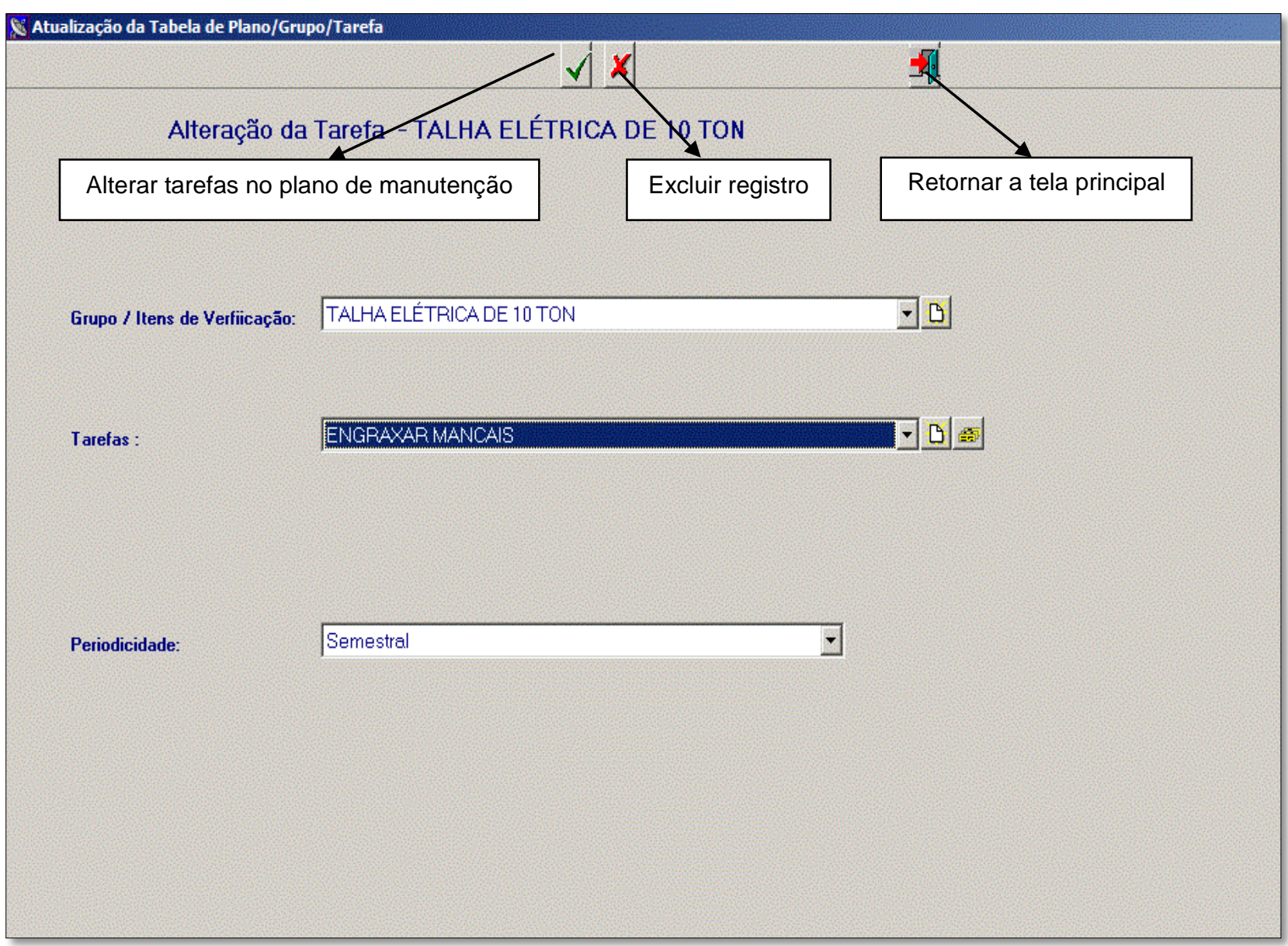

Figura 18 - Alteração de tarefas no plano de manutenção preventiva.

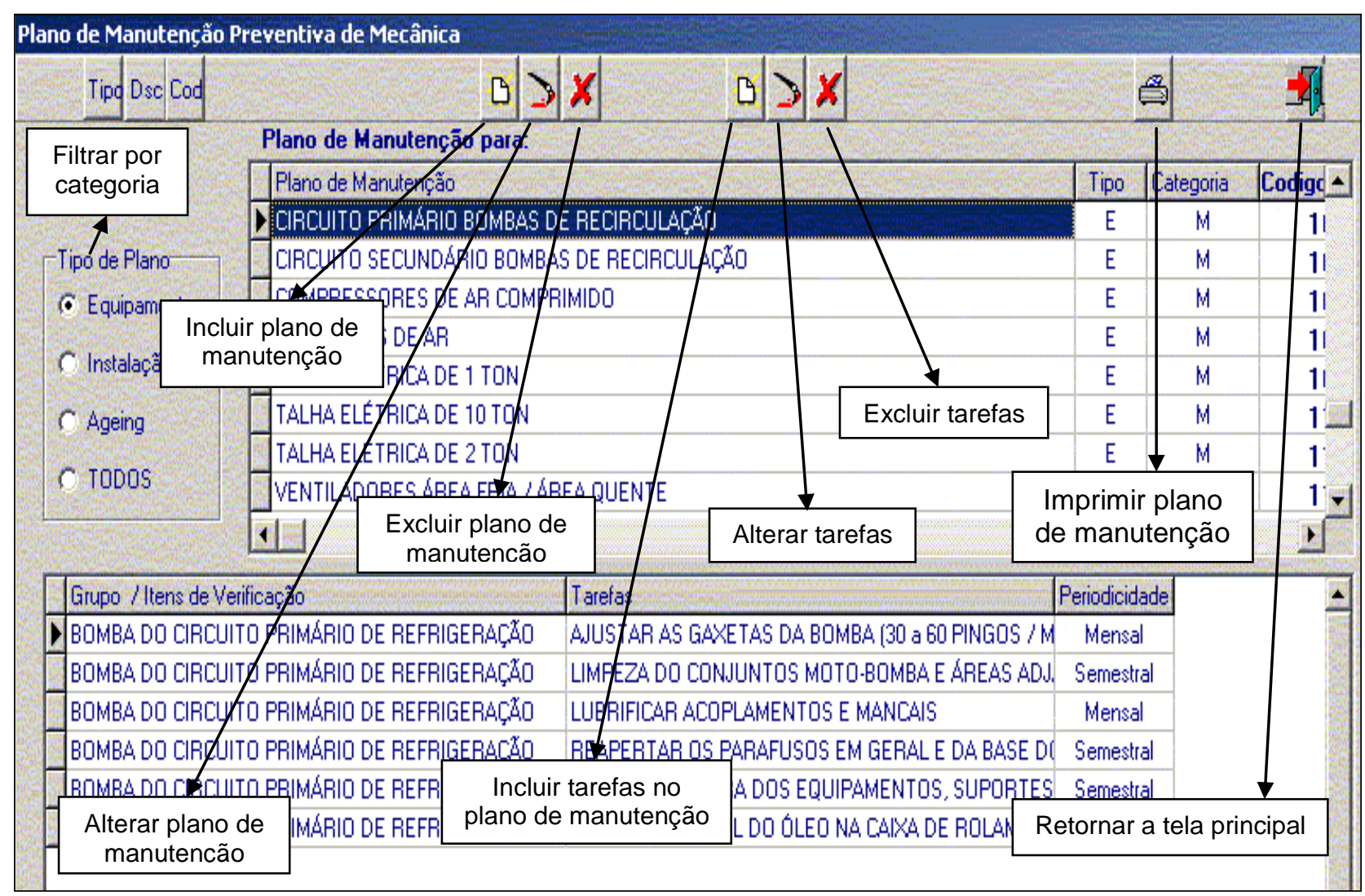

Figura 19 - Inclusão de plano ou tarefa de manutenção preventiva. 


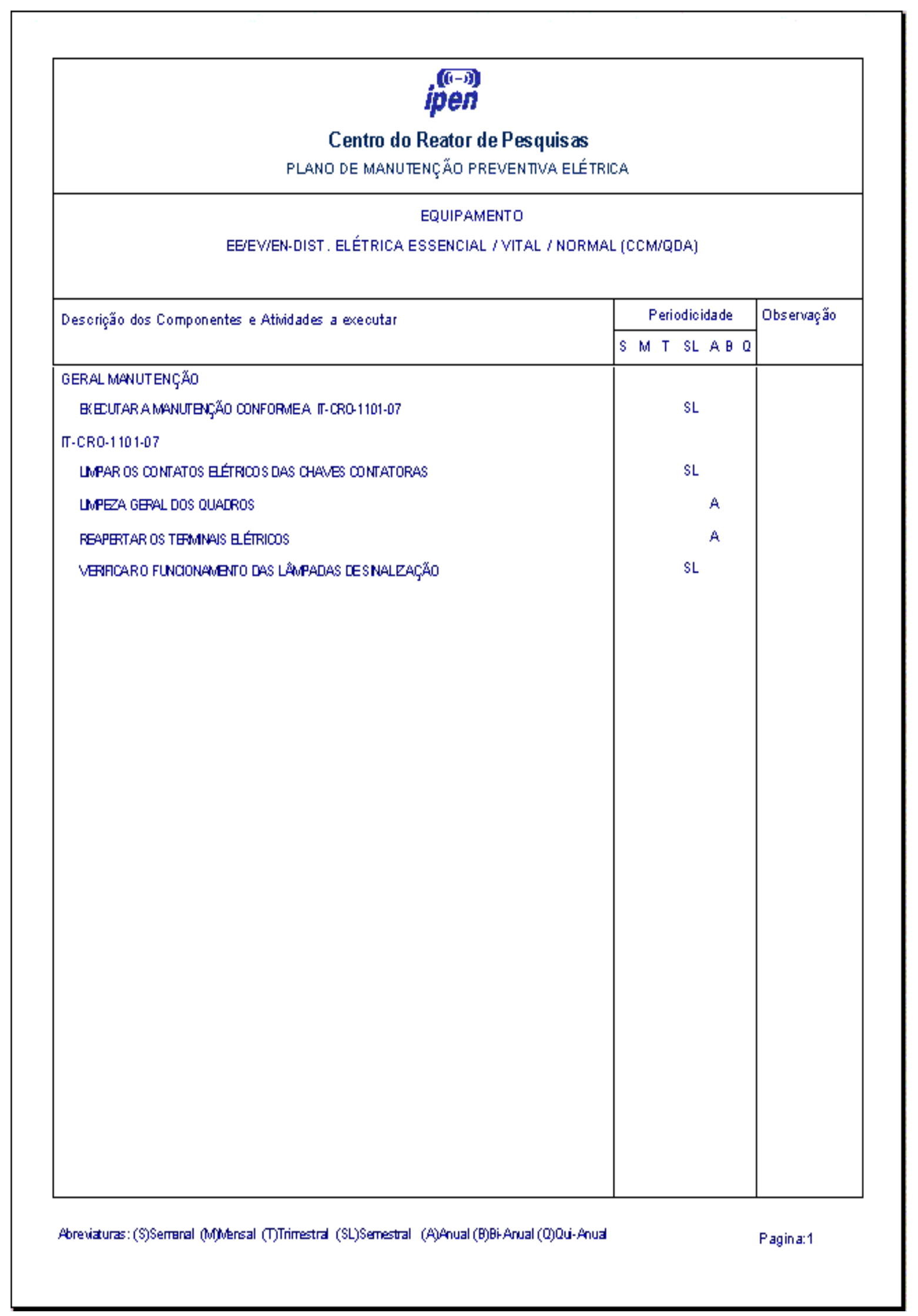

Figura 20 - Impressão de plano de manutenção preventiva. 


\subsection{2 - Atualização}

A Atualização é a responsável pela geração do registro de manutenção preventiva, o controle sobre essas fichas e o histórico de todos os registros. Todo registro de manutenção preventiva recebe um número de controle sequencial, que não poderá ser utilizado por outro equipamento. Caso necessite de uma complementação ou substituição, este registro de manutenção preventiva poderá ser cancelado, e um novo registro de manutenção preventiva será gerado obedecendo a sequência numérica. A Atualização está dividida em: Consulta do RMP, Consulta das tarefas e Atualização da situação do RMP. As Figuras 21, 22 e 23 apresentam as telas descritas acima.

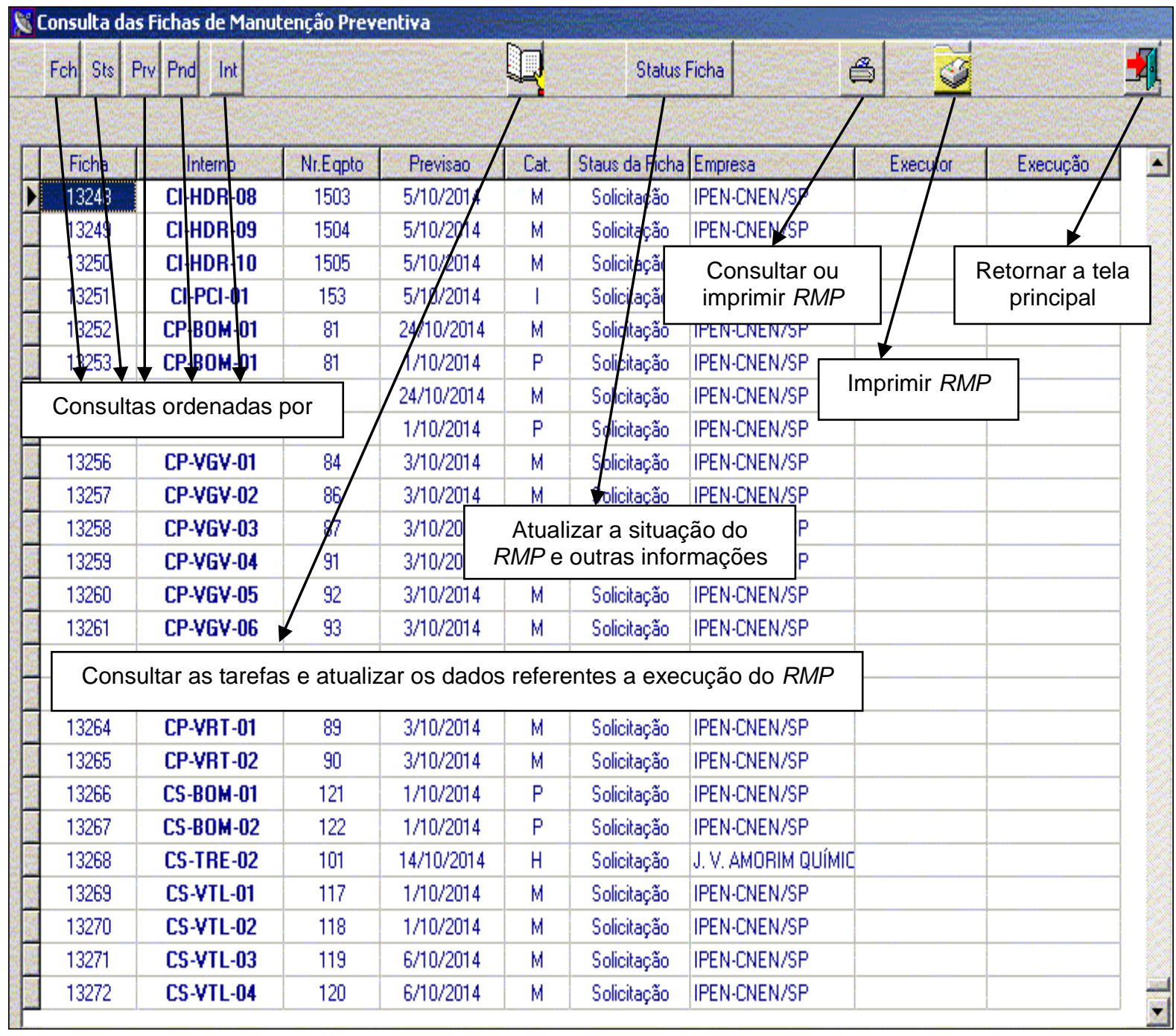

Figura 21 - Consulta do registro de manutenção preventiva - RMP. 


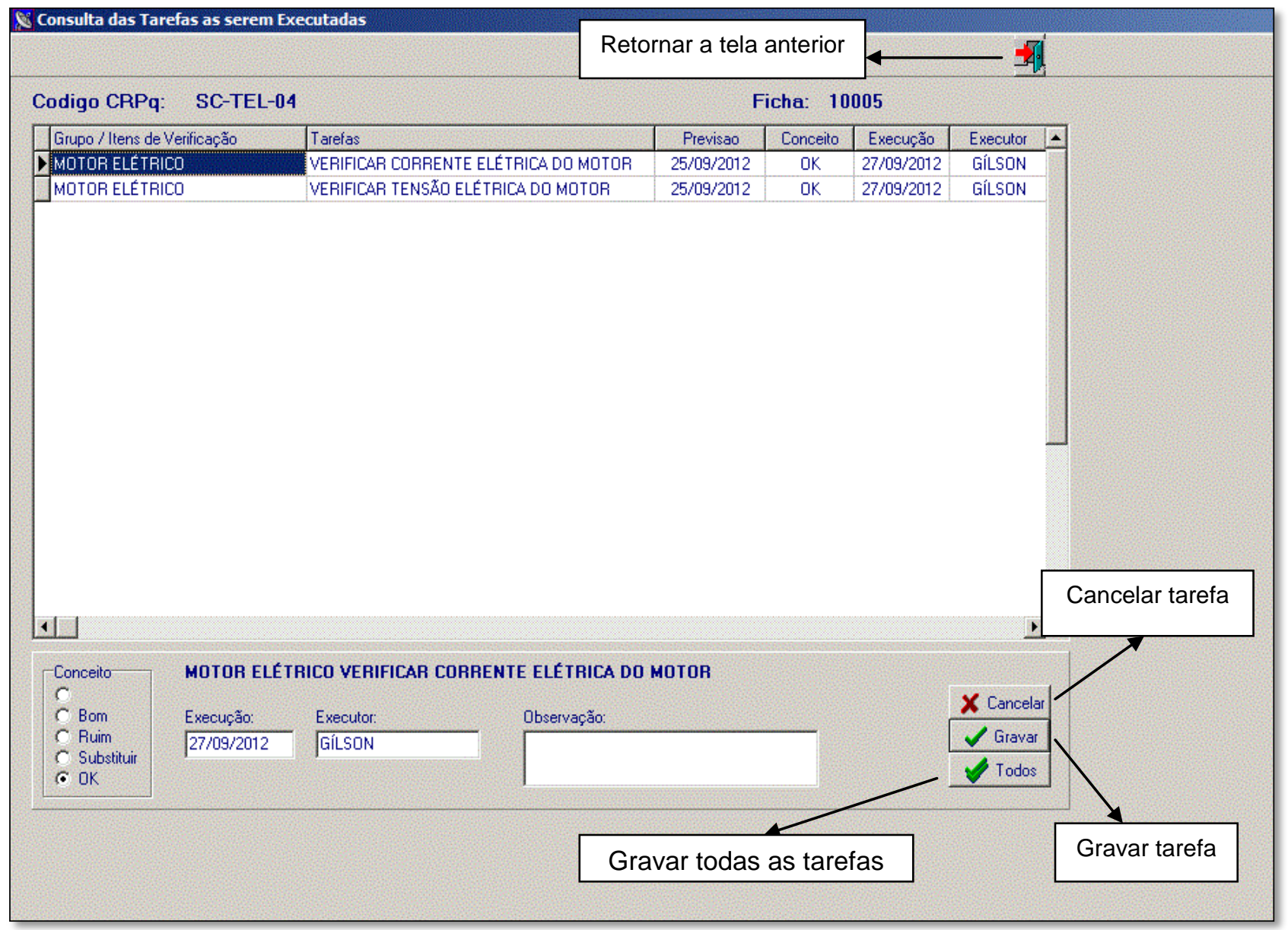

Figura 22 - Consulta das tarefas a serem executadas no RMP.

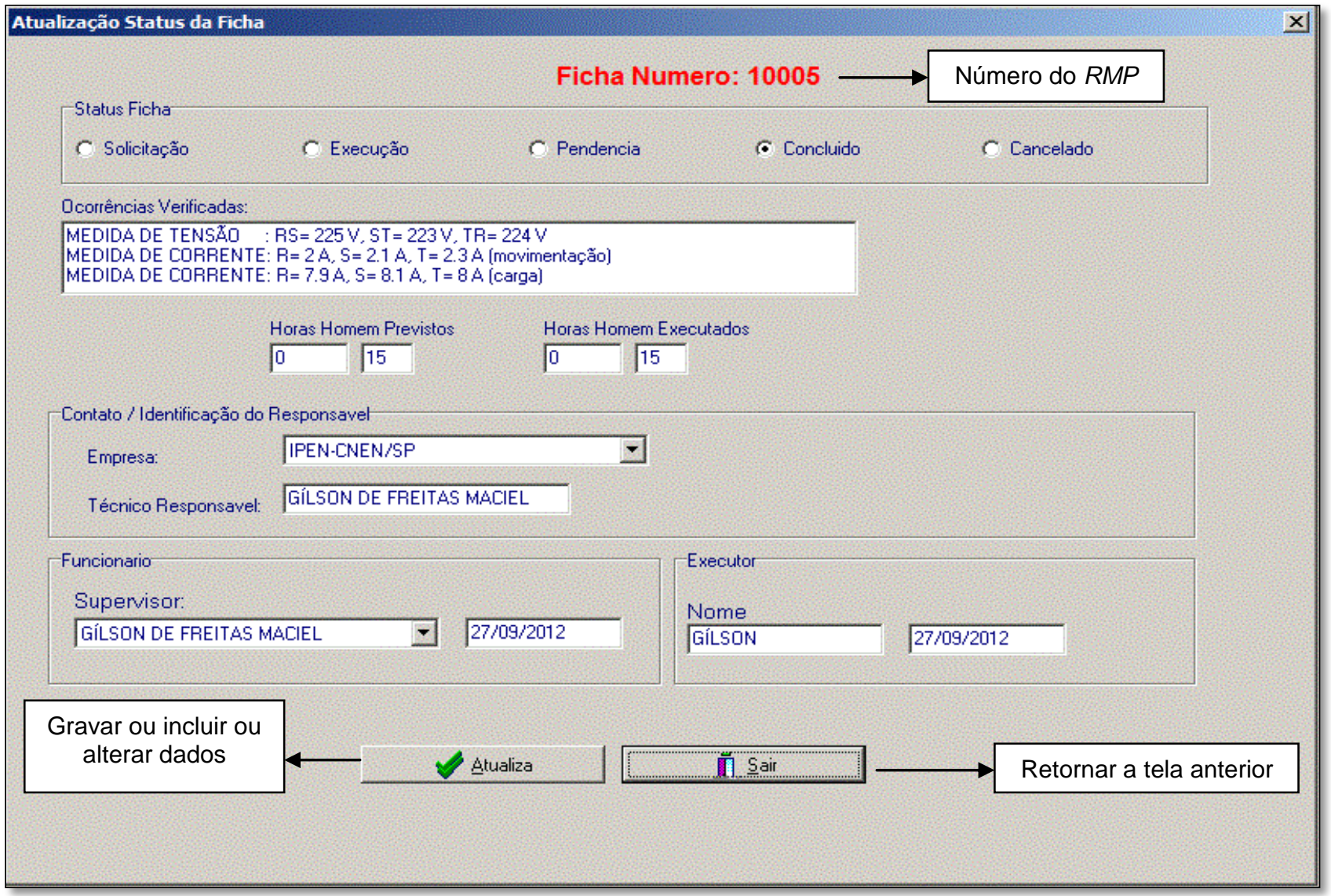

Figura 23 - Atualização da situação do RMP. 


\subsubsection{1 - Programação de manutenção preventiva}

O sistema relaciona o equipamento com o seu respectivo plano de manutenção, bem como a periodicidade, a data prevista para a sua execução e o responsável pela tarefa. A Figura 24 mostra a tela descrita acima.

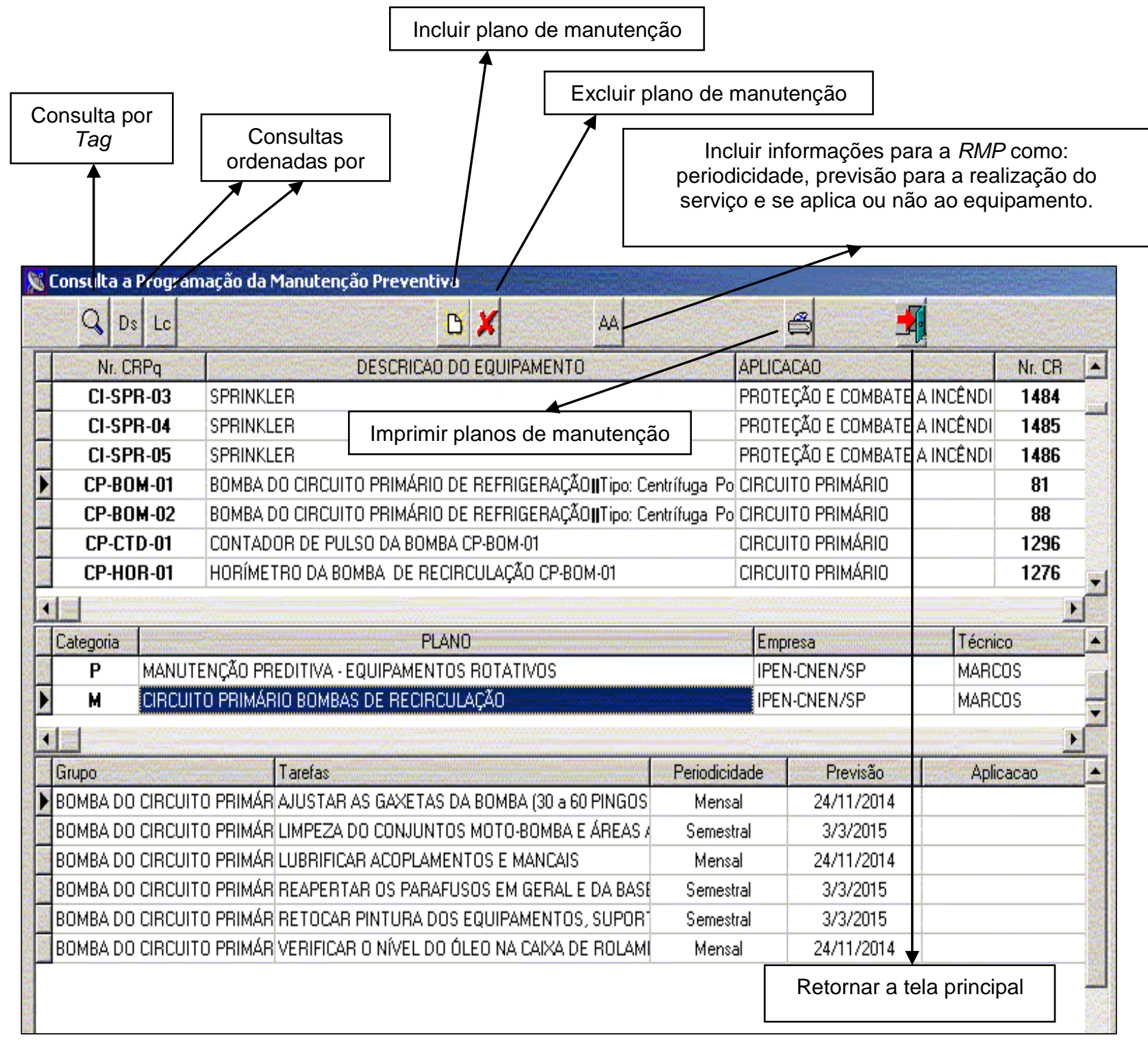

Figura 24 - Consulta ou atualização da programação do RMP.

\subsubsection{2 - Gerar registro de manutenção}

O sistema gera os registros de manutenção preventiva de cada equipamento ou sistema, de acordo com o período desejado. Os registros são numerados e impressos para execução. Uma vez realizada a manutenção preventiva, e corretamente preenchido, o registro é devolvido para atualização do banco de dados. A Figura 25 apresenta a tela descrita acima. 


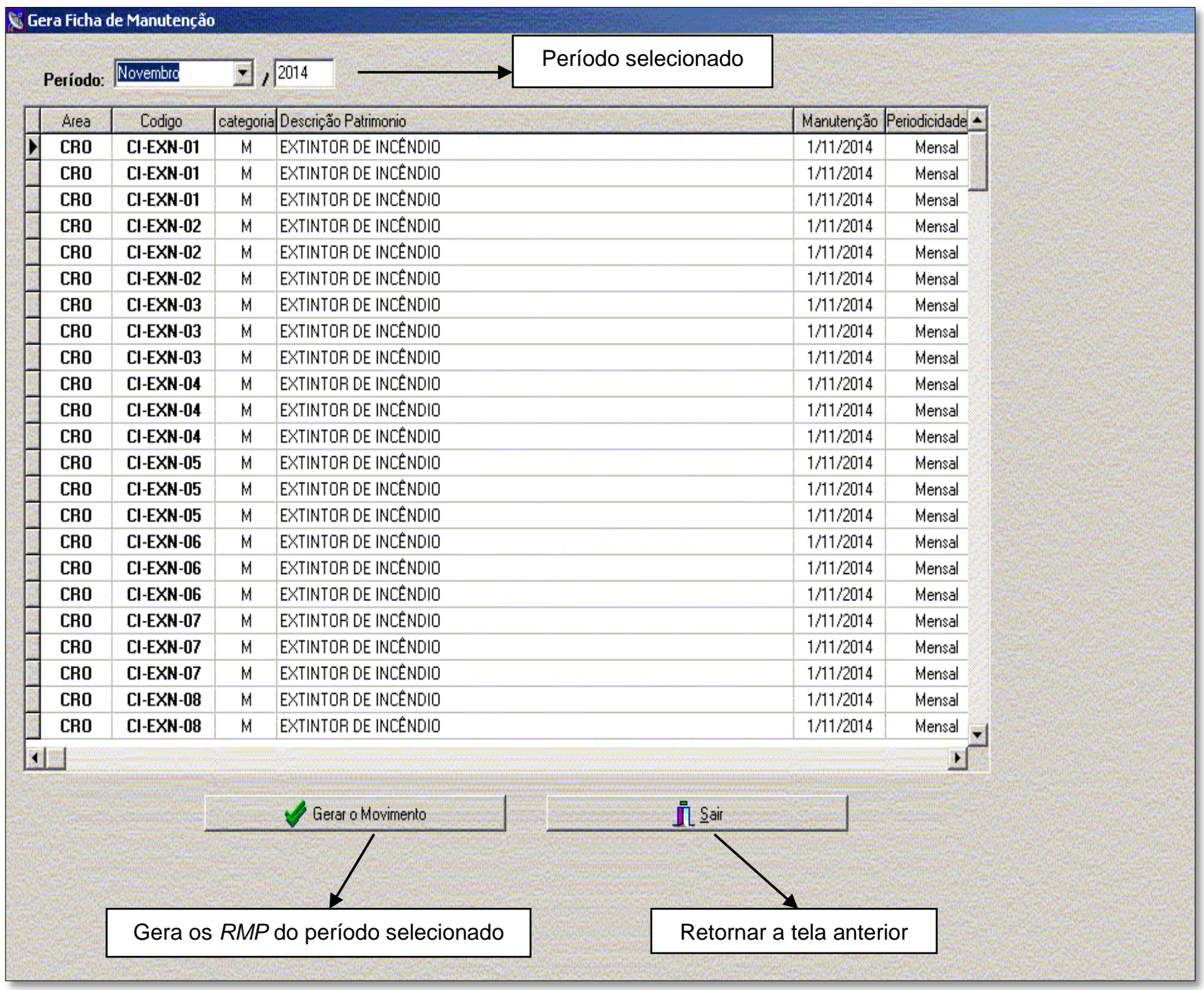

Figura 25 - Gera registro de manutenção preventiva - RMP.

\subsubsection{3 - Acompanhamento do Registro}

O sistema atualiza o banco de dados do registro de manutenção preventiva, de acordo com o status da execução (solicitação ou execução ou pendência ou concluído ou cancelado). São anotadas as ocorrências que não estavam previstas durante a manutenção, bem como são identificados o executor e a data em que foi realizada a manutenção preventiva. As Figuras 26 e 27 apresentam o RMP a ser elaborado e impresso.

Estas informações são muito importantes, pois é a partir delas que serão gerados os relatórios de Histórico de Manutenção, que contém todas as manutenções preventivas realizadas em cada equipamento ou sistema. Estas 
informações são fundamentais para as previsões de futuras ações preventivas no Reator, como o Módulo de Manutenção Preditiva.

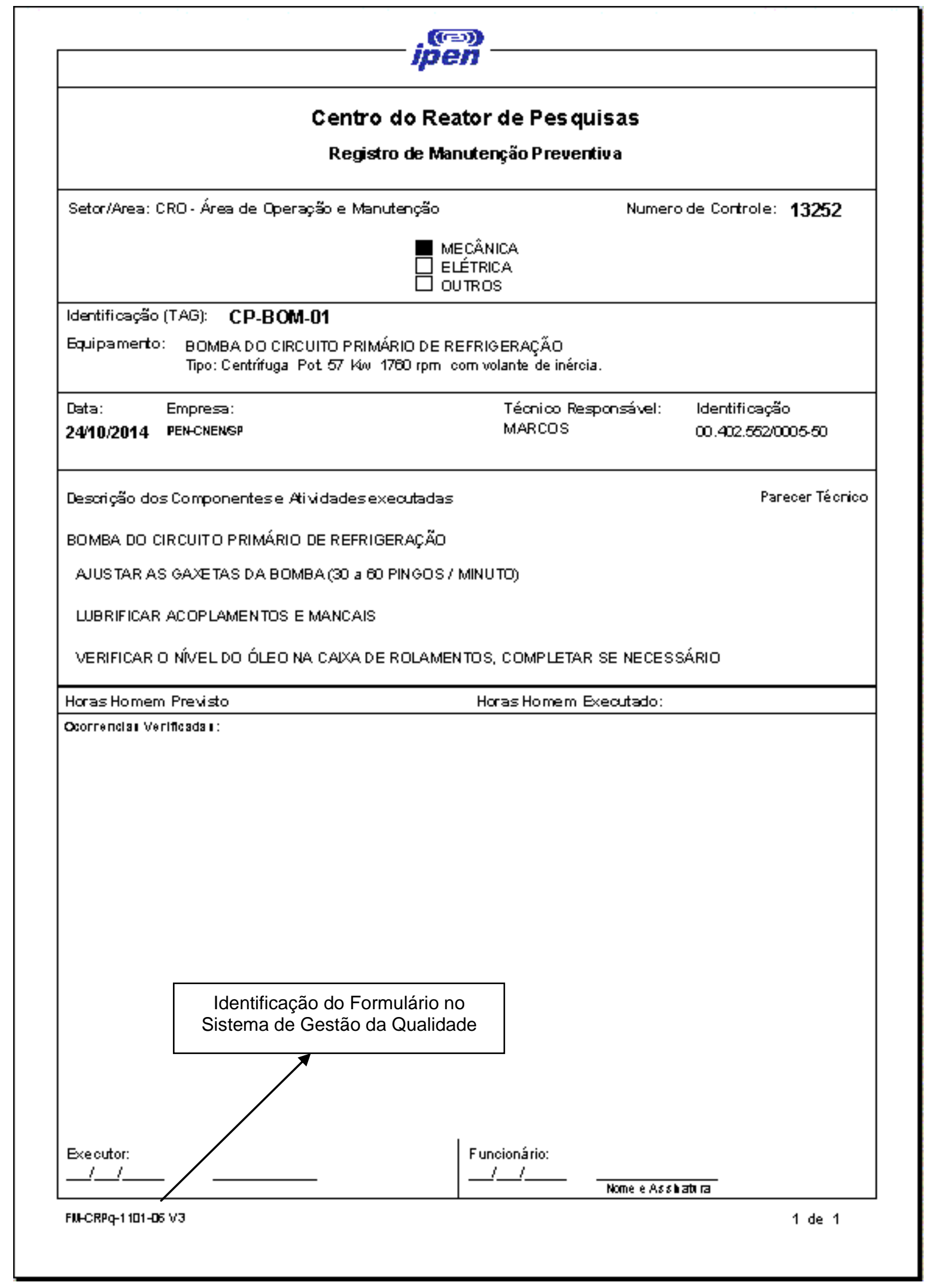

Figura 26 - Registro de manutenção preventiva - RMP. 


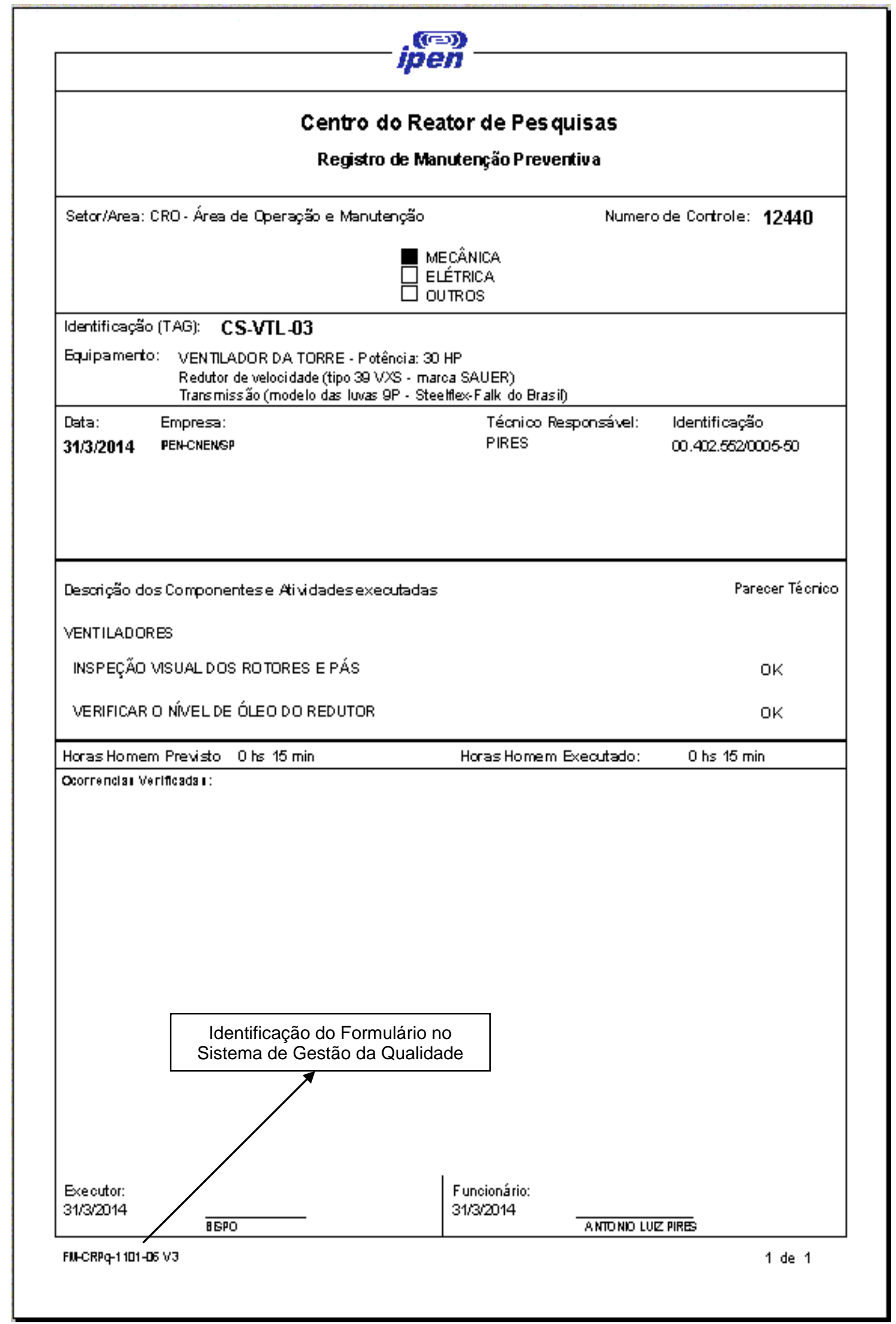

Figura 27 - Registro de manutenção preventiva executado. 


\subsubsection{4 - Histórico de equipamento}

O sistema computacional gera o histórico da manutenção preventiva de cada equipamento por aplicação como apresenta a Figura 28. Depois de selecionado a aplicação o sistema computacional imprime o histórico. A Figura 29 mostra o histórico do equipamento a ser elaborado e impresso.

\subsubsection{5 - Lista de planos}

O sistema computacional gera listas de planos existentes no banco de dados, selecionados por categoria e por equipamento. As Figuras 30 e 31 apresentam as telas a serem elaboradas.

\subsubsection{6 - Lista de equipamentos}

O sistema computacional gera listas de equipamentos existentes no banco de dados, selecionados por código de aplicação. As Figuras 32, 33 e 34 apresentam as telas descritas e impressas.

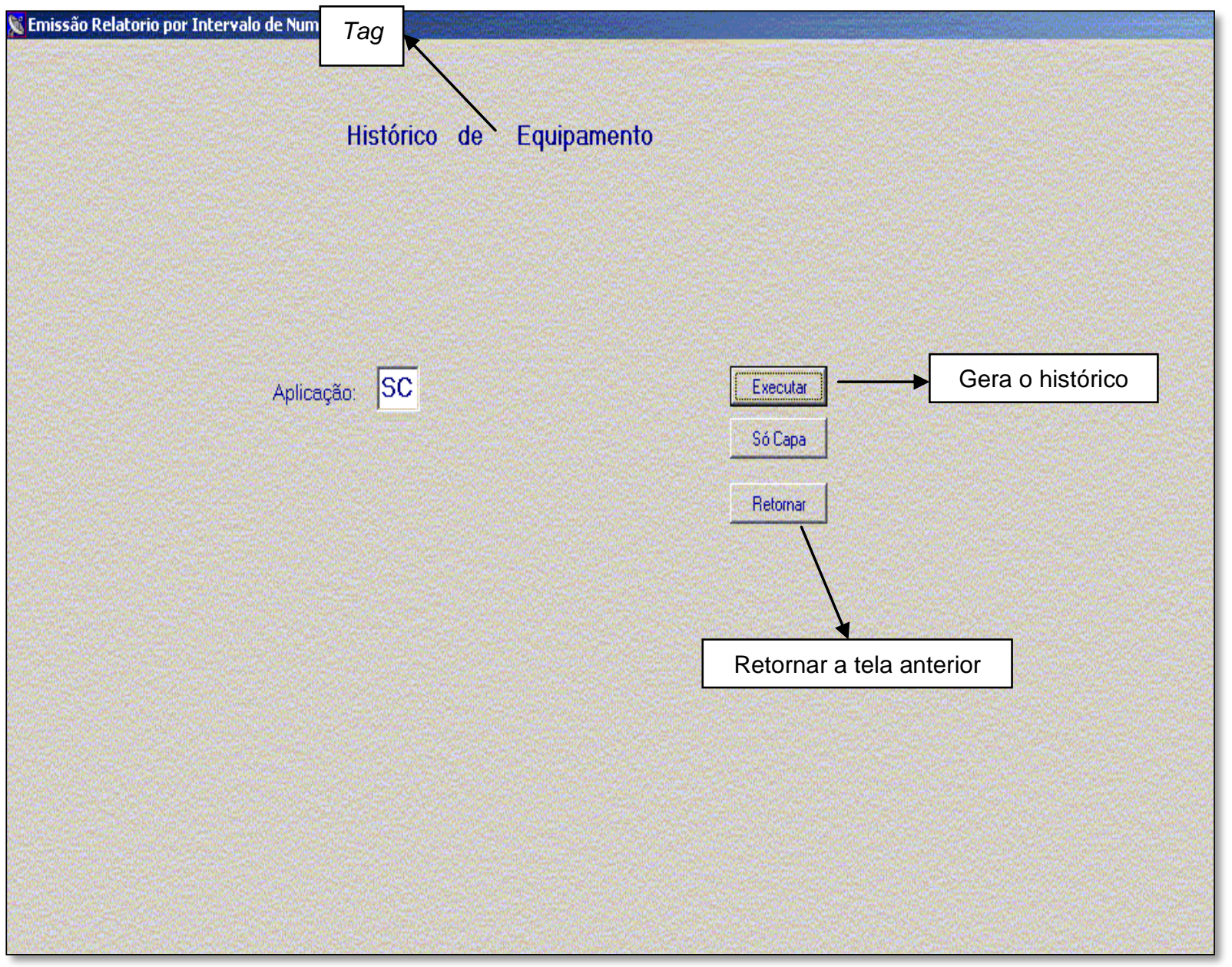

Figura 28 - Criação de histórico de manutenção preventiva. 


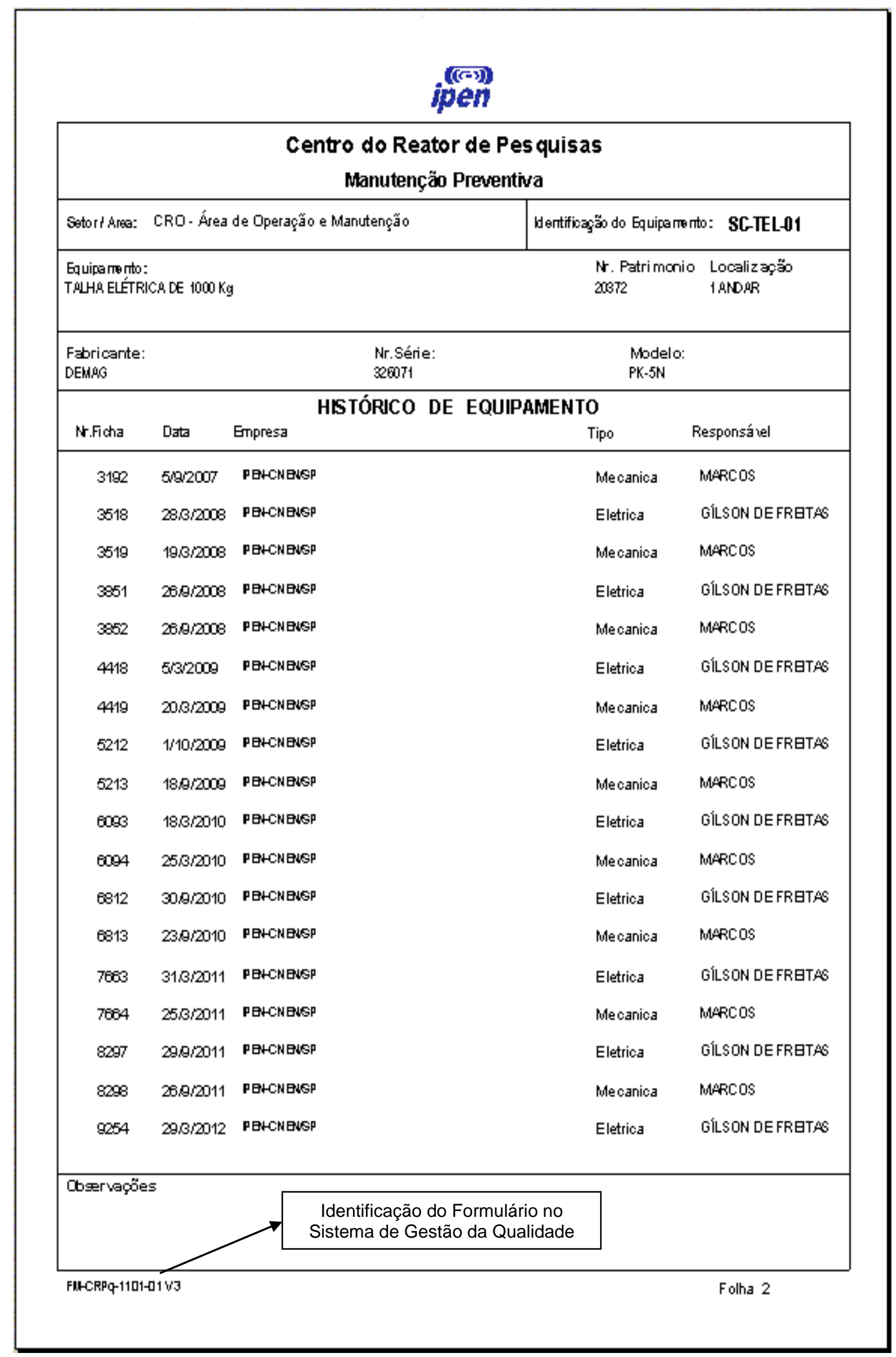

Figura 29 - Histórico de manutenção preventiva. 


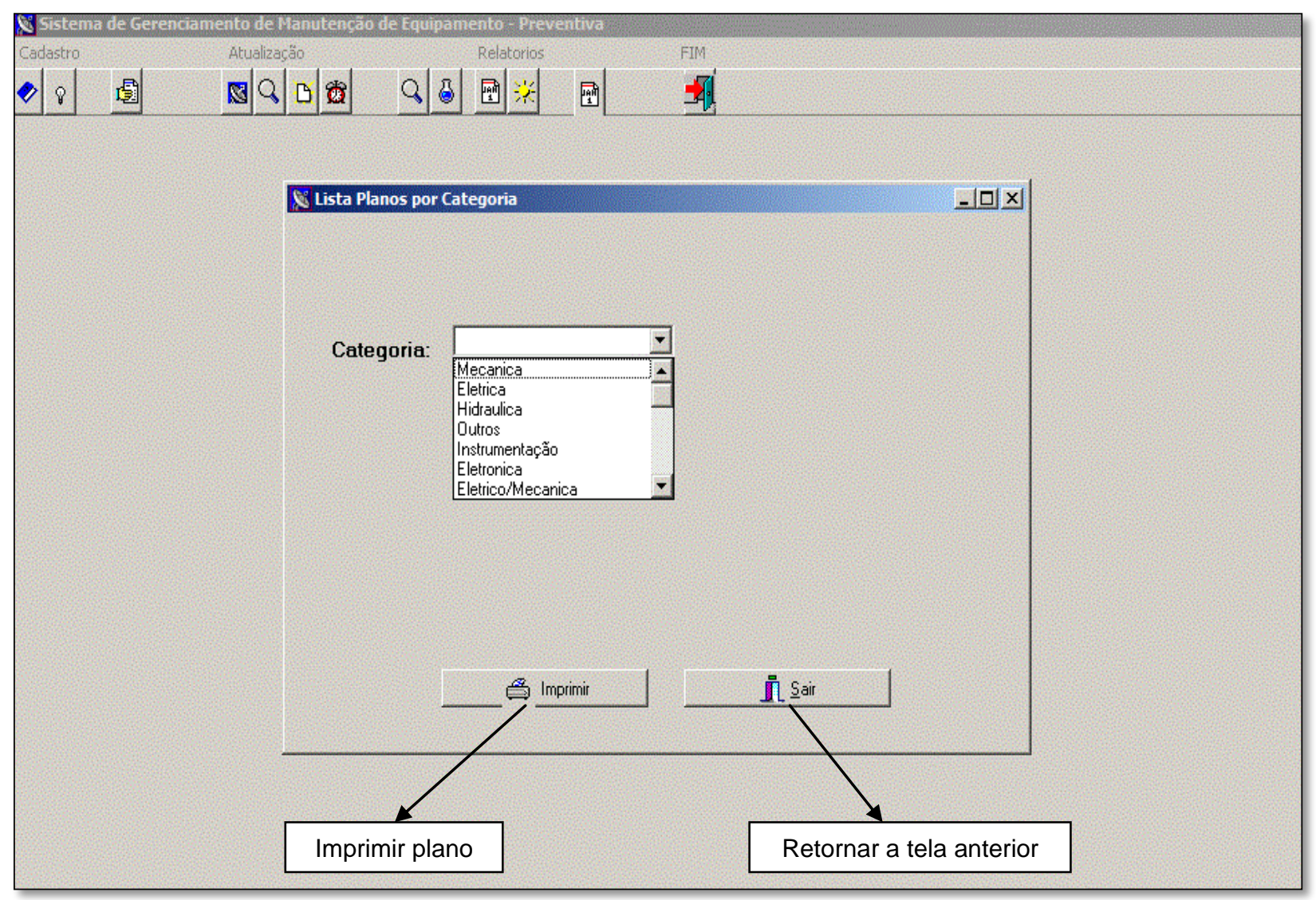

Figura 30 - Seleciona lista de plano por categoria.

\begin{tabular}{|c|c|c|c|c|c|c|}
\hline \multicolumn{7}{|c|}{ Q Sistema de Gerenciamento de Manut } \\
\hline Cadastr. & & Atualizaçáo & & Relatorios & & FIM \\
\hline 88 & 偪 & 圈 $Q$ & 90 & 四湖 & 檣 & $=0$ \\
\hline
\end{tabular}

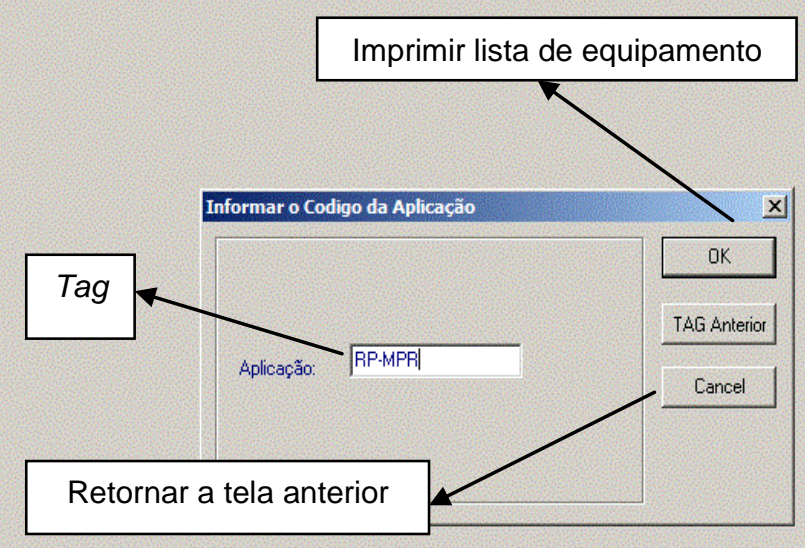

Figura 31 - Seleciona lista de equipamento por aplicação. 
Centro do Reator de Pesquisas

Plano de Manutenção Preventiva - ELETRICA

\begin{tabular}{|c|c|c|c|}
\hline Aplicaçäo & Componentes & Atividade & Feriodcidade \\
\hline CENTRO DECONANDO DENOTORES & $\mathrm{CCM}$ & LMPAR OS CONTATOS EÍERICOS DAS CHAVES CONTATORAS & Senestral \\
\hline CENTRO DE COMANDO DENOTCRES & $\mathrm{CCM}$ & VERACARO FUNOONAMENTO DAS LAMPADAS DE SINALIZA O̧O & Serestral \\
\hline CENTRO DECOULANDO DEMOTORES & $\mathrm{CCM}$ & LNFEZA GERA L DOS QUADRCS & Ancal \\
\hline CENTRO DE CONANDO DENOTORES & $\mathrm{CCM}$ & FAPGRJARCS TERUINAIS BEETACOS & Anual \\
\hline $\begin{array}{l}\text { IESISTENAA DEILUMNACCAO DE } \\
\text { EVERGEANCAA }\end{array}$ & BATERAS & ECECUTARA MANUTENÇAO CONFORNEA T-CRO-1101- 08 & Trilestral \\
\hline $\begin{array}{l}\text { IE-SISTENA DEILUMNACCAO DE } \\
\text { EIERGENCAA }\end{array}$ & T-CRO-1101-08 & FALZARLMPZA EAFERTO DOS TERUINAIS DA BATERA & Trivestral \\
\hline $\begin{array}{l}\text { ESISTEMA DELLUMNAÇÄO DE } \\
\text { ENERGÉNCAA }\end{array}$ & T.CRO-1101-Q8 & $\begin{array}{l}\text { FEALZARTETE DEFUNOONAMENTO DO EQUPAMBNTO MhMNO DE } \\
15 \text { MIN }\end{array}$ & Trillestral \\
\hline $\begin{array}{l}\text { IESISTENA DELLUMNACCAO DE } \\
\text { EVERGEANAA }\end{array}$ & T-CRO-1101-08 & VERFCARA EATERA & Trilestral \\
\hline LUMNACCAO DEEVERGENCIA & EATERAS & FALZARLMPZZA EAFERTO DOS TERUNAIS DA BATERAA & Trillestral \\
\hline 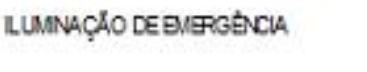 & BATERAS & $\begin{array}{l}\text { FALLZARTETE DEFINCONAMENTO DO BQUPAUBNO WhWNO DE } \\
15 \text { MN }\end{array}$ & Trillestral \\
\hline LUMNAÇLO DEEMGRGÉNCIA & DATENAS & VERFCARA BATERIA & Trilestral \\
\hline MOTORE EÉtrCOS & MOTCREETRACO & VERACAR COMREVTE EETTRICA DO MOTOR & Serestral \\
\hline Motores aétroos & MOTCREEETRCO & VERFCARTEVSA O ELETICA DO MOTOR & Senestra! \\
\hline $\begin{array}{l}\text { QUADRO DE DSTREUCOATO DE } \\
\text { FORÇA }\end{array}$ & QDF & LNFEZA GEPAL DOS QUADROS & Anual \\
\hline $\begin{array}{l}\text { QUADRO DE DSTREUÇ, DE } \\
\text { FORCQA }\end{array}$ & $Q D F$ & FEAPERIAROS TERUMNAIS EIÉTACOS & Anul \\
\hline 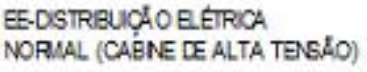 & $\begin{array}{l}\text { MANUTENÇLO } \\
\text { GERAL }\end{array}$ & $\begin{array}{l}\text { EXECUTARA MANUTENCAO DO EQFTO CEMISSAO DEREATCRIO } \\
\text { PEAA FIRMA PESPONSAVE. }\end{array}$ & Mersal \\
\hline
\end{tabular}




\section{$((r=y))$ \\ pen}

Centro de Reator de Pesquisas

\section{Relação de Equipamento/nstalação por Aplicação}

Aplicação: PROTEÇÃ̃ RADIOLÓGICA

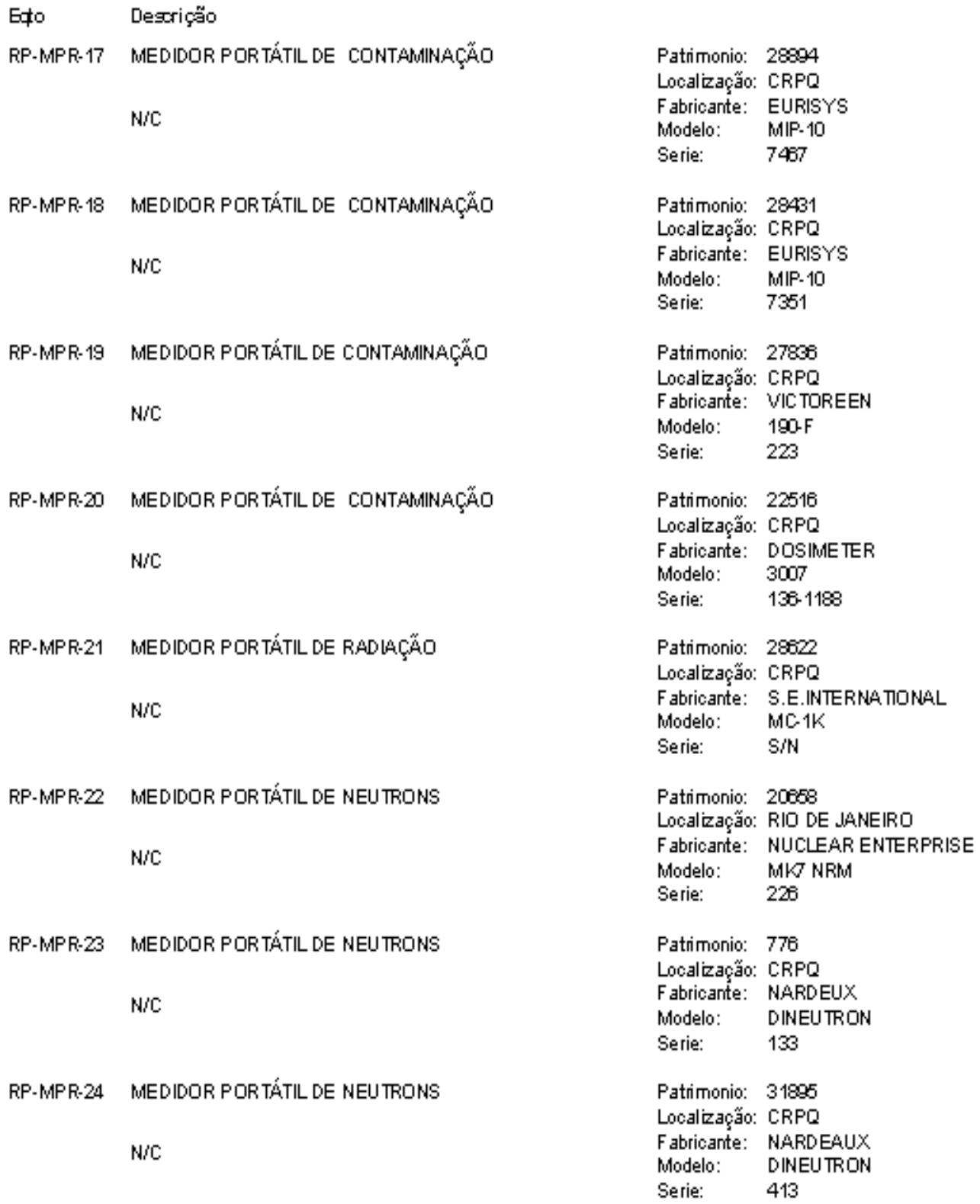

Figura 33 - Lista de equipamento por aplicação. 
Centro do Reator de Pesquis as

Plano de Manutenção Preventiva - Equipamento

AC. SISTEMA DEAR COMPRIMIDO. VASOS DEPRES SÃO

\begin{tabular}{|c|c|}
\hline Eqpto & Descrica o do Equipamento \\
\hline ACVPA.02 & RESERVATĆRIO PULUAO - VASO DEFRESS \\
\hline ACVPA-N3 & RESERVAT $\ R I O$ RULUAOO - VASO DEFRES \\
\hline cVi & RESERVATOONO RULUAO -VASO DEPF \\
\hline
\end{tabular}

Categoria

Mecanica

Mecanica

Mecanica

CENTRO DECONANDO DEMOTORES

\begin{tabular}{|c|c|c|}
\hline Eqpto & Descrica o do Equipamento & Categoria \\
\hline EV-COAO1 & CENTRO DE COMANDO DEMOTORG & Betica \\
\hline $\mathrm{EV}-\mathrm{CON}-02$ & QUALRO DEHAELITA ÇAO DAS BOMEAS DO FAIMARD E SECUNDÁRIO & Berica \\
\hline $\mathrm{EV}-\mathrm{COM}: 03$ & CONANDO DAS BOMEAS DEREIRATAMENTO & Betica \\
\hline $\mathrm{EV}-\mathrm{CON}-05$ & CENRO DE CONTROLE DEMOTORES & Betica \\
\hline EvCONo1 & CENTRO DE CONTROLE DEMOTORES & Betica \\
\hline EE-CONOH & CENRO DE CONANDO DEMOTORES & Berica \\
\hline TA-CONO1 & CENRO DE CONANDO DEMOTORES & Betica \\
\hline RA-CON-O1 & CENRO DE COUANDO DEMOTORGS & Betica \\
\hline \multicolumn{3}{|c|}{ CLCOMBATEA IICÉIDIO - ACIONADORES MAIUUAS } \\
\hline Eqpto & Descrica o do Equipamento & Categoria \\
\hline CLAON-O1 & AOCNADORMA NAAL DEALARIE DE NCËDIO & hstunentȩ̣ăo \\
\hline OAOM:02 & ACONADOR MA NUAL DEALARIE DE NCÉNIO & hatumentȩ̣à \\
\hline CHAONO3 & A COONA DOR UA NUAL DEALARU,E DE NCENDO & hstumentaçăo \\
\hline CAON-04 & A CONADORMANUAL DEALARJIE LE NCGDDIO & hstumenbọăo \\
\hline CLAON-05 & AOONA DORMA NUAL DEALARUE DE NCGDIO & hstunentẹ̆a \\
\hline CAAOM-06 & AOONA DOR MANUAL DEALARU,E DE NCÉDIO & hstuntentę̧̄o \\
\hline C.AOM-07 & ACONADORMA NUAL DEALARIE DE NCEDIO & hstumenteg \\
\hline
\end{tabular}

Figura 34 - Plano de manutenção preventiva por aplicação e categoria. 


\section{2 - Módulo de manutenção corretiva}

Muitos procedimentos da Manutenção Preventiva são usados e descritos na manutenção corretiva. Para acessar o módulo de Manutenção Corretiva é necessário informar o crachá e a senha. Ao selecionar a opção "Cadastramento", será criado um usuário com direitos apenas de consulta e impressão de relatórios. Para criar usuários com direitos de atualização somente por intermédio do administrador, a Figura 35 apresenta a tela de acesso ao módulo de manutenção corretiva.

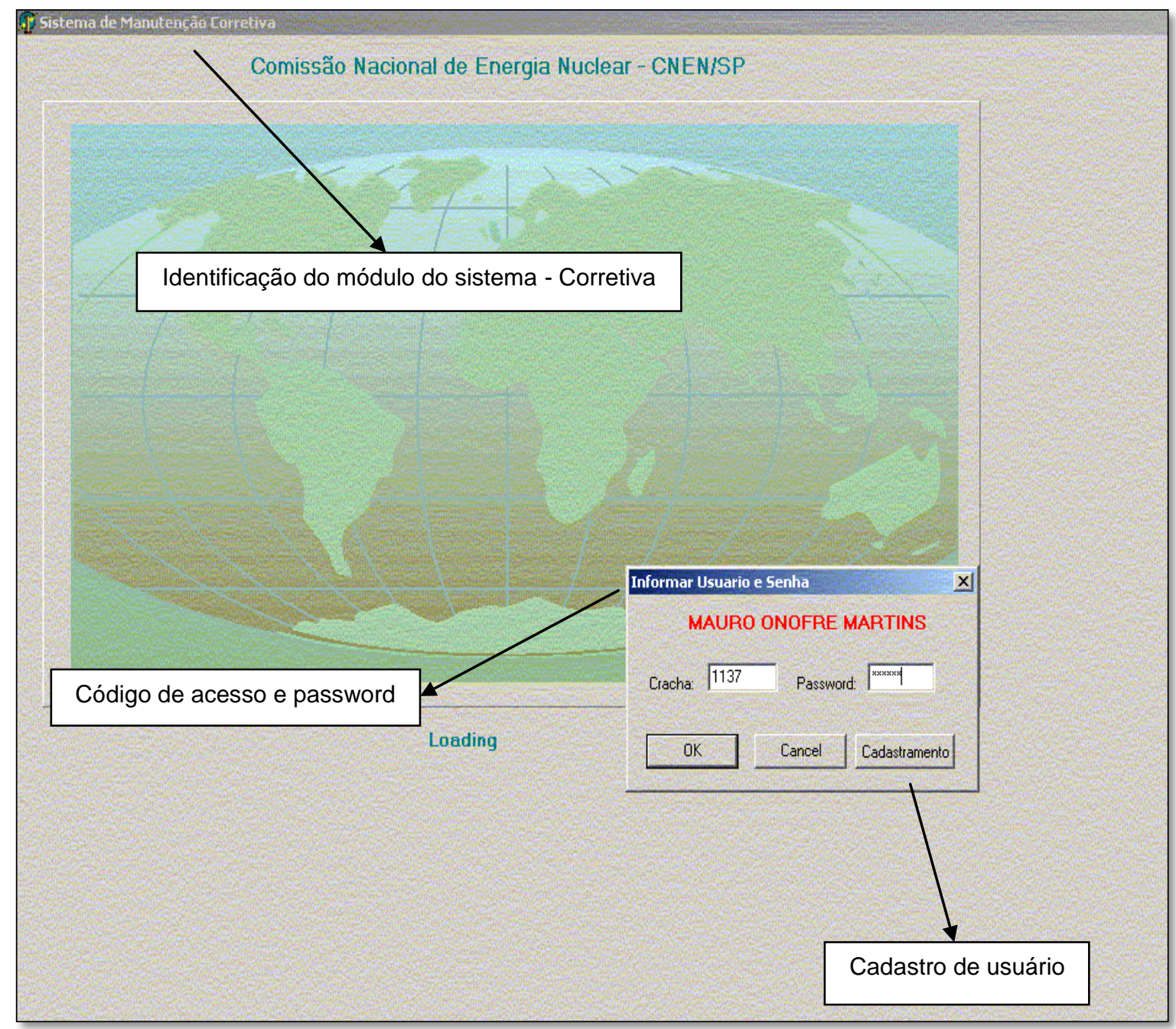

Figura 35 - Tela de acesso do módulo de manutenção corretiva.

O módulo de Manutenção Corretiva é dividido em: Corretiva, Consulta e Tabelas.

A Figura 36 apresenta a tela principal da Manutenção Corretiva 


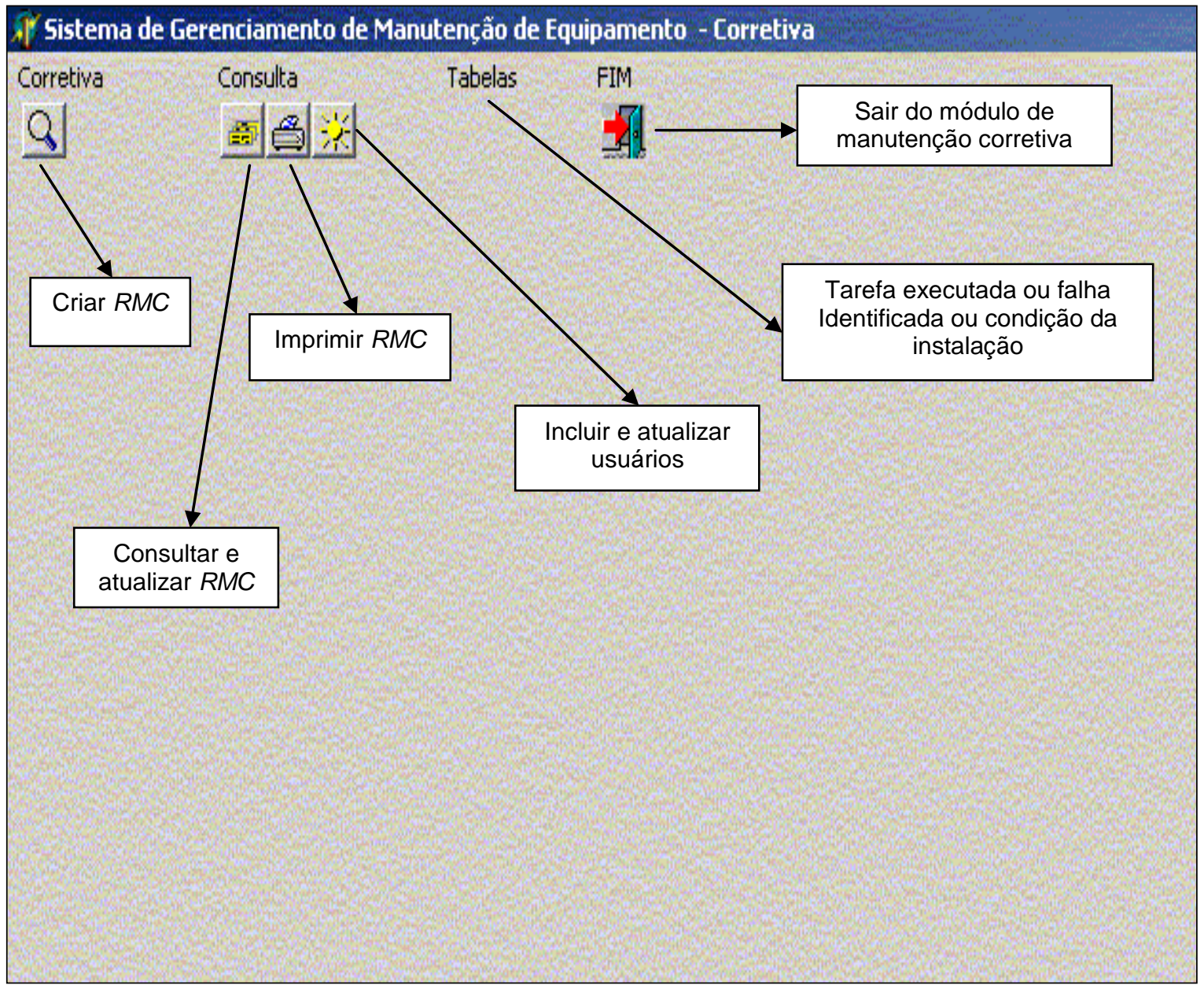

Figura 36 - Tela principal do módulo de manutenção corretiva.

\subsection{1 - Corretiva}

A opção Corretiva é o responsável pela criação do $R M C$ de cada equipamento de acordo com:

- Modalidade: equipamento ou instalação;

- Natureza do serviço: mecânica ou elétrica ou eletrônica ou instrumentação ou hidráulica ou outros;

- Atendimento da ocorrência: imediato ou urgente ou normal;

- Solicitante: o técnico que relatou a ocorrência ou falha;

- Contato: executor que irá realizar a manutenção corretiva;

- Descrição da ocorrência ou falha: motivo da parada.

Todo $R M C$ recebe um número de controle sequencial, que não poderá ser utilizado por outro equipamento ou instalação. Caso necessite de uma complementação ou substituição, este RMC pode ser cancelado, e um novo $R M C$ será gerado obedecendo a sequência numérica. 
A Figura 37 apresenta a tela a ser elaborada no instante da criação do $R M C$.

O RMC é numerado e impresso para execução. Uma vez realizada a manutenção corretiva, e corretamente preenchido, o $R M C$ é devolvido para atualização do banco de dados.

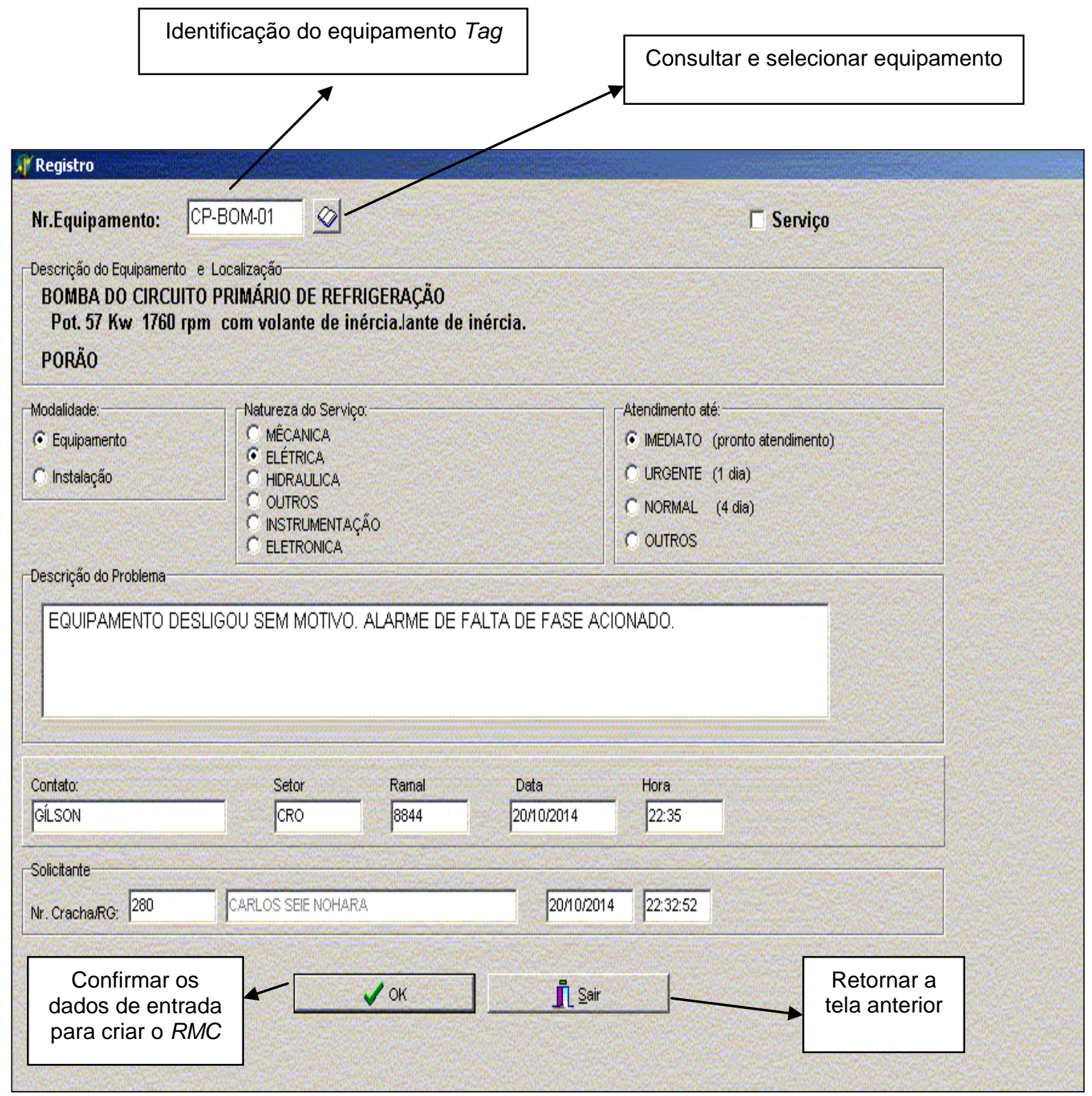

Figura 37 - Criação do registro de manutenção corretiva - RMC.

\subsection{2 - Consulta}

$\mathrm{Na}$ opção Consulta, o sistema computacional atualiza o banco de dados do RMC, de acordo com o status da execução (solicitação ou execução ou pendência ou concluído ou cancelado). Neste momento são registradas as descrições dos componentes utilizados e as tarefas realizadas durante a 
manutenção corretiva, bem como são identificados o executor e a data em que foi realizada a manutenção corretiva.

Estas informações são muito importantes, pois a partir delas que serão gerados os relatórios de Histórico de Manutenção, que contém todas as manutenções corretivas realizadas em cada equipamento ou instalação. Estas informações são fundamentais para as previsões de futuras ações preventivas no Reator, como o Módulo de Manutenção Preditiva.

A Consulta permite a inclusão, correção e exclusão dos registros, bem como elaboração de relatórios para simples conferência. As Figuras 38, 39 e 40 apresentam as telas descritas e as impressas.

\begin{tabular}{|c|c|c|c|c|c|c|c|c|c|}
\hline \multirow{2}{*}{\multicolumn{2}{|c|}{$\begin{array}{l}\text { Ordenado por: } \\
\text { C Nr.Ficha } \\
\text { Nr. FICHA }\end{array}$}} & \multicolumn{2}{|c|}{ C Nr.Eqpto } & \multicolumn{2}{|l|}{ Geral } & \multicolumn{2}{|l|}{ Natureza: Eletronica } & \multicolumn{2}{|c|}{$\Gamma$ Servico } \\
\hline & & Nr.Eqpto & Status Ficha & Natureza & Alendimento & Solicitante & cutor & Parecer & Conta $A$ \\
\hline \multirow[t]{7}{*}{ D } & 1044 & RP-MPR-25 & Concluido & Eletronica & Normal & FLAVIO LUIZROSS & 1822 & 1591 & ALGE \\
\hline & 1060 & CI.PSI-02 & Concluido & Eletronica & Normal & ANTONIO CARLOS & 1822 & 1721 & ALGE \\
\hline & 1067 & IC-MSC-01 & Concluido & Eletronica & Normal & ALBERTO DE JESL & 1822 & 721 & ALGE \\
\hline & 1068 & Cl.PSI.02 & Concluido & Eletronica & Normal & ALBERTO DE JESL & 1822 & $1 \gtrless 1$ & ALGE \\
\hline & 1070 & Cl.PSI-02 & Concluido & Eletronica & Normal & MALURO ONOFRE N & 1822 & $113 \lambda$ & ALGE \\
\hline & 1071 & IC-MSC-01 & Concluido & Eletronica & Imediato & ALBERTO DE JESL & 257 & 257 & ALGE \\
\hline & 1072 & IC.MSC-01 & Concluido & Eletronica & Imediato & \multirow{2}{*}{$\begin{array}{l}\text { ALBERTO DE JESL } \\
\text { FLEVIO LUIZ ROSS }\end{array}$} & \multirow{2}{*}{\multicolumn{3}{|c|}{ Consulta ordenado po }} \\
\hline & 1073 & \multirow{3}{*}{$\begin{array}{c}\text { Consulta } \\
\text { ordenado por }\end{array}$} & \multirow{2}{*}{$\begin{array}{l}\text { Concluido } \\
\text { Concluido }\end{array}$} & Eletronica & Normal & & & & \\
\hline & 1075 & & & Eletronica & Normal & ALBERTO DE JESL & 257 & 257 & LOYO \\
\hline & 1077 & & Concluido & Eletronica & Imediato & CARLOS SEIE NOH & 257 & 257 & LOYO \\
\hline & 1083 & SV-ACC-01 & Concluido & Eletronica & Normal & MARCOS RODRIGL & 1822 & 1721 & ALGE \\
\hline & 1085 & MP.PRE-01 & Concluido & Eletronica & Normal & ALBERTO DE JESL & 1822 & 1721 & ALGE \\
\hline & 1086 & RP-MFR-10 & Concluido & Eletronica & Imediato & RICARDO NUNES I & 1822 & 1302 & ALGE \\
\hline & 1087 & MP.PRE-01 & Concluido & Eletronica & Normal & WALLTER RICCI & 1822 & 106 & ALGE \\
\hline & 1088 & RA-INC-02 & Concluido & Eletronica & Normal & MAUURO ONOFRE N & 1822 & 1137 & ALGE \\
\hline & 1090 & RP-MPR-36 & Concluid & \multirow{2}{*}{$\begin{array}{l}\text { Selecionar RMC } \\
\text { por situação }\end{array}$} & Normal & FLAVIO LUIZROSS & 1822 & 1591 & ALGE \\
\hline & 1091 & RP-MPR-28 & Concluid & & Normal & FLAVIO LUIZ ROSS & 1822 & 1591 & ALGE \\
\hline & 1092 & RP-MPR-19 & \multirow{2}{*}{ Contuid___ } & & Normal & \multirow{2}{*}{ Imprimir $R M C$} & & \multirow{3}{*}{\multicolumn{2}{|c|}{$\begin{array}{l}\text { Retornar a } \\
\text { tela principal }\end{array}$}} \\
\hline & 1093 & RP-MPR-27 & & Eletronica & Urgente & & & & \\
\hline & 1095 & RP-MFR-10 & Concluido & Eletronica & Normal & 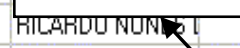 & 7822 & & \\
\hline & 1096 & RP-MFR-11 & Concluido & Eletronica & Normal & RICARDO NUNES & 1822 & 150 & स्रLपर \\
\hline & 1100 & IE-BSY.06 & Solicitação & Eletronica & Normal & GÍLSON DE FREIT/ & & & $A \mathrm{LGE}=$ \\
\hline & & & & & & & & & I) \\
\hline & Geral & Não Concluido & & tualizar dados re & ente & Atualiza & & & Säair \\
\hline & Concluidos & Pendente & & $\begin{array}{l}\text { execução ou aval } \\
\text { do } R M C\end{array}$ & ção & & & & \\
\hline
\end{tabular}

Figura 38 - Consulta ao registro de manutenção corretiva - RMC. 


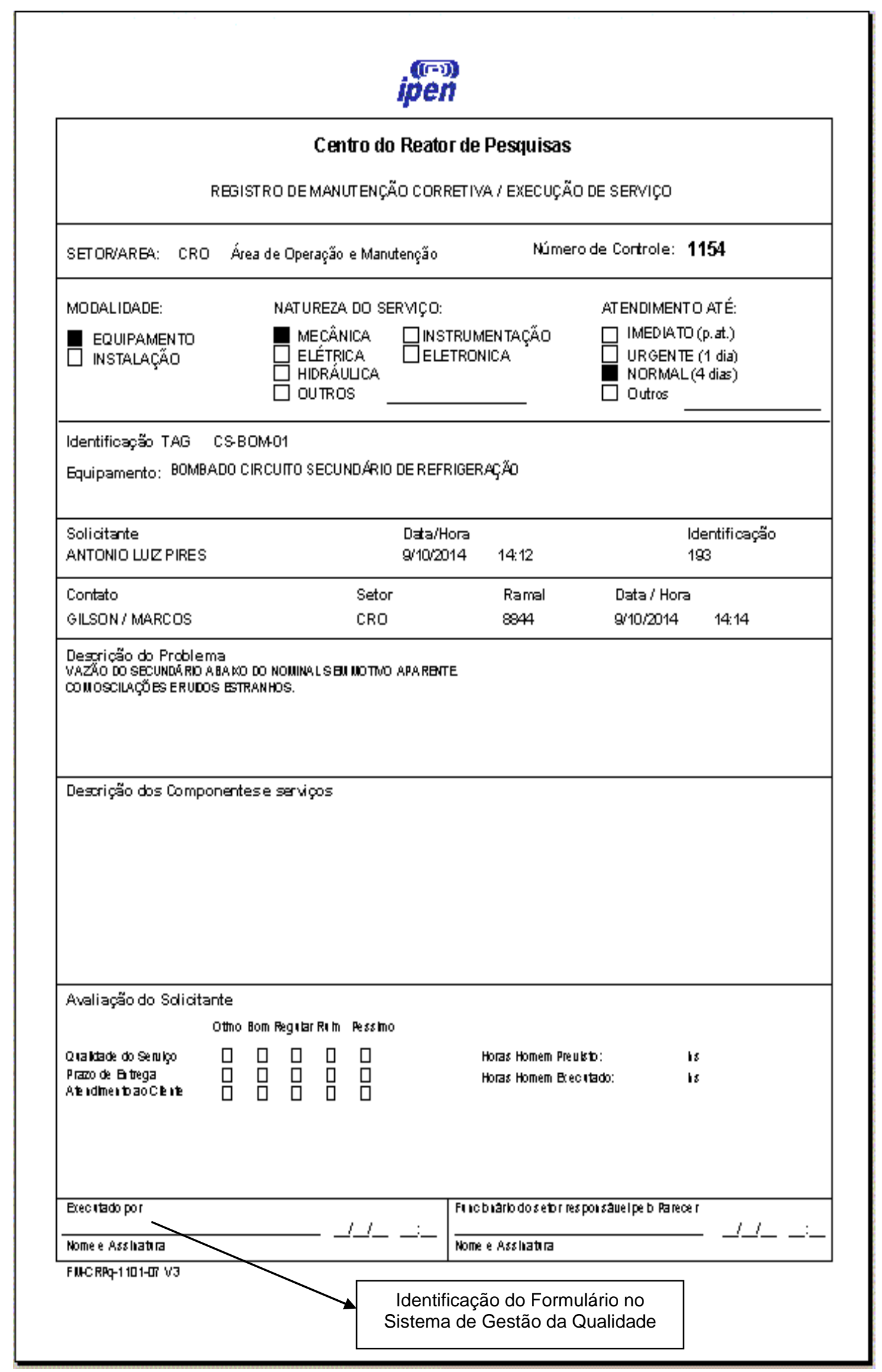

Figura 39 - Registro de manutenção corretiva - RMC. 


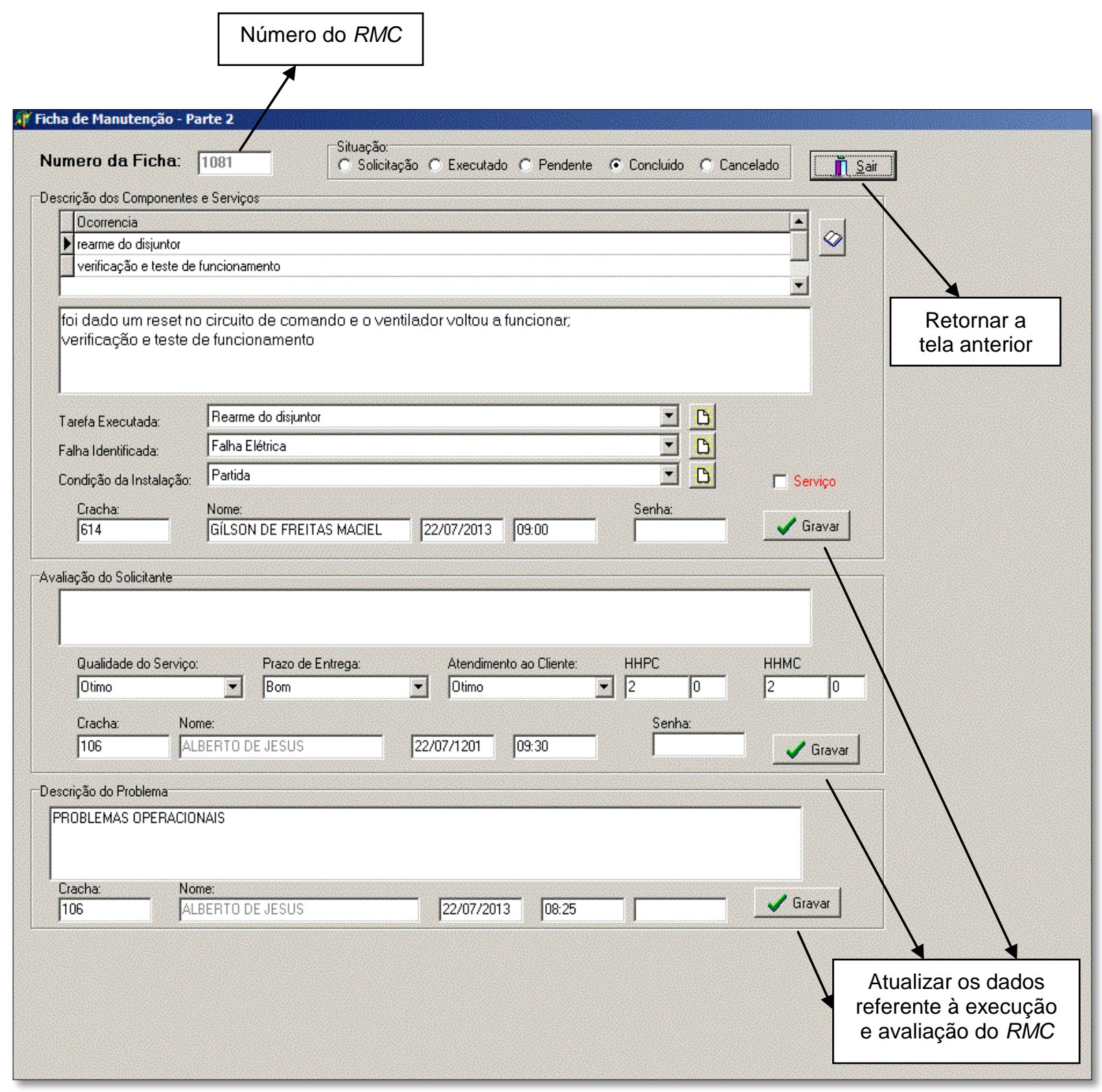

Figura 40 - Atualização do registro de manutenção corretiva - RMC.

\subsection{3 - Tabelas}

A opção Tabelas é dividida em: Tabela de tarefa executada, Tabela de falha identificada e Tabela de condição da instalação. Elas foram criadas para:

- Facilitar uma consulta rápida ao histórico da manutenção corretiva;

- Facilitar as atualizações no sistema computacional quando forem realimentadas as informações contidas no $R M C$;

- Estudo de falhas de componentes;

- Estudo de confiabilidade de equipamentos e quais são os processos em que ocorrem as falhas durante a operação da instalação.

As Figuras 41, 42 e 43 apresentam as telas descritas acima. 


\begin{tabular}{|c|l|}
\hline Codigo & Descricao da Tarefa Executada \\
\hline 1 & Teste \\
\hline 2 & Inspeção Visual \\
\hline 3 & Calibração \\
\hline 4 & Verificação \\
\hline 5 & Aiuste \\
\hline 6 & Susbstituição \\
\hline 7 & Reparo \\
\hline 8 & Limpeza \\
\hline 9 & Pintura \\
\hline 10 & Lubrificação \\
\hline 11 & Analise de Vibração \\
\hline 12 & Reforma Geral \\
\hline
\end{tabular}
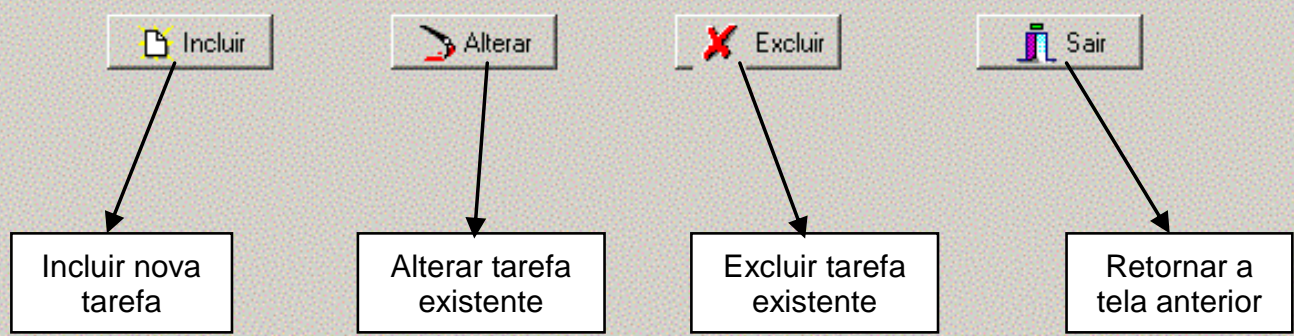

Figura 41 - Tabela de tarefa executada.

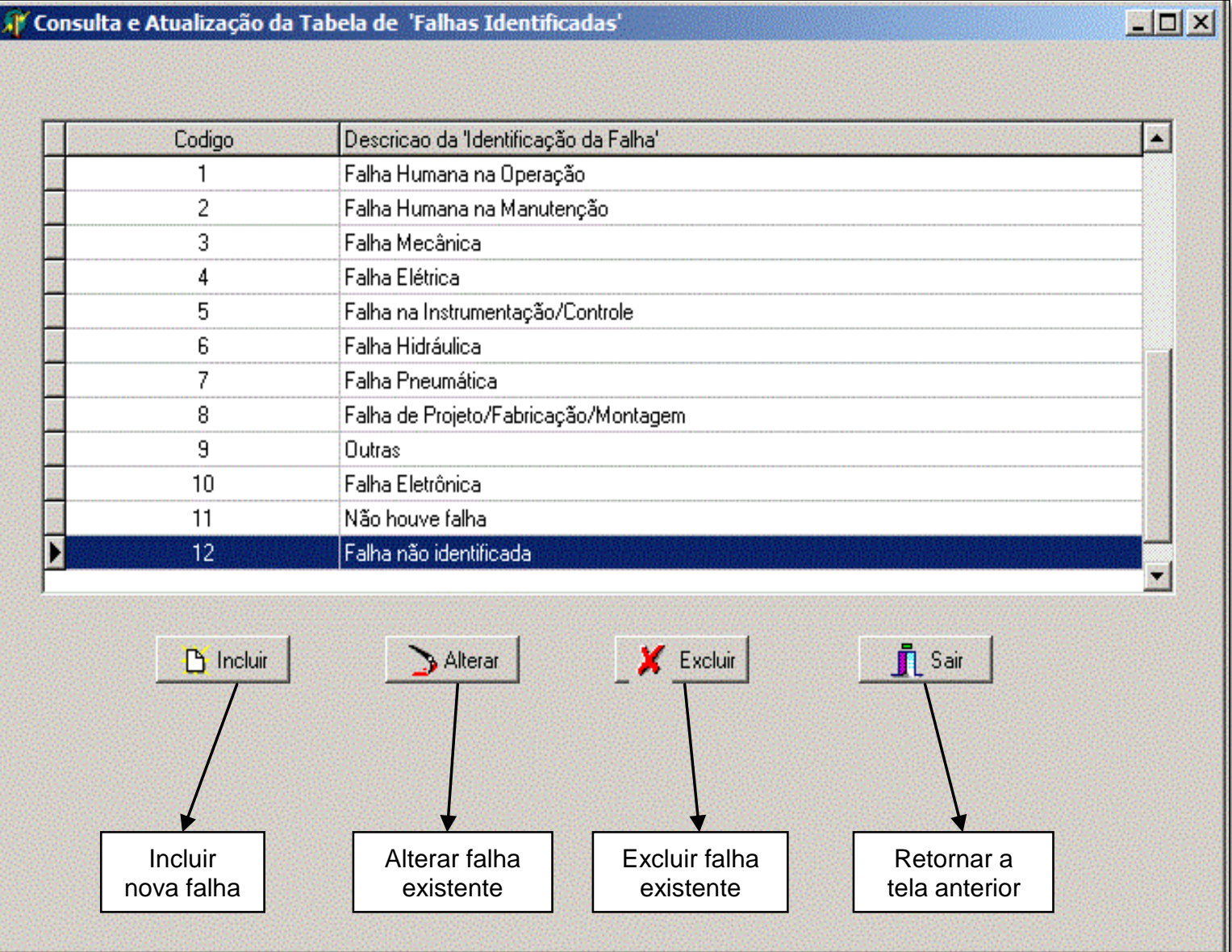

Figura 42 - Tabela de falha Identificada. 


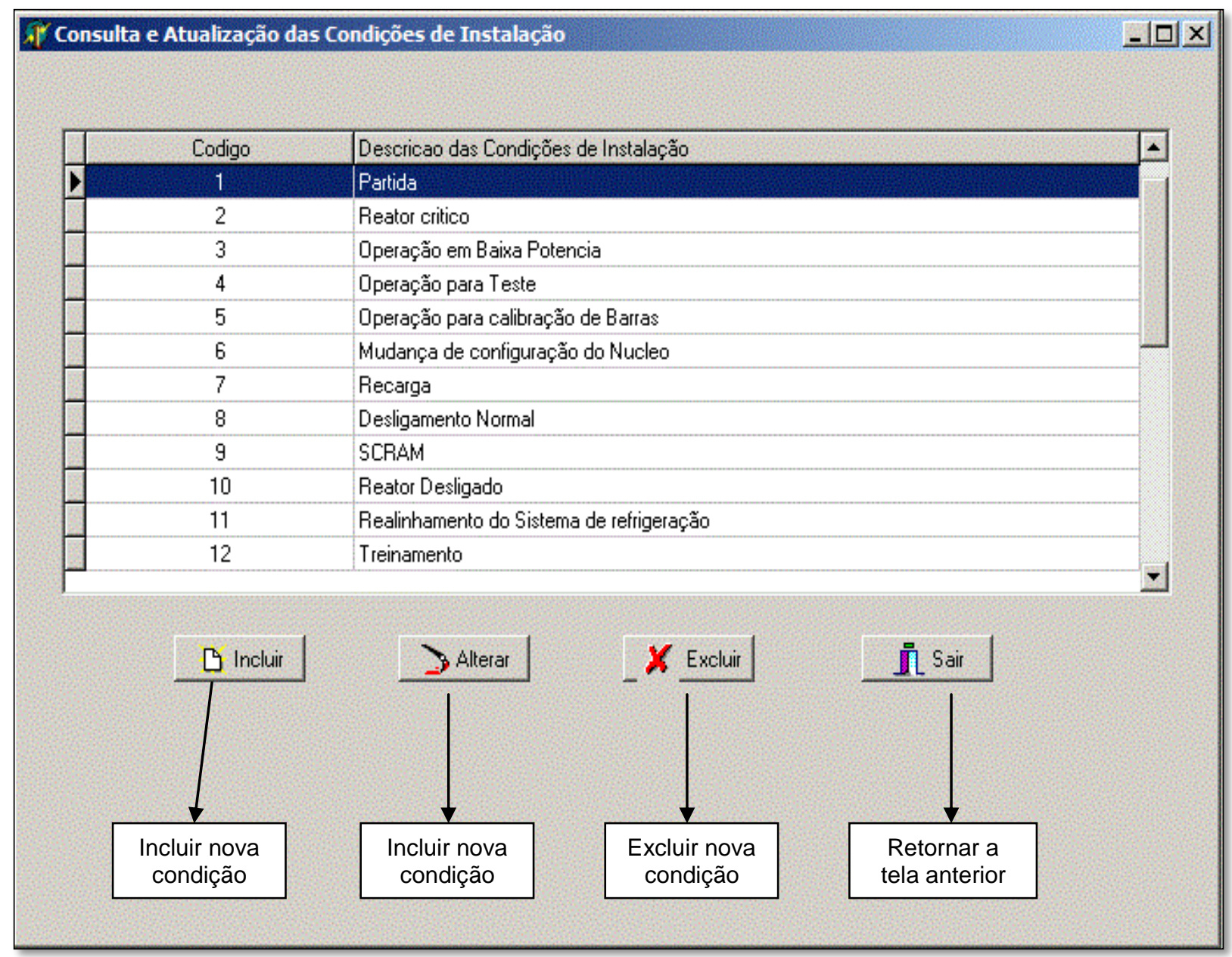

Figura 43 - Tabela da condição da instalação.

\subsection{4 - Histórico de equipamento}

O sistema computacional gera o histórico dos RMCs de cada equipamento por meio de lista ou relatório selecionado por data da ocorrência ou número do RMC (ficha) ou Tag e classifica as listas por:

- Tag;

- Número da ficha $(R M C)$;

- Data de ocorrência, Tag e número da ficha $(R M C)$;

- Tarefa executada, data da ocorrência, Tag e número da ficha $(R M C)$

- Tarefa executada, Tag e número ficha (RMC);

- Falha identificada, data da ocorrência, Tag e número da ficha $(R M C)$, e outras combinações entre esses itens.

As Figuras 44, 45, 46, 47 e 48 apresentam as telas descritas e as impressas. 


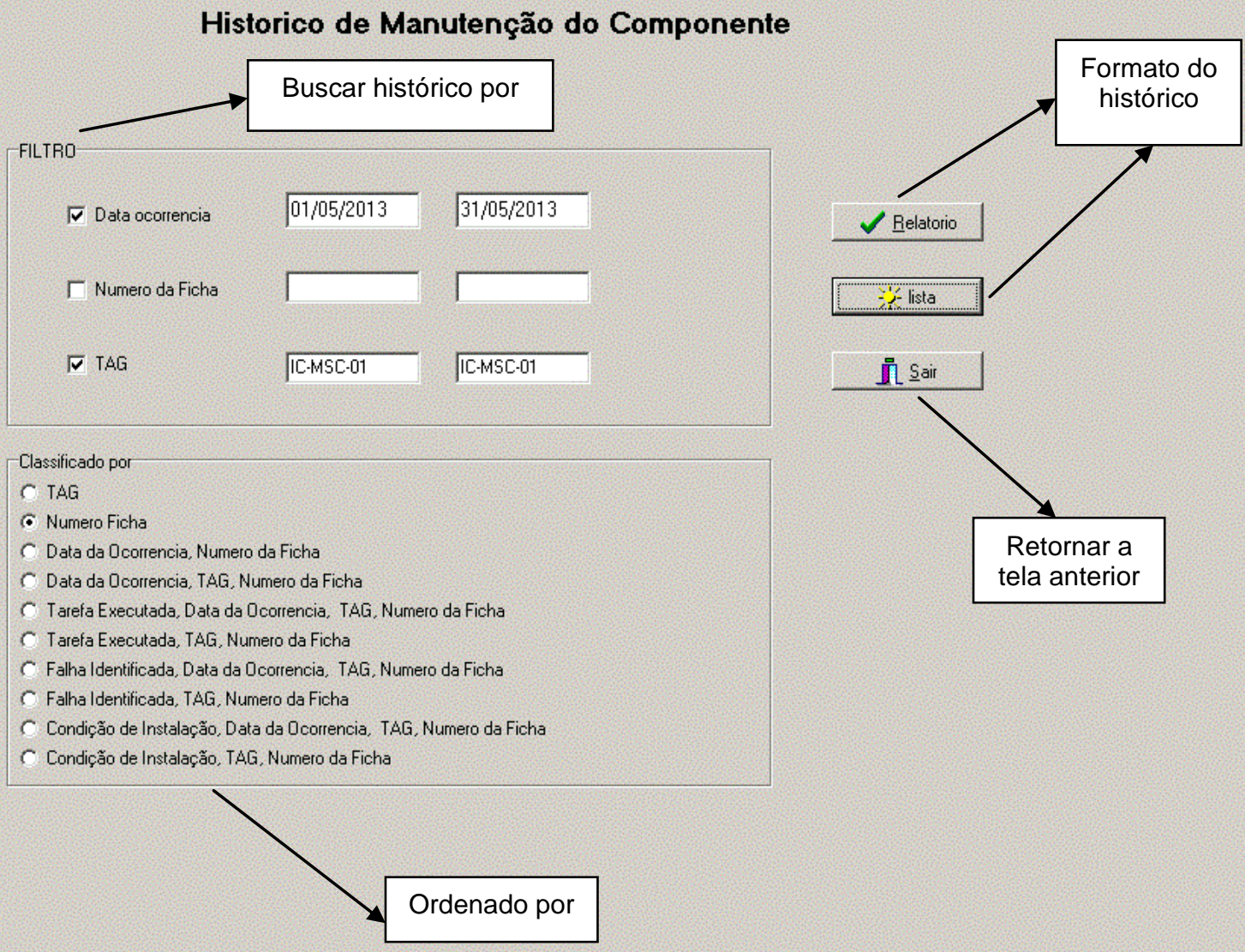

Figura 44 - Tela de histórico de manutenção corretiva.

Setor

Equipamento: MESA DE CONTROLE DO REATOR

Nr.Patrimonio: 299

Aplicaçãa: INSTRUMENTACCÃO E CONTROLE

Data/Hora

Ocorrenc

20/05/2013

$20 / 05 / 2013$

\section{Falha}

Susbstituição for troc ada a lampada do tubo colimador

1072 Susbstituição verific ação e teste de funcionamento
TAG: IC-MSC-01

Fabric ante: GENERAL ATOMIC

Nr.Serie: $\quad S / N$

\section{Condição da} Instalação

Partida

Execução Responsave

24/05/2013 CARLOS ALBERTO LOYOLA

Partida

Figura 45 - Histórico de manutenção corretiva por equipamento. 
Setor Proteção Radiológica

Equipamento: MEDIDOR PORTÁTIL DE CONTAMINAÇÃO

Nr.Patrimonio: 387

Localização $\quad \mathrm{CRPQ}$

Aplicação: $\quad$ PROTEÇÃO RADIOLÓGICA

Data/Hora Ficha Tarefa Executada

Ocorrencia

02/09/2005 481 Substituição de componente

Identific ad

Falha Eletrônica

21/08/2009 826 Susbstituição

Falha Eletrônica

SUBSTITUIÇÃO DO GEIGER TIPO PANCAKE

$22 / 09 / 2009833$

Susbstituição

Falha Eletrônica

DEFETOESTAVANASONDAPANCAKE.

FORAMSUBSTITUIDOS TRANSISTOR, CAPACITOR E UMDIODO

14/06/2012 1020 Substituição de componente

foitrocado a bateria de alimentação e o plug:

testes de funcionamento
TAG: RP-MPR-18

Fabricante: EURISYS

Nr.Senie: $\quad 7351$

Modelo: $\quad$ MIP-10

Execução Responsavel

05/09/2005 VALDIR COSMOS DASILVA

210802009 ALGENYMEIRALETE

27/10/2009 ALGENYMEIRALEITE

14/06/2012 ALGENYMEIRALEITE

Figura 46 - Histórico de manutenção corretiva por aplicação.

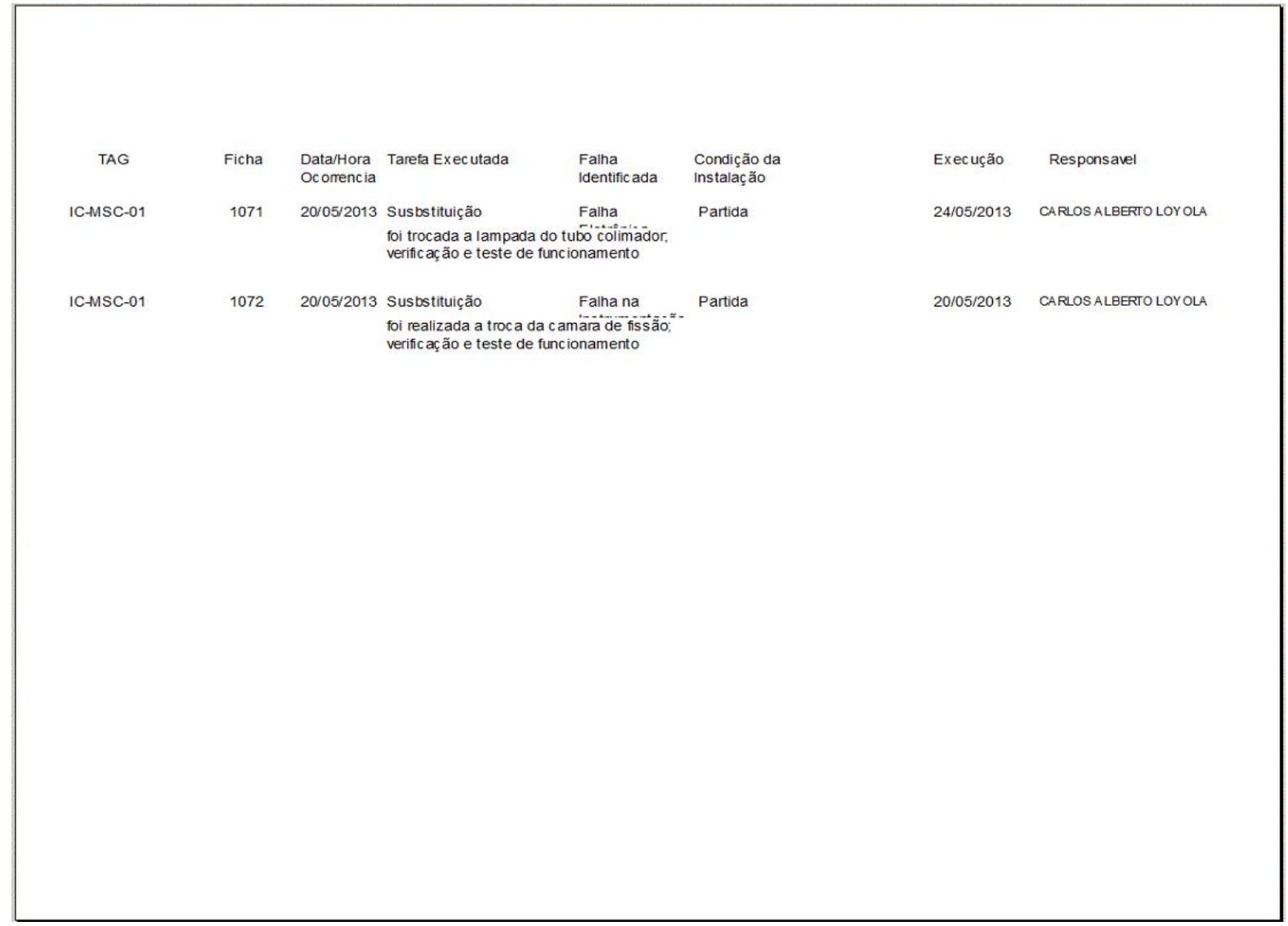

Figura 47 - Histórico de manutenção corretiva: lista. 


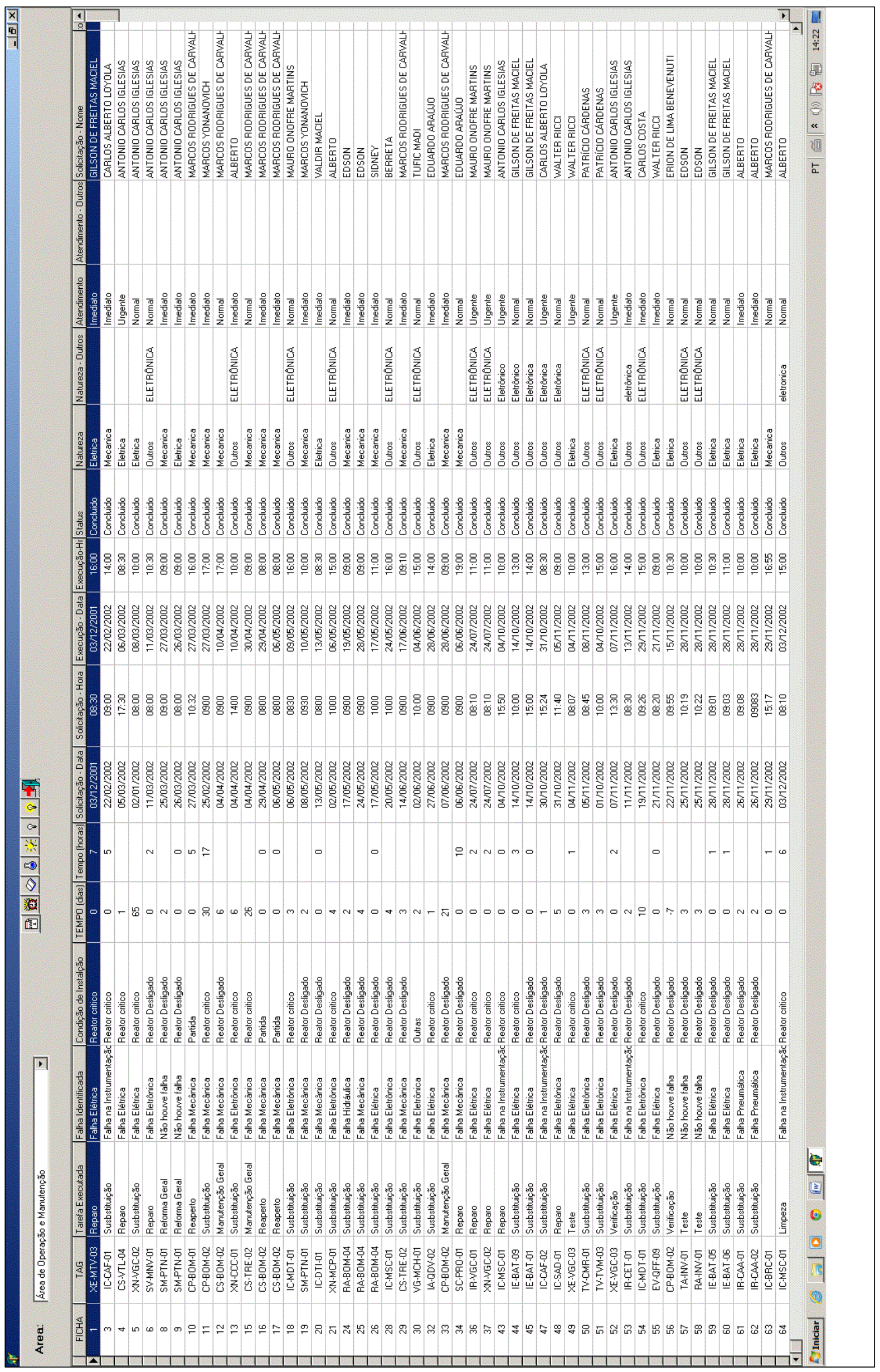

Figura 48 - Histórico de manutenção corretiva: lista por área 


\section{3 - Módulo de Calibração}

Para acessar o módulo de Calibração, se faz necessário informar o crachá e a senha. Ao selecionar a opção "Cadastramento", será criado um usuário com direitos apenas de consulta e impressão de relatórios. Para criar usuários com direitos de atualização somente por intermédio do administrador. A Figura 49 apresenta a tela de acesso do módulo de calibração.

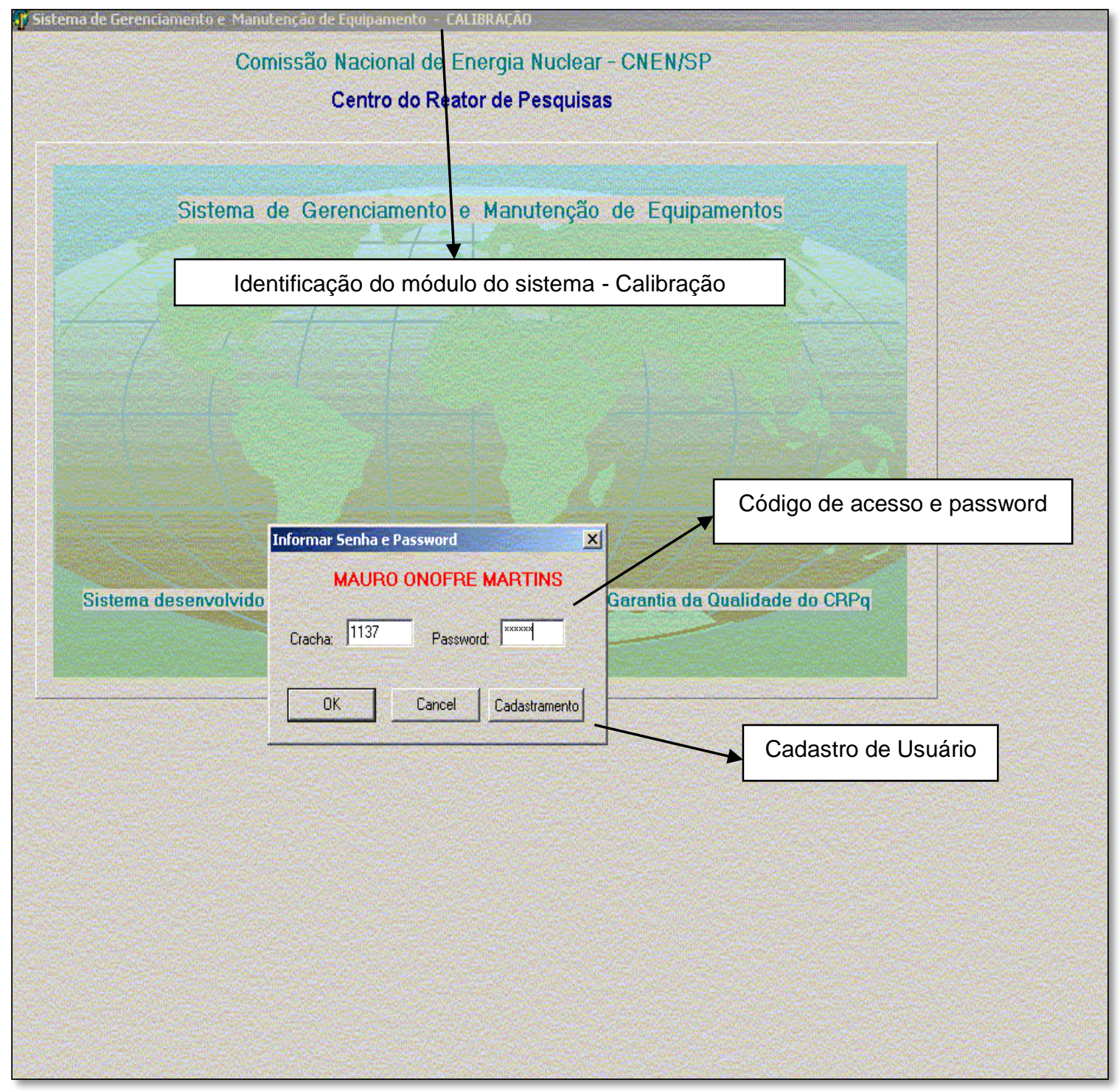

Figura 49 - Tela de acesso do módulo de calibração.

O módulo de Calibração de equipamentos ou medidores é dividido em: Cadastro e Consulta. 


\subsection{1 - Cadastro}

É responsável pelo armazenamento das informações no banco de dados dos instrumentos ou medidores da instalação que necessitam de calibração periodicamente. O Cadastro está dividido em: Atualização do plano, Cadastro de equipamento e Histórico de calibração. A Figura 50 apresenta a tela principal do módulo de Calibração.

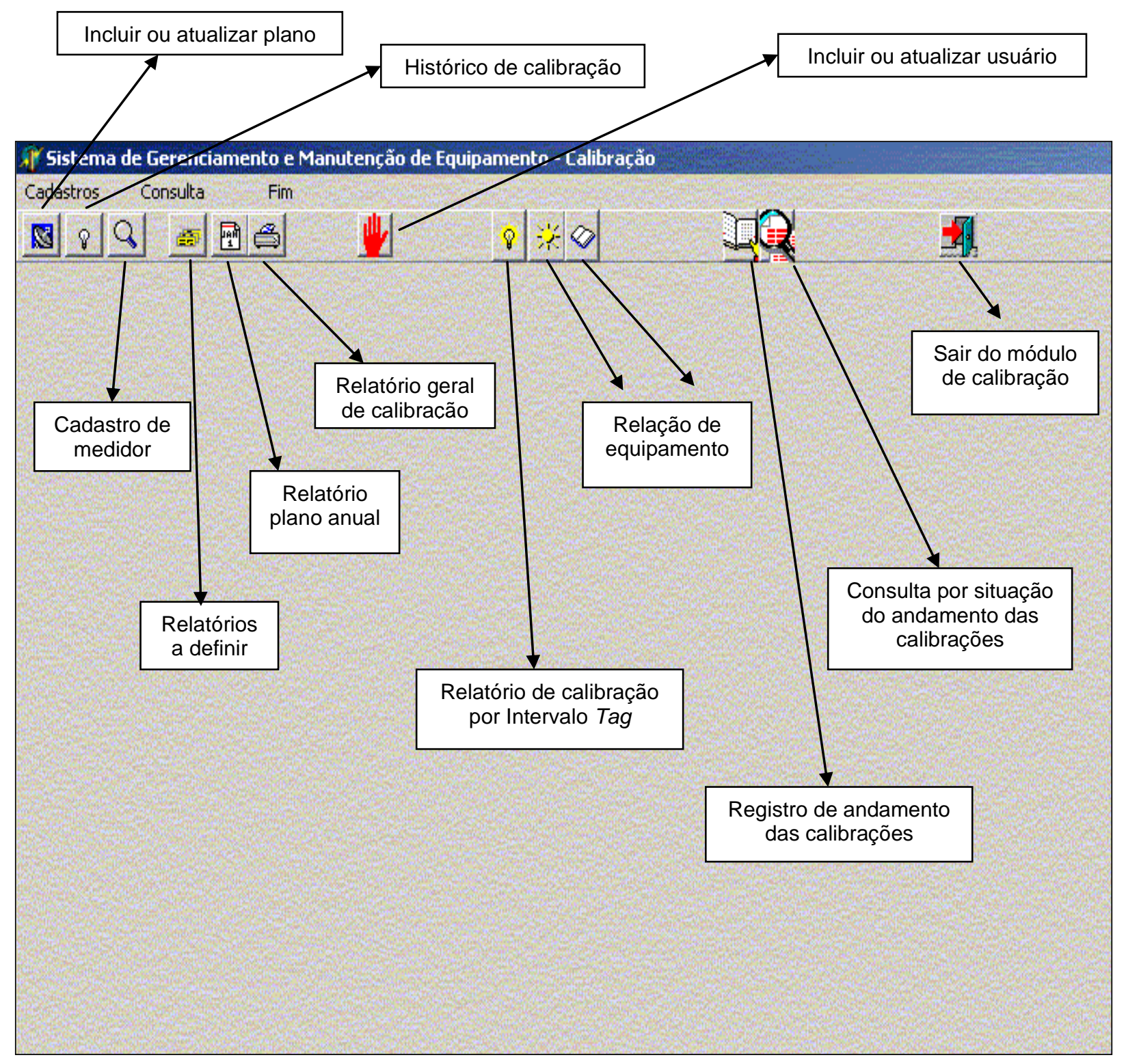

Figura 50 - Tela principal do módulo de calibração.

\subsubsection{1 - Atualização do plano}

A Atualização do Plano gera o registro de calibração de cada instrumento ou medidor, conforme a periodicidade. Uma vez realizada a 
calibração, o registro deverá ser atualizado com a data de execução, o numero do certificado e o laboratório ou empresa que executou o serviço. A Figura 51 apresenta a tela descrita.

Estas informações são muito importantes, pois é a partir delas que serão gerados os relatórios de registro de calibração, que contém todas as calibrações realizadas em cada instrumento ou medidor.

\begin{tabular}{|l|l|l|l|l|l|}
\hline $\begin{array}{c}\text { Consulta } \\
\text { ordenada por }\end{array}$ & \begin{tabular}{|l|l|l|}
\hline \\
\hline
\end{tabular} \\
\hline
\end{tabular}

Figura 51 - Incluir ou alterar ou excluir medidor do plano de calibração.

O sistema permite a inclusão, correção e exclusão de registros, bem como elaboração de relatórios para simples conferência. A Figura 52 apresenta a tela descrita acima. 


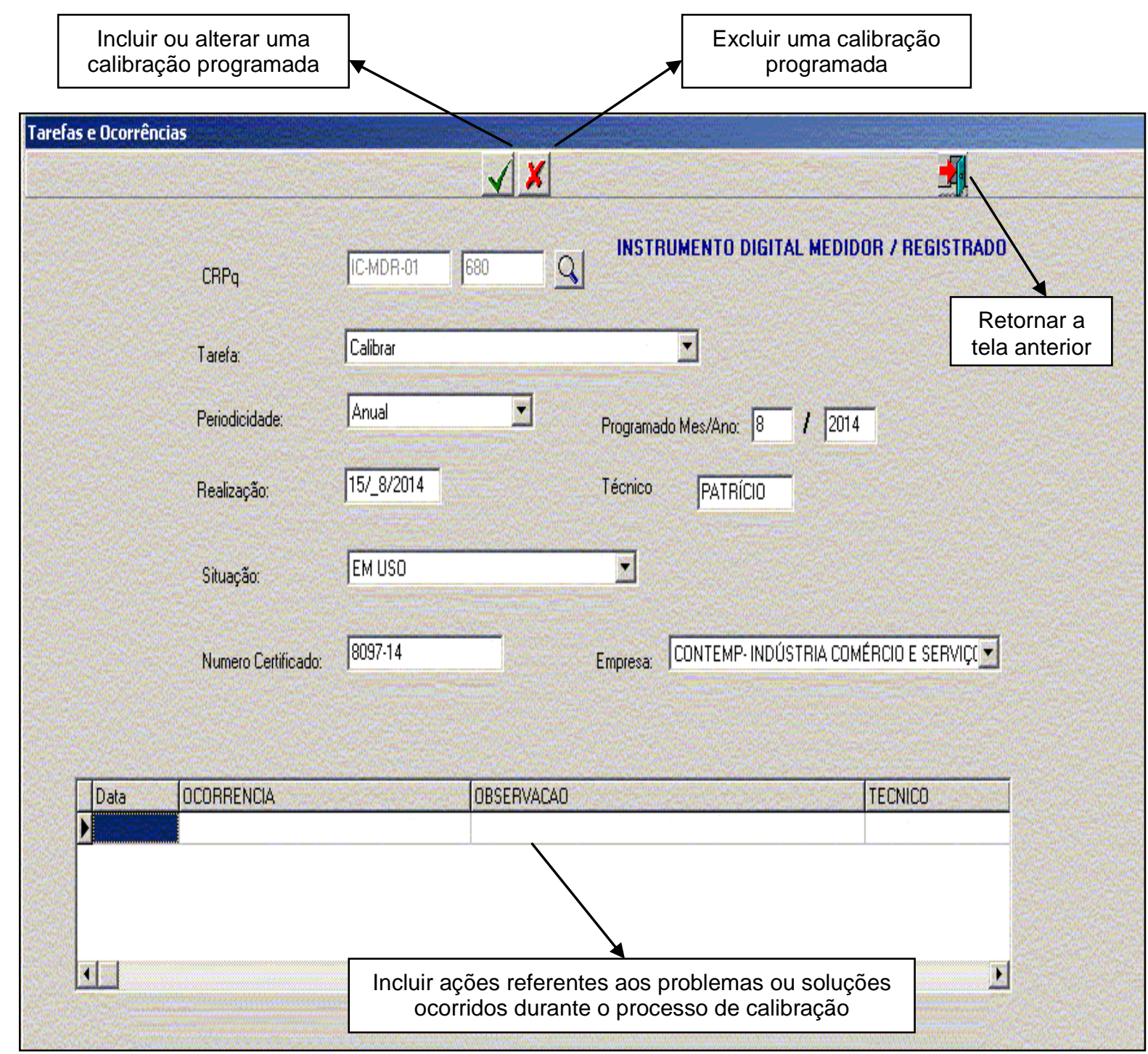

Figura 52 - Incluir ou alterar uma programação de calibração.

\subsubsection{2 - Cadastro de medidor}

O Cadastro de medidor ou instrumento segue os mesmos procedimentos do módulo de Manutenção Preventiva para equipamento.

\subsubsection{3 - Histórico}

O Histórico gera o registro de calibrações de cada instrumento ou medidor que contém o histórico de cada calibração realizada identificando o instrumento ou medidor através do seu número de identificação Tag, os parâmetros de calibração e a incerteza da medição, número do certificado, quando foi feita a calibração, qual o laboratório, a previsão da próxima 
calibração e o responsável pelo instrumento ou medidor. A Figura 53 apresenta a tela do histórico de calibração a ser elaborado e impresso.

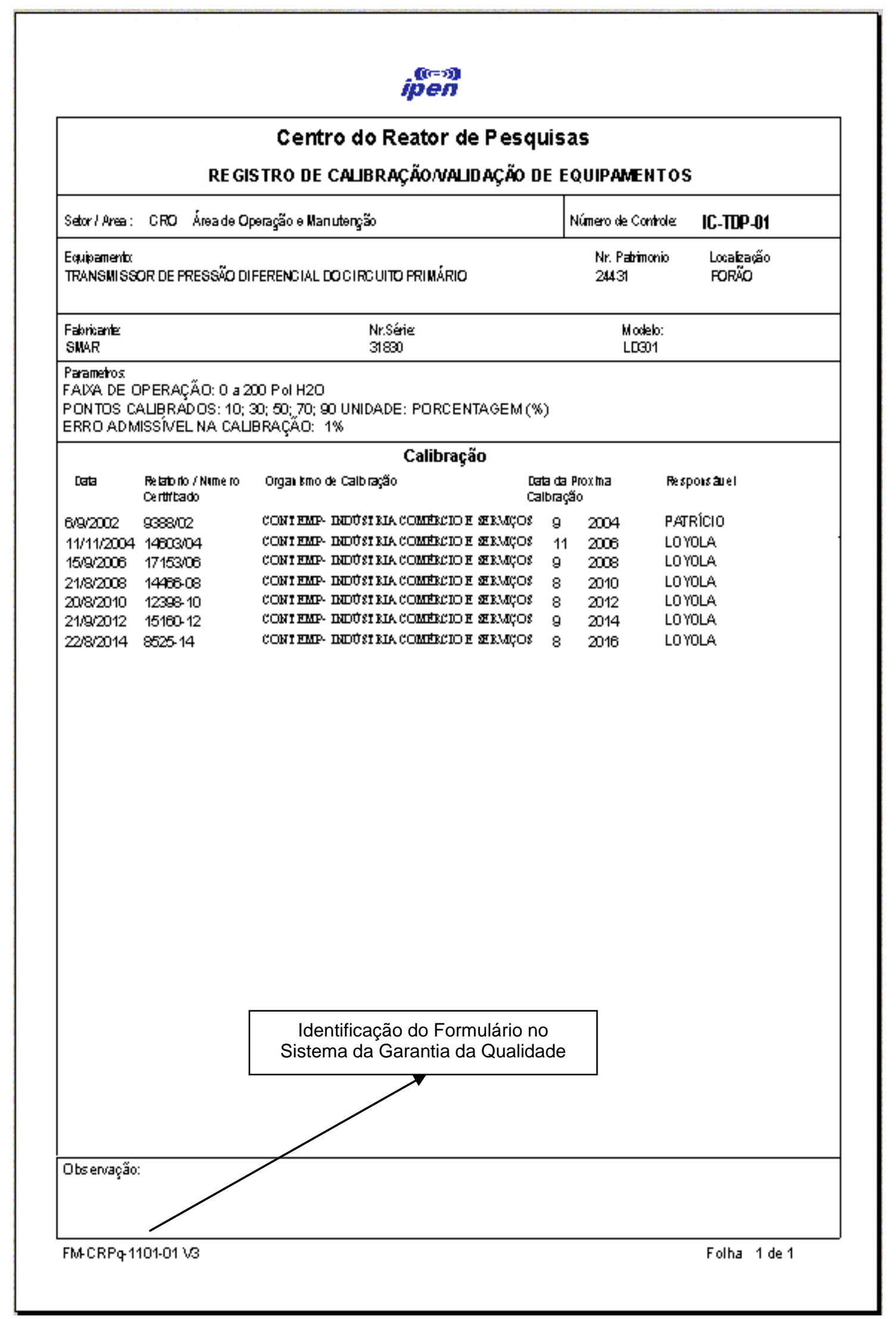

Figura 53 - Histórico de calibração do instrumento ou medidor. 


\subsection{2 - Consulta}

A consulta gera e imprime o Plano de Calibração da instalação, para controle ou simples conferência. O módulo possibilita vários filtros para a elaboração dos relatórios durante a execução das tarefas como a situação (concluído ou não concluído), separação por área, aplicação e o período (anual ou mensal ou até um determinado mês). As Figuras 54, 55 e 56 apresentam as telas descritas acima e os relatórios impressos.

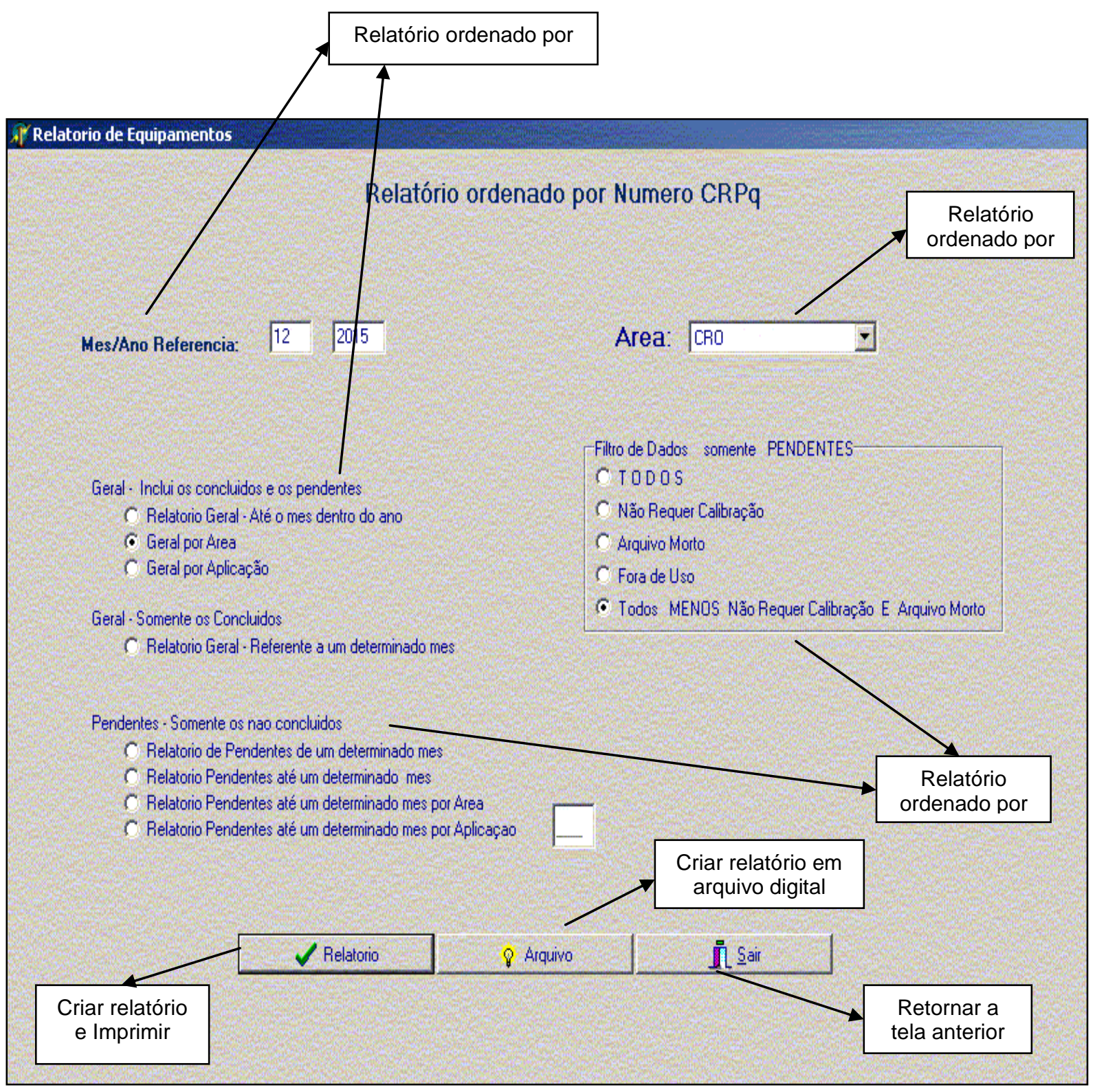

Figura 54 - Relatório de calibração a ser definido pelo usuário. 
COMISSÃO NACIONAL DE ENERGIA NUCLEAR - SP

PLANo de Calibraçäo de EQUiPAMENTOS

Emissão: 20/10/2014

Centro do Reator de Pesquisas

Pagina: 1

Area: CRO

EQUIPAMENTO/MARCAMMODELO

Localização

CRPq PERIODICIDADE

CALIBRA ÇÄ 0

Patrimonio

IC-FTC $02 \quad$ Bi-Anual $\quad 8 \quad 2014 \quad 8 / 8 / 2014 \quad 8 \quad 2016$

FONTE DE TENSÄOICORRENTE (POWER SUPPLY) LABORAT.ELET

$0-60 \mathrm{~V}, 0.5 \mathrm{~A} / 0-3.0 \mathrm{~V}, 1.0 \mathrm{~A}$

11070

INDICADOR DE PORCENTAGEM DO N16

SALA DE

$S / N$

MULTIMETRO DIGITAL

LABORAT.ELET $S / N$

INSTRUMENTO DIGITAL MEDIDOR/REGISTRADOR SALADE DE TEMPERATURA (PADRÄO INDUSTRIAL) DE $24 \quad 24811$

CANAIS

INSTRUMENTO DIGITAL MEDIDOR /REGISTRADOR SALA DE DE VAZÄO (PADRÄO INDUSTRIAL) DE 6 CANAIS SIN

INSTRUMENTO DIGITAL MEDIDOR / REGISTRADOR SALA DE DE SINAIS ANALÓGICOS (PADRÄO INDUSTRIAL) 32223

DE 4 CANAIS

TRANSMISSOR DE PRESSÄO DIFERENCIAL DO PORẨO

CIRCUITO PRIMÁRIO 24431

TRANSMISSOR DE PRESSÃO DIFERENCIALDO PORÃO

CIRCUITO SECUNDÁRIO

TRANSMISSOR DE PRESSÃO DIFERENCIAL DO PORÄO

CIRCUITO SECUNDÁRIO

SN

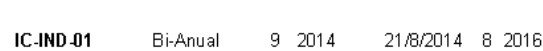

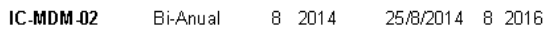

$\begin{array}{llllll}\text { IC-MDR 01 Anual } & 8 & 2014 & 15 / 8 / 2014 & 8 & 2015\end{array}$

$\begin{array}{llllll}\text { IC-MDR 02 Anual } & 8 & 2014 & 15 / 8 / 2014 & 8 & 2015\end{array}$

$\begin{array}{llllll}\text { IC-MDR -03 Anual } & 8 & 2014 & 21 / 8 / 2014 & 8 & 2015\end{array}$

IC-TDP -01 Bi-Anual $\quad 92014 \quad 22 / 8 / 2014 \quad 82016$

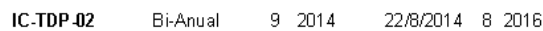

$\begin{array}{llllll}\text { IC-TDP } \mathbf{0 3} \quad \text { Bi-Anual } & 9 & 2014 & 22 / 8 / 2014 & 8 & 2016\end{array}$

OBSNISTO 
A Consulta gera e imprime uma lista de equipamentos para controle ou simples conferência. A Figura 57 mostra uma lista de equipamento impressa.

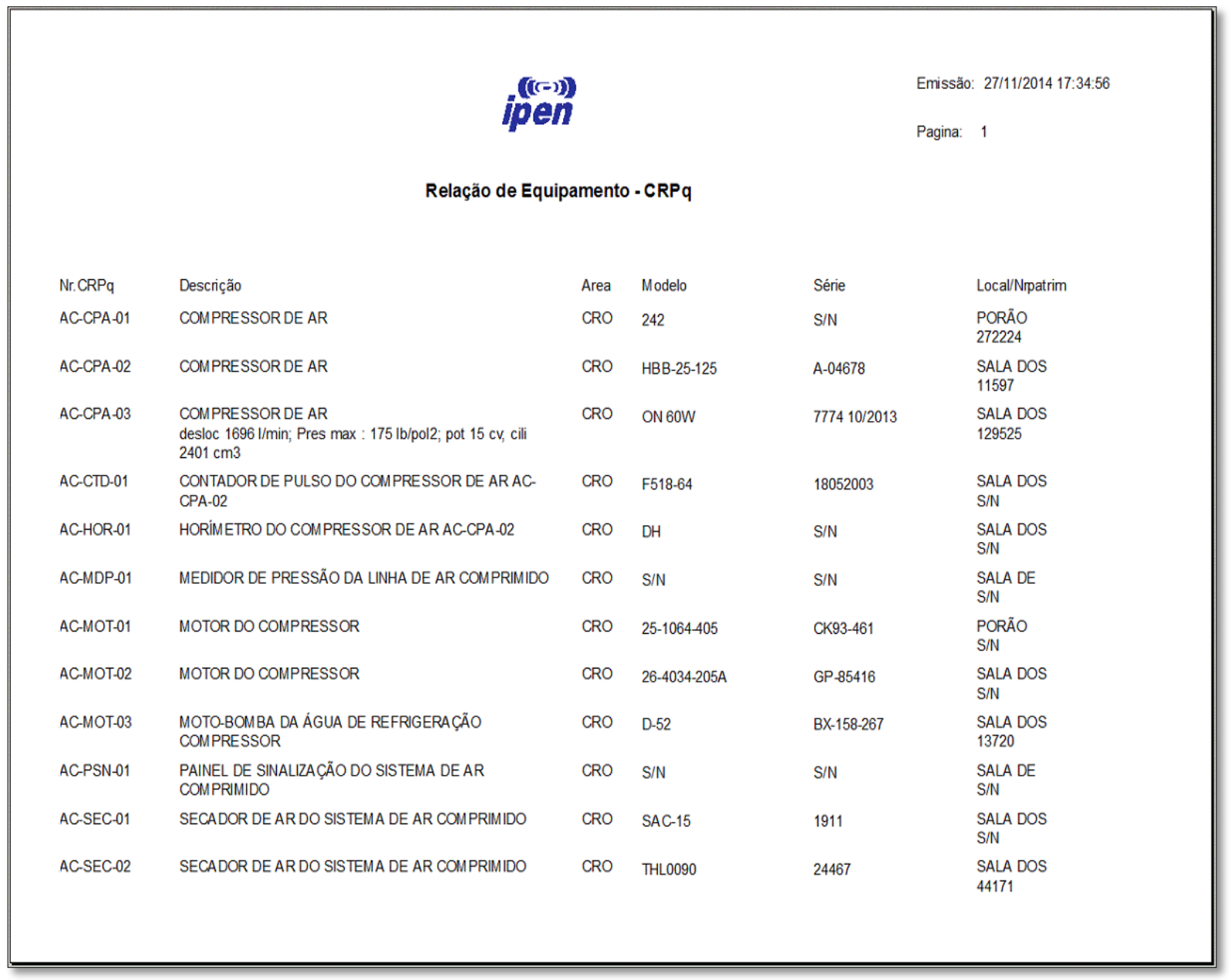

Figura 57 - Lista de equipamento por código de identificação: Tag. 


\section{4 - Indicadores e Índices de manutenção}

O grupo de manutenção do Reator, em qualquer nível, tem como finalidade prestar serviços de manutenção e zelar para que os equipamentos estejam sempre nas melhores condições de funcionamento para que o Reator tenha a maior produtividade possível.

Uma dificuldade da equipe é saber como estão os equipamentos de cada sistema, comparar uns equipamentos com outros e saber como a equipe está realizando a tarefa, comparar o que foi feito com o que foi preestabelecido. Outra dificuldade é fazer com que os serviços sejam realizados no momento mais adequado, de uma forma ordenada e planejada para a máxima eficiência, medir o que foi feito e comparar com o que foi preestabelecido.

Para resolver essas dificuldades é necessário o conhecimento do que poderá acontecer e estar preparado para as tarefas com sobressalentes, materiais e mão de obra treinada e especializada.

Para ter o processo de manutenção sob controle é necessário ter o domínio sobre o que poderá ocorrer sobre o que está acontecendo e ter condição de interferir para corrigir desvios eventuais.

Só é possível manter o processo de manutenção de forma controlada, devido ao domínio tecnológico que o grupo de manutenção possui sobre os processos de manutenção.

\subsection{1 - Indicadores}

Itens de controle são características mensuráveis do produto ou serviço, cuja verificação ou constatação de que estão de acordo com o esperado, deverá garantir a satisfação do cliente ou tomador de serviços em relação ao produto acabado ou serviço prestado. Apesar de inicialmente haver sido concebido para medir apenas o produto acabado em processos industriais, este conceito teve que ser ampliado para serviços e para todos os itens do Sistema de Gestão da Qualidade e para o atendimento ao cliente. Os itens de controle deverão ser definidos em função da expectativa do cliente [24].

Itens de verificação são valores usados durante as tarefas de execução dos serviços e nos trabalhos de manutenção. É um conjunto de parâmetro do processo de trabalho, de fabricação ou de prestação de serviços, 
pelos quais se podem avaliar e influenciar de um modo direto ou indireto os valores em curso para atingir os valores adequados dos itens de controle [24].

\subsection{2 - Índices}

O sistema computacional foi desenvolvido de forma a armazenar e indicar de maneira simples e direta índices de execução de tarefas, mão de obra e dos $R M P, R M C$ e calibração dos equipamentos ou medidores.

No $R M C$ é feita uma avaliação do serviço prestado pela equipe de manutenção e o tempo previsto e executado para a realização da tarefa. A Figura 58 apresenta quais são os itens avaliados.

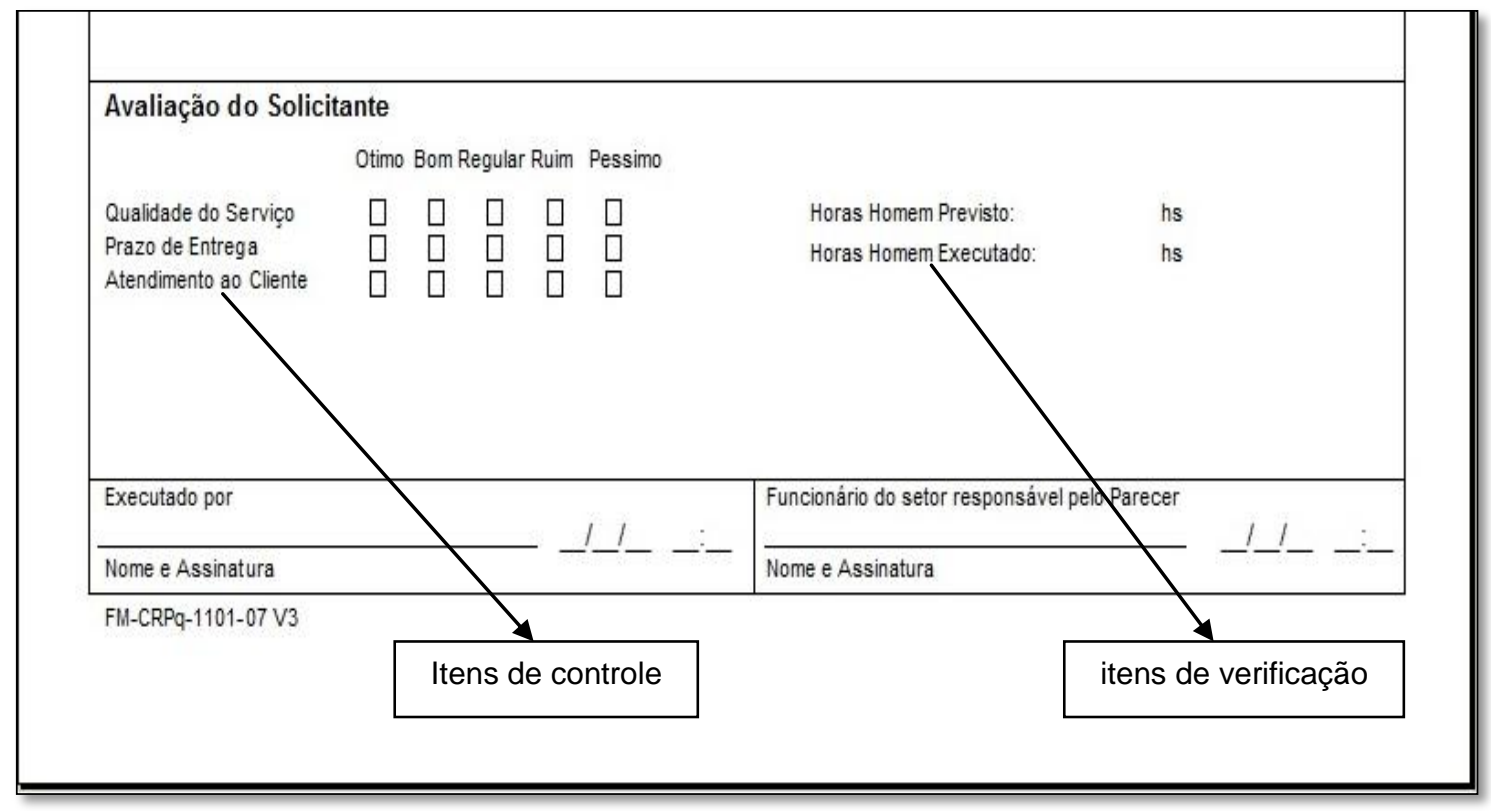

Figura 58 - Avaliação do serviço prestado pelo solicitante no RMC.

No RMP é solicitado o tempo previsto e o tempo executado, como mostra a Figura 59, para a realização da tarefa.

Na tela principal do módulo de manutenção preventiva existem dois ícones que são dedicados a índices e indicadores de manutenção, como mostra a Figura 60, que são usados para medir e quantificar as variáveis: os itens de controle e verificação. 


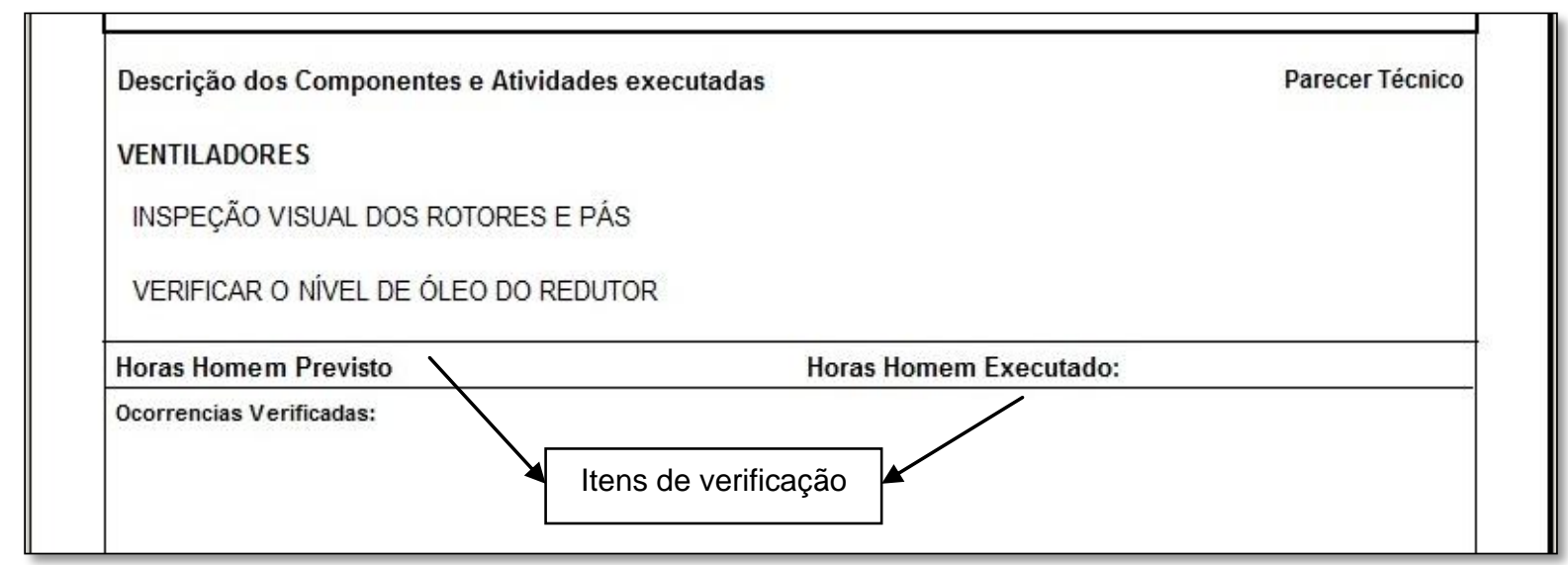

Figura 59 - Horas homem previsto e horas homem executado no RMP.

Ci Sistema de Gerenciamento de Manutenção de Equipamento - Preventiva

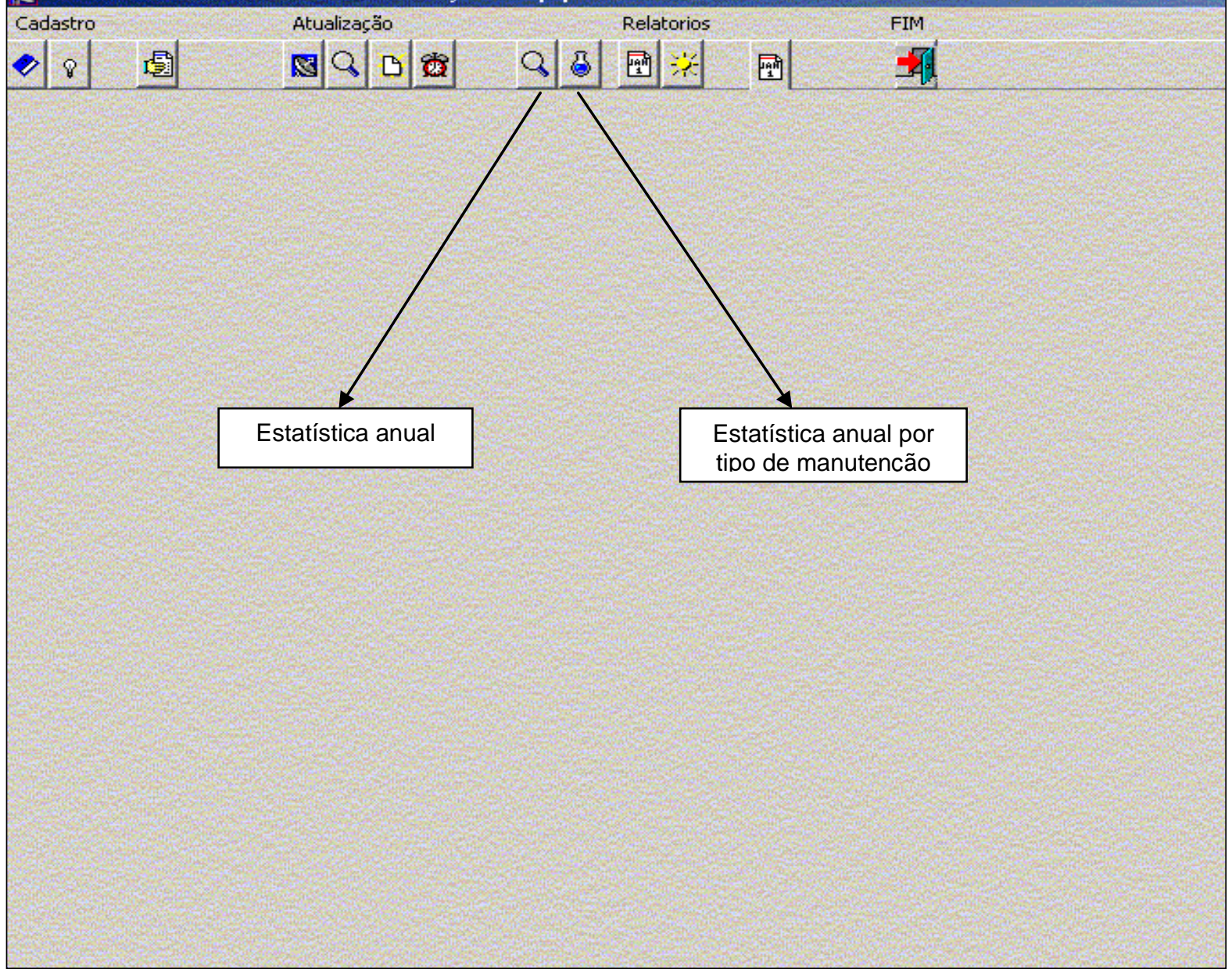

Figura 60- Tela de Índices de manutenção.

O sistema permite o levantamento anual, dividido pelos meses, de todas as manutenções preventivas criadas, executadas em andamento ou pendentes, como também por tipo de manutenção, incluindo as corretivas realizadas no período desejado. As Figuras 61 e 62 apresentam as telas de estatísticas elaboradas. 


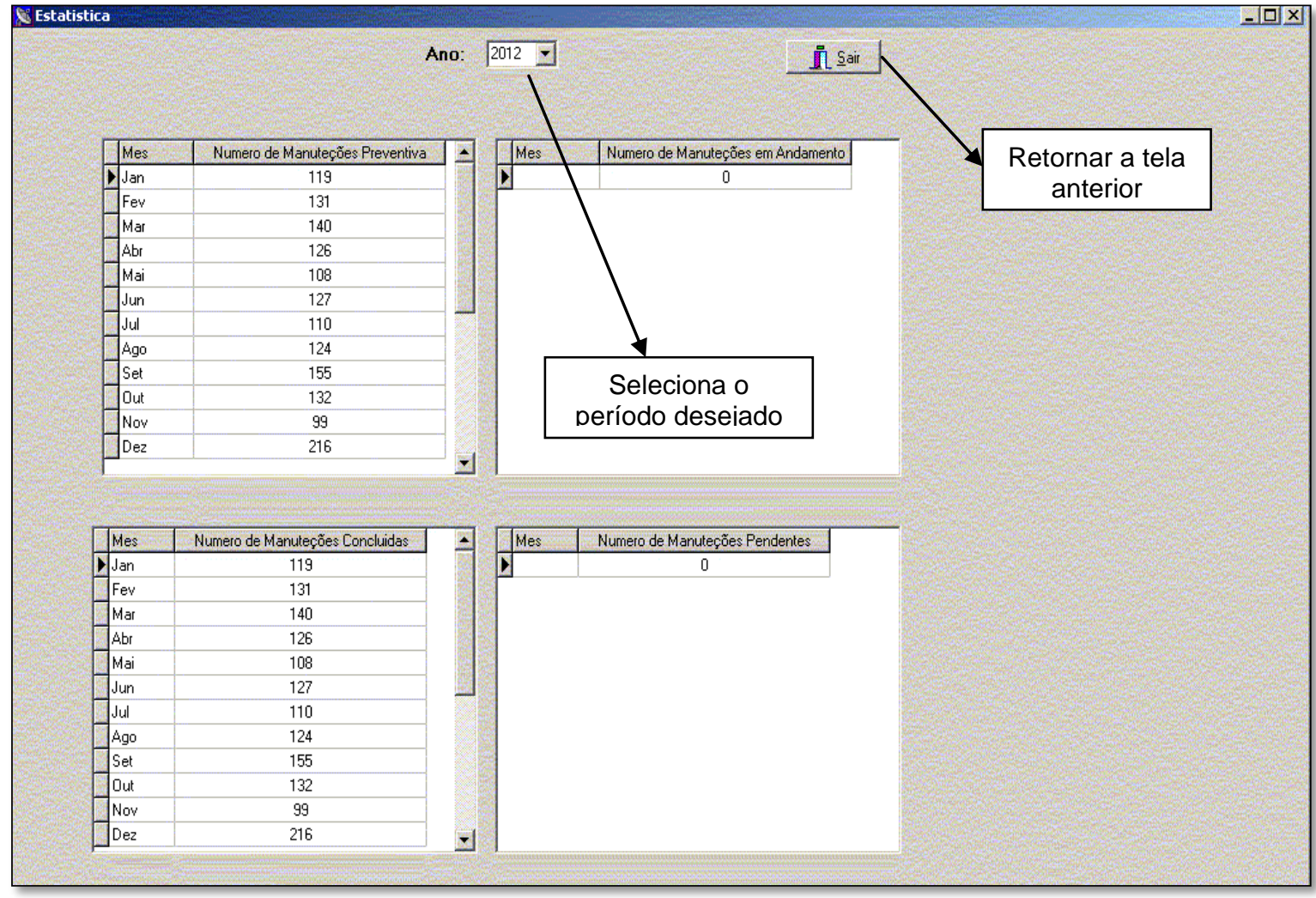

Figura 61 - Tela de estatística anual da manutenção preventiva.

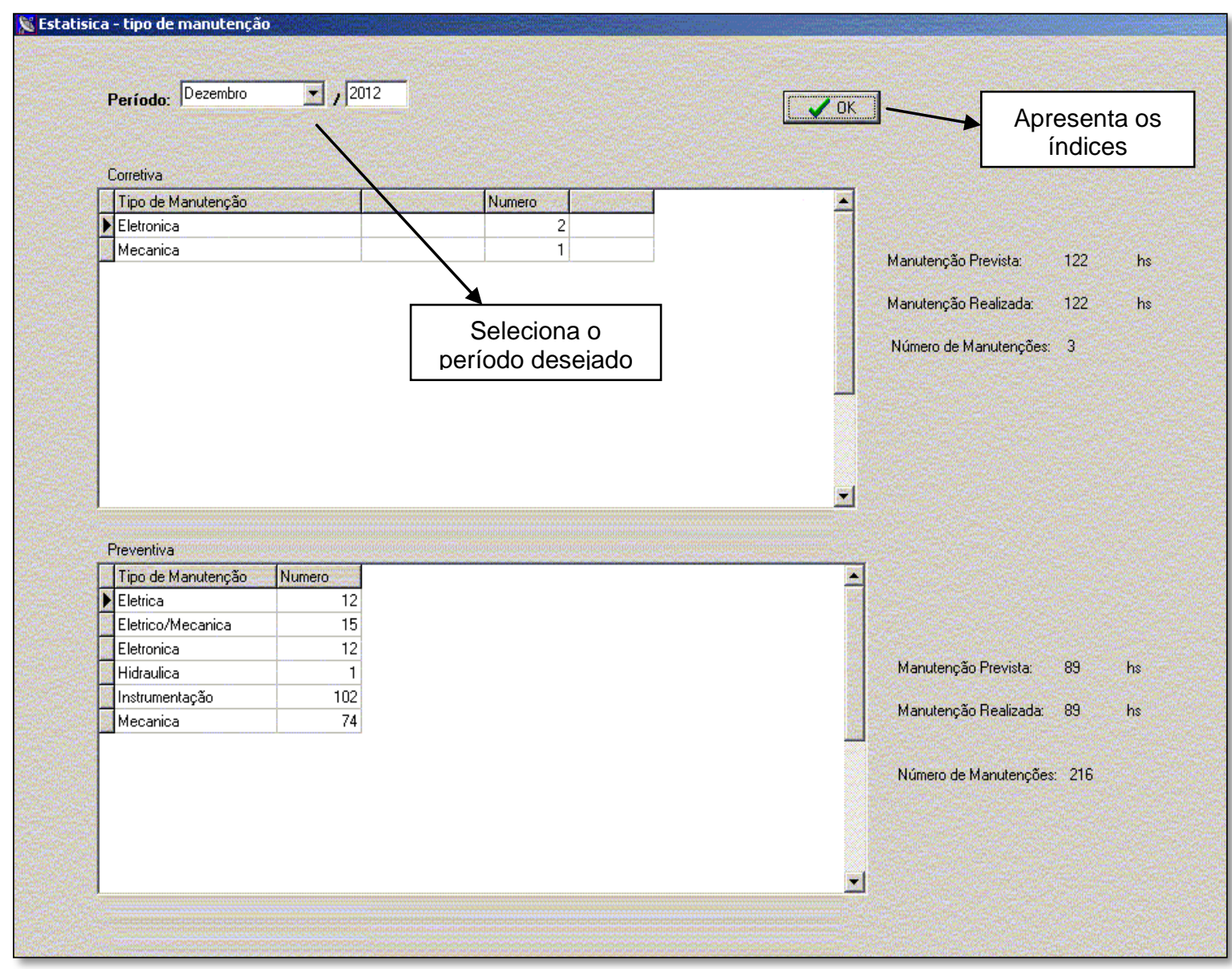

Figura 62 - Tela de estatística por tipo de manutenção. 


\subsection{3 - Relatórios gerenciais}

Estes índices são utilizados pela gerência da instalação para medir a produção do Reator, o desempenho do grupo de operação e do grupo de manutenção. São utilizados no Relatório Mensal de Atividades do Reator, para atender as exigências dos órgãos reguladores, como a CNEN, ABNT e AIEA.

\subsubsection{1 - Produção e disponibilidade}

A produção é calculada na Planilha de Índices Manutenção e Operação Mensal. A Figura 63 apresenta cálculo destes índices.

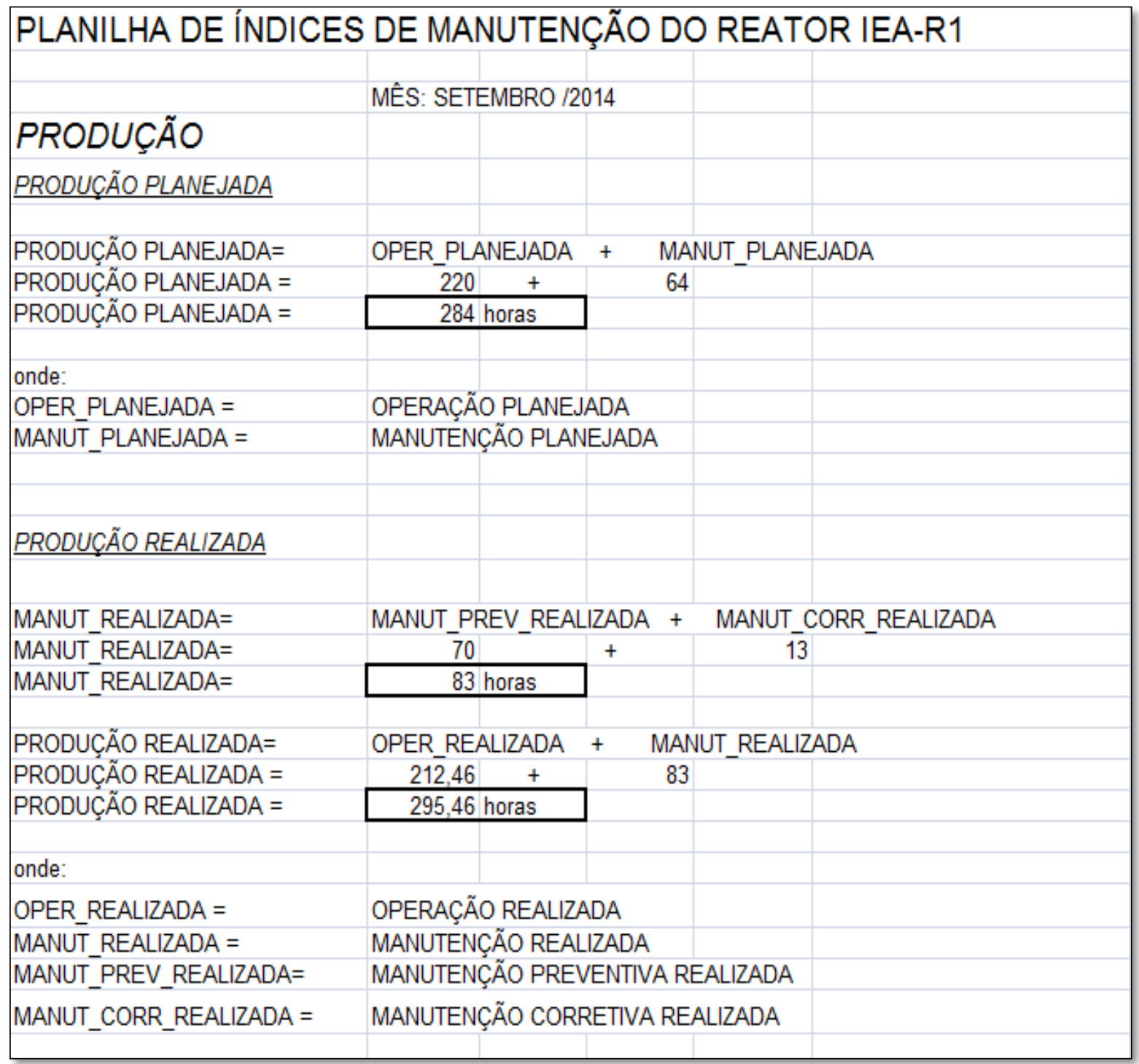

Figura 63 - Cálculo da produção realizada no período.

Com esse valor podemos calcular a disponibilidade [5] do Reator durante o período desejado. A Figura 64 apresenta este índice calculado. 


\begin{tabular}{|c|c|c|c|}
\hline PLANILHA DE ÍNDICES & DE MANUTENÇ & ÇÃO DO REAT & OR IEA-R1 \\
\hline & MÊS: SETEMBRO $/ 20$ & & \\
\hline & & & \\
\hline DISPONIBILIDADE & & & \\
\hline DISPONIBILIDADE & & & \\
\hline Definição: DISPONIBILIDADE É A & PROBABILIDADE DE U & JMA INSTALAÇÃO / & QUIPAMENTO \\
\hline ESTAR PRODUZINDO O & U EM CONDIÇÕES DE & PRODUZIR & \\
\hline DISPONIBILIDADE PLANEJADA & & & \\
\hline & & & \\
\hline DISP_PLANEJADA = & & & \\
\hline DISPŌNIBILIDADE PLANEJADA = & OPER PLANEJADA / & (OPER_PLANEJADA & + MANUT_PLANEJADA) $\times 100$ \\
\hline & $77,5 \%$ & & \\
\hline DISPONIBILIDADE REALIZADA & & & \\
\hline DISP REALIZADA = & & & \\
\hline DISPONIBILIDADE REALIZADA = & OPER REALIZADA / & OPER_REALIZADA - & MANUT_REALIZADA) $\times 100$ \\
\hline & \begin{tabular}{|l}
$71,9 \%$ \\
\end{tabular} & & \\
\hline
\end{tabular}

Figura 64 - Cálculo da disponibilidade no período.

\subsubsection{2 - Grupo de manutenção - GM}

Os índices do grupo de manutenção são divididos em preventiva e corretiva. A Figura 65 apresenta os tipos, a quantidade e o tempo de execução dos $R M P$.

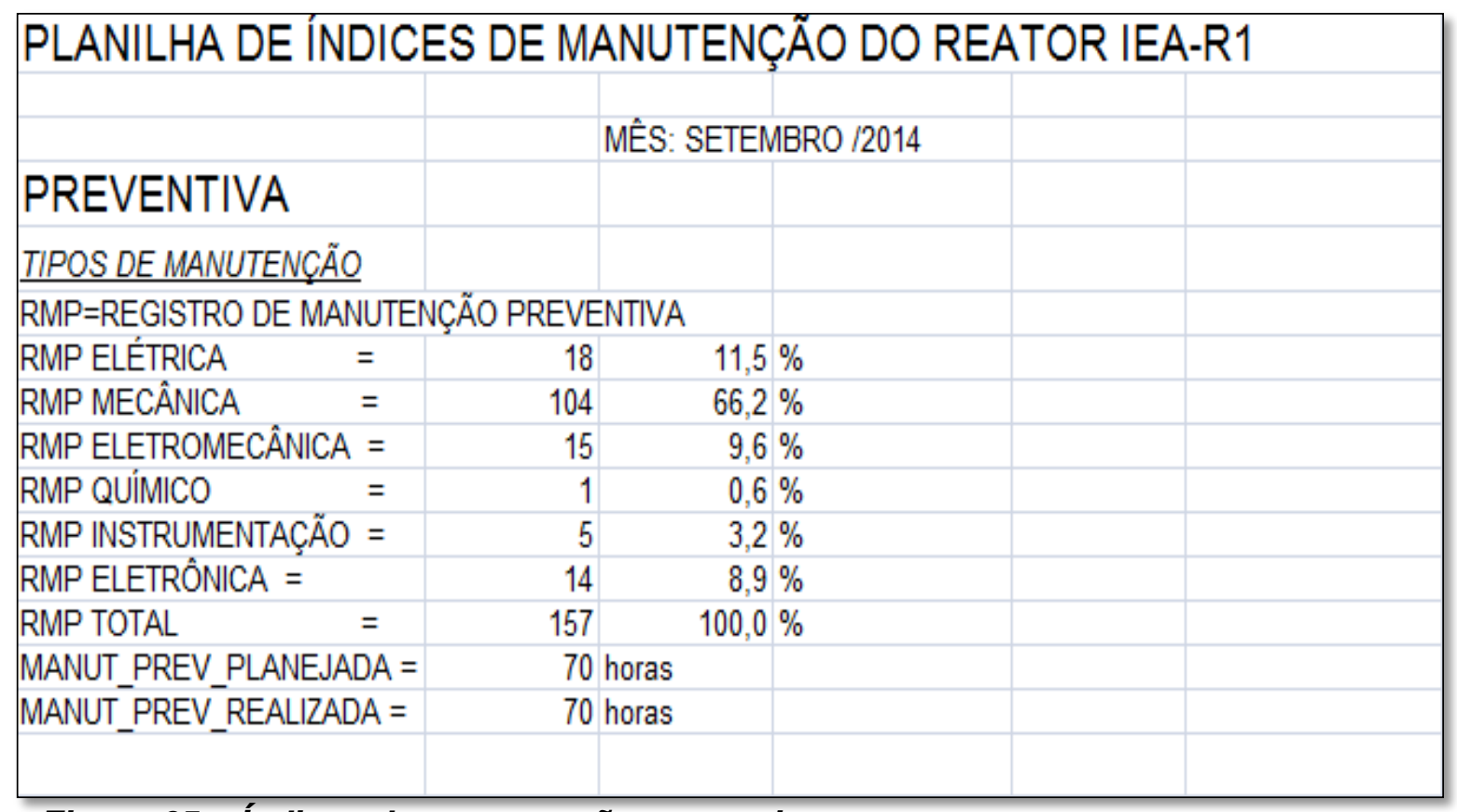

Figura 65 - Índices de manutenção preventiva. 
A Figura 66 apresenta a porcentagem de utilização em trabalhos, a capacidade de absorção e a eficiência da equipe que realizou os $R M P$.

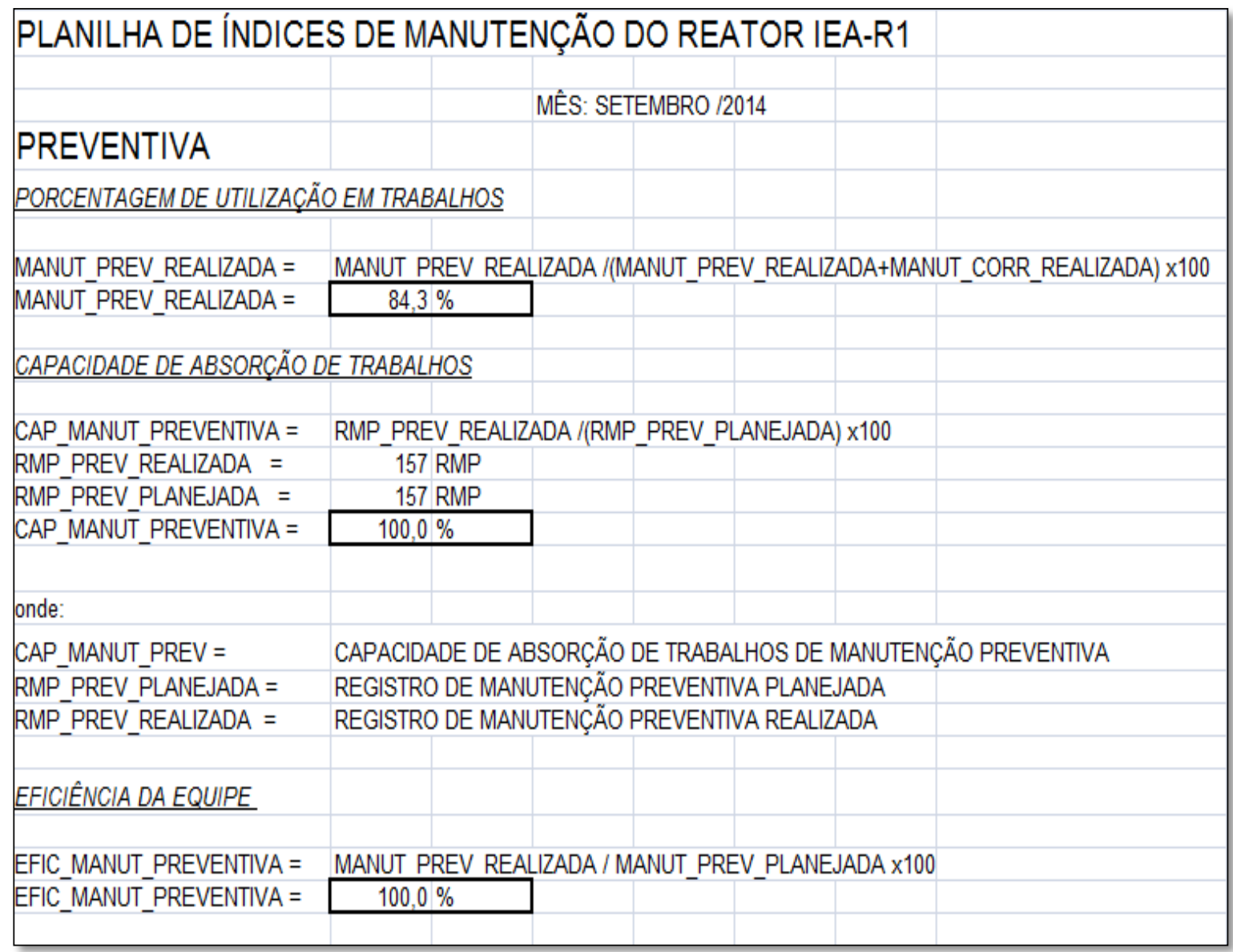

Figura 66 - Índices de manutenção preventiva: porcentagem, capacidade e eficiência da equipe.

A planilha de índices de manutenção corretiva apresenta:

- Tipos de RMC,

- Quantidade o tempo de execução dos RMC,

- Índice de satisfação junto ao cliente pela execução da tarefa.

Existe uma categoria que não se enquadra como manutenção, apesar do acesso ser através do módulo de manutenção corretiva, essa categoria foi definido no sistema computacional como serviço. Fazem parte desta categoria:

- Montagem ou instalação de equipamentos ou medidores novos;

- Serviço predial como: pintura, limpeza, rede elétrica e hidráulica;

- Serviços prestados pela oficina mecânica em geral;

- Qualquer tarefa que necessite de acompanhamento do GM. 
A Figura 67 apresenta a planilha com os valores dos índices calculados e impresso.

\begin{tabular}{|c|c|c|c|c|c|}
\hline \multicolumn{6}{|c|}{ PLANILHA DE ÍNDICES DE MANUTENÇÃO DO REATOR IEA-R1 } \\
\hline & & \multicolumn{2}{|c|}{ MÊS: SETEMBRO /2014 } & & \\
\hline & & & & & \\
\hline \multicolumn{6}{|l|}{ CORRETIVA } \\
\hline \multicolumn{6}{|l|}{ TIPOS DE MANUTENÇÃO } \\
\hline \multicolumn{5}{|c|}{ RMC=REGISTRO DE MANUTENÇÃO CORRETIVA / EXECUCCAO DE SERVIÇO } & \\
\hline RMC ELÉTRICA = & 0 & 0,0 & $\%$ & & \\
\hline RMC MECÂNICA & 0 & 0,0 & $\%$ & & \\
\hline RMC HIDRÁULICA & 0 & 0,0 & $\%$ & & \\
\hline RMC INSTRUMENTAÇÃO = & 1 & 14,3 & $\%$ & & \\
\hline RMC ELETRÔNICA = & 6 & 85,7 & $\%$ & & \\
\hline RMC QUIMICA & 0 & 0,0 & $\%$ & & \\
\hline RMC TOTAL & 7 & 100,0 & $\%$ & & \\
\hline MANUT_CORR_PLANEJADA= & 13 & horas & & & \\
\hline MANUT_CORR_REALIZADA = & 13 & horas & & & \\
\hline \multicolumn{6}{|c|}{ SERVIÇOS EXECUTADOS } \\
\hline \multicolumn{6}{|c|}{ TIPOS DE MANUTENÇÃO } \\
\hline \multicolumn{5}{|c|}{ RMC=REGISTRO DE MANUTENÇÃO CORRETIVA / EXECUÇAO DE SERVIÇO } & \\
\hline RMC ELÉTRICA = & 0 & 0,0 & $\%$ & & \\
\hline RMC MECÂNICA & 1 & 100,0 & $\%$ & & \\
\hline RMC HIDRÁULICA = & 0 & 0,0 & $\%$ & & \\
\hline RMC INSTRUMENTAÇÃOO = & 0 & 0,0 & $\%$ & & \\
\hline RMC ELETRÔNICA & 0 & 0,0 & $\%$ & & \\
\hline RMC QUIMICA & 0 & 0,0 & $\%$ & & \\
\hline RMC PREDIAL & 0 & 0,0 & $\%$ & & \\
\hline RMC TOTAL & 1 & 100,0 & $\%$ & & \\
\hline SERVIÇO_PLANEJADO = & 40 & horas & & & \\
\hline SERVIÇO_REALIZADO = & 40 & horas & & & \\
\hline \multicolumn{6}{|c|}{ ÍNDICE DE SATISFAÇÃO JUNTO AO CLIENTE } \\
\hline & OTIMO & $B O M$ & REGULAR & RUIM & PÉSSIMO \\
\hline QUALIDADE DO SERVIÇO = & 4 & 3 & 0 & 0 & 0 \\
\hline PRAZO DE ENTREGA = & 2 & 5 & 0 & 0 & 0 \\
\hline \multirow[t]{3}{*}{ ATENDIMENTO AO CLIENTE = } & 5 & 2 & 0 & 0 & 0 \\
\hline & & & INDICE DE & & \\
\hline & OBTIDO & IDEAL & SATISFAÇÃO & & \\
\hline QUALIDADE DO SERVIÇO = & 32 & 35 & 91 & $\%$ & \\
\hline PRAZO DE ENTREGA = & 30 & 35 & 86 & $\%$ & \\
\hline ATENDIMENTO AO CLIENTE = & 33 & 35 & 94 & $\%$ & \\
\hline
\end{tabular}

Figura 67 - Índices de manutenção corretiva, serviço e satisfação junto ao cliente. 
A Figura 68 apresenta a porcentagem de utilização em trabalhos, a capacidade de absorção e a eficiência da equipe de manutenção que realizou os RMC. A Figura 69 apresenta a eficiência dos grupos GO e GM.

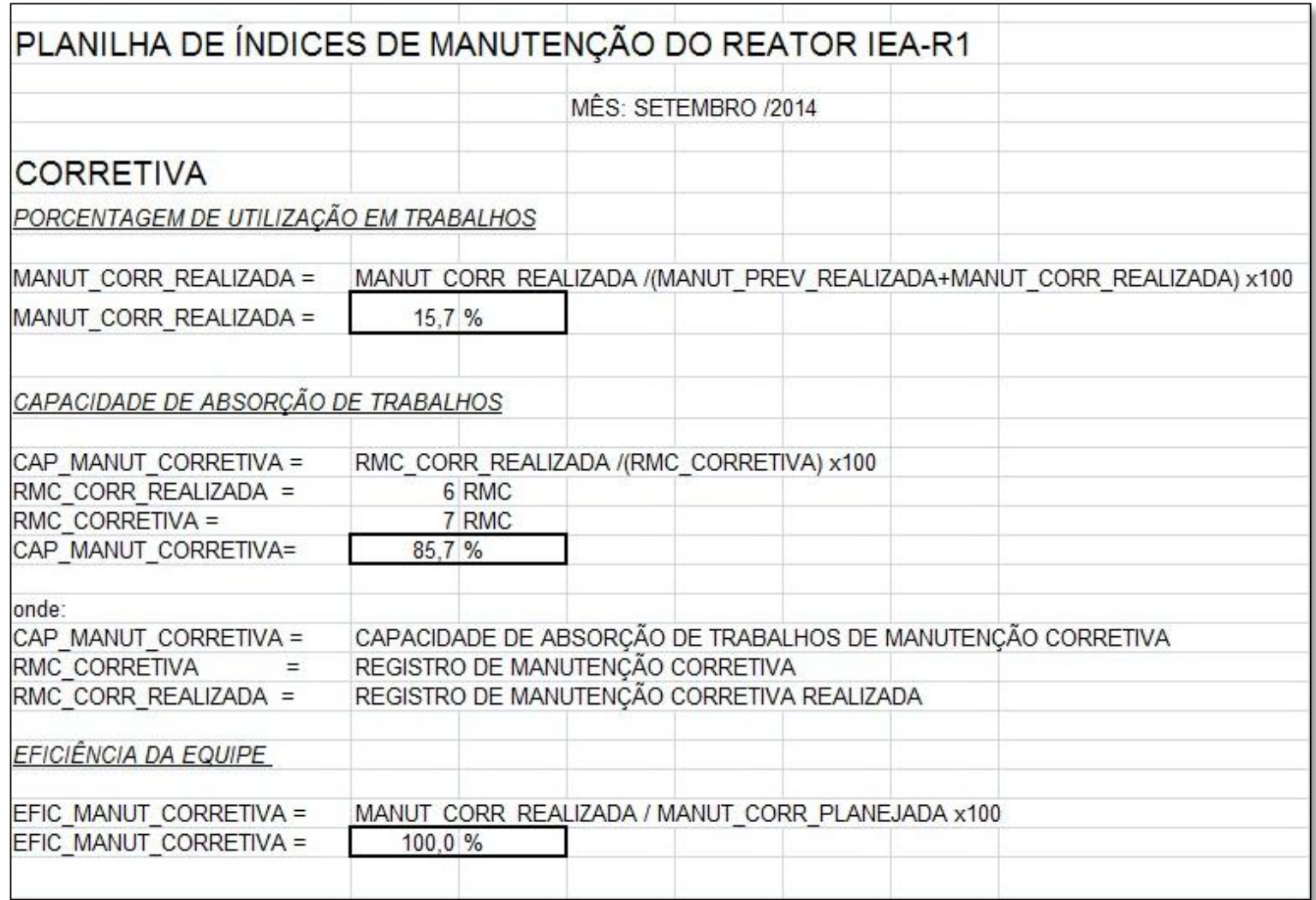

Figura 68 - Cálculo da porcentagem, capacidade e eficiência da equipe.

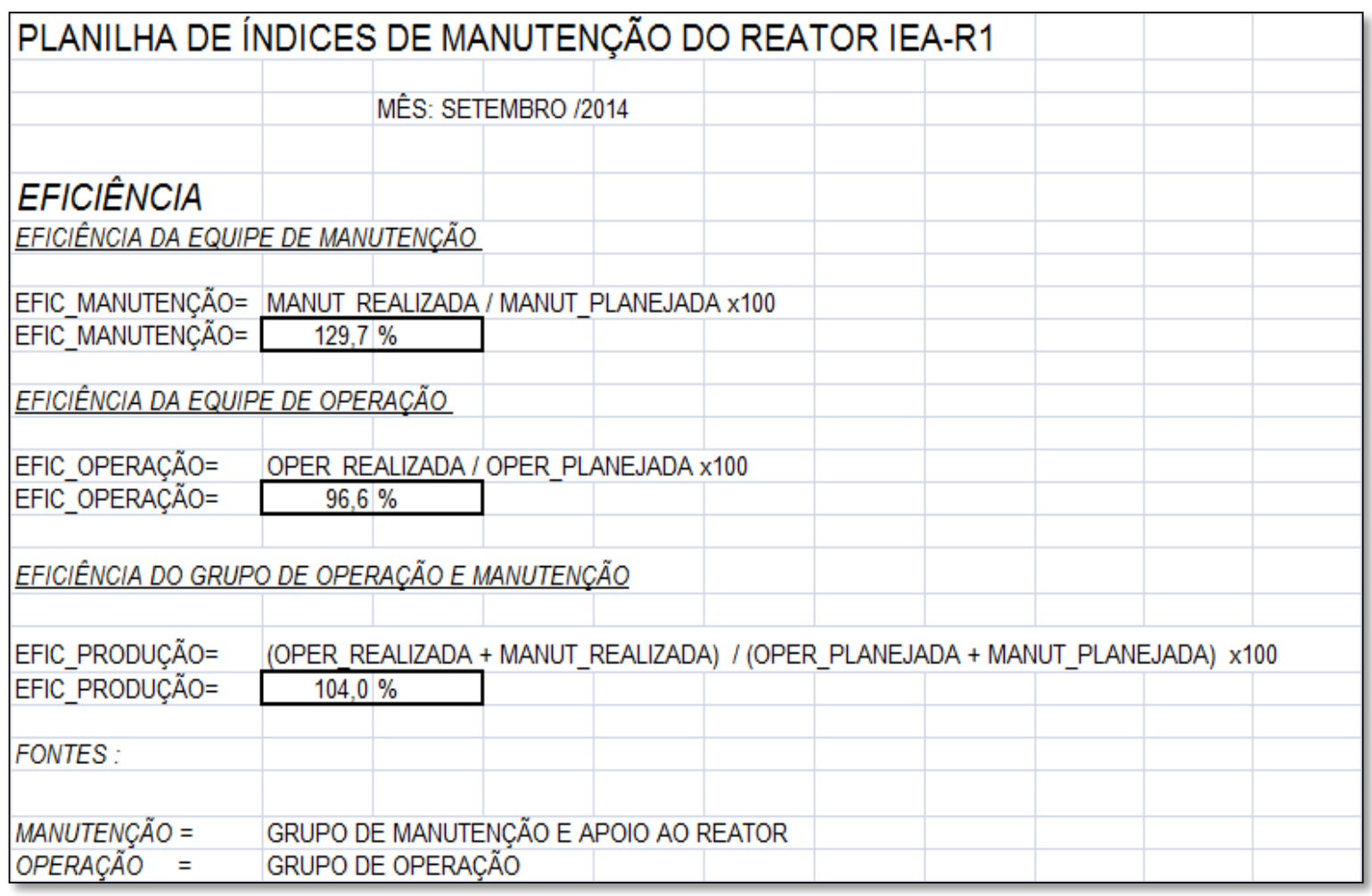

Figura 69 - Cálculo da eficiência do GM, GO e da produção (GM+GO) do Reator. 


\subsubsection{3 - Relatório mensal de atividades}

O Relatório Mensal de Atividades do Reator IEA-R1, é um documento gerencial que faz parte do Sistema da Gestão da Qualidade, na categoria de relatório técnico, é constantemente utilizado durante as auditorias dos órgãos reguladores $C N E N, A B N T$ e AIEA. O objetivo principal do documento é mostrar as principais atividades desenvolvidas no Reator IEA-R1 e fornecer informações consideradas importantes para a operação segura e confiável da instalação.

Os gráficos a seguir foram retirados do Relatório Mensal de Atividades do Reator IEA-R1 do mês de janeiro de 2013. As Figuras 70, 71, 72, 73 e 74 apresentam os gráficos elaborados e impressos.

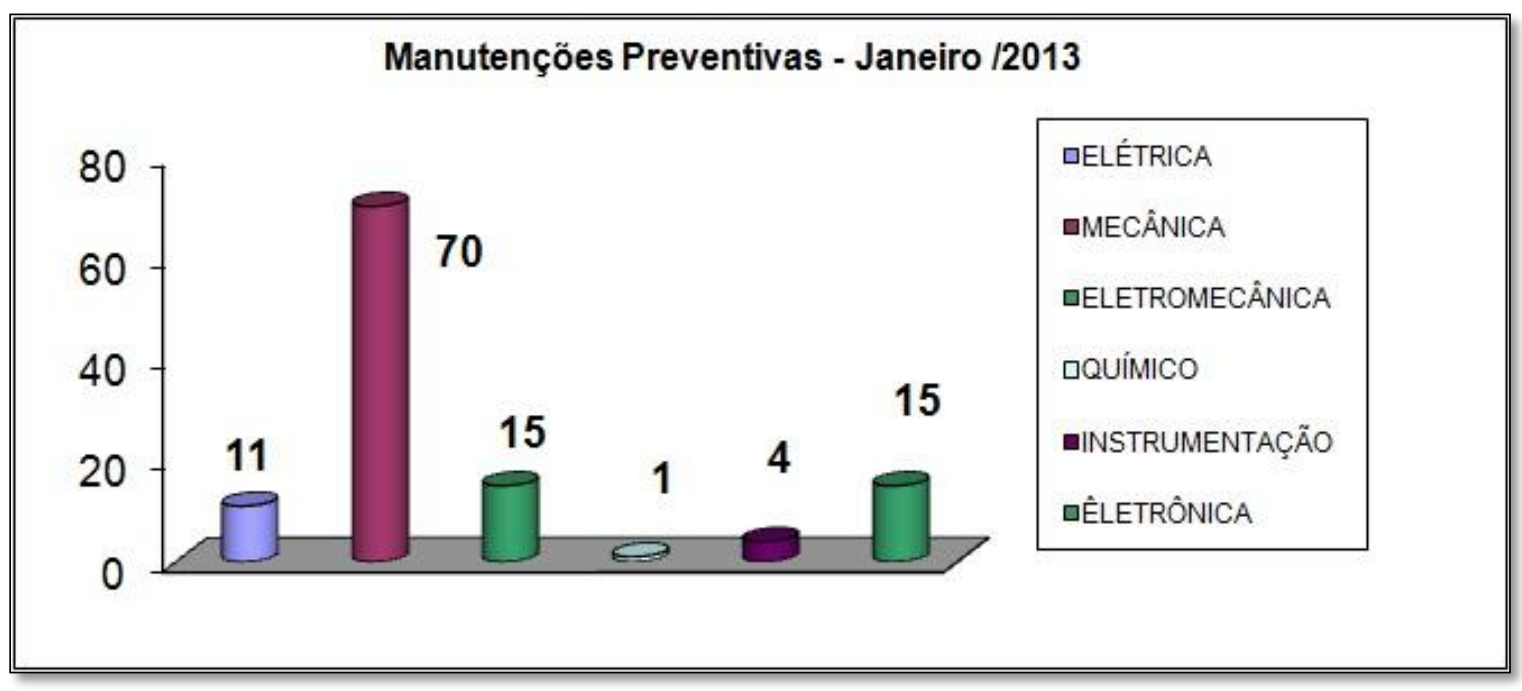

Figura 70 - Número de manutenções preventivas: RMP.

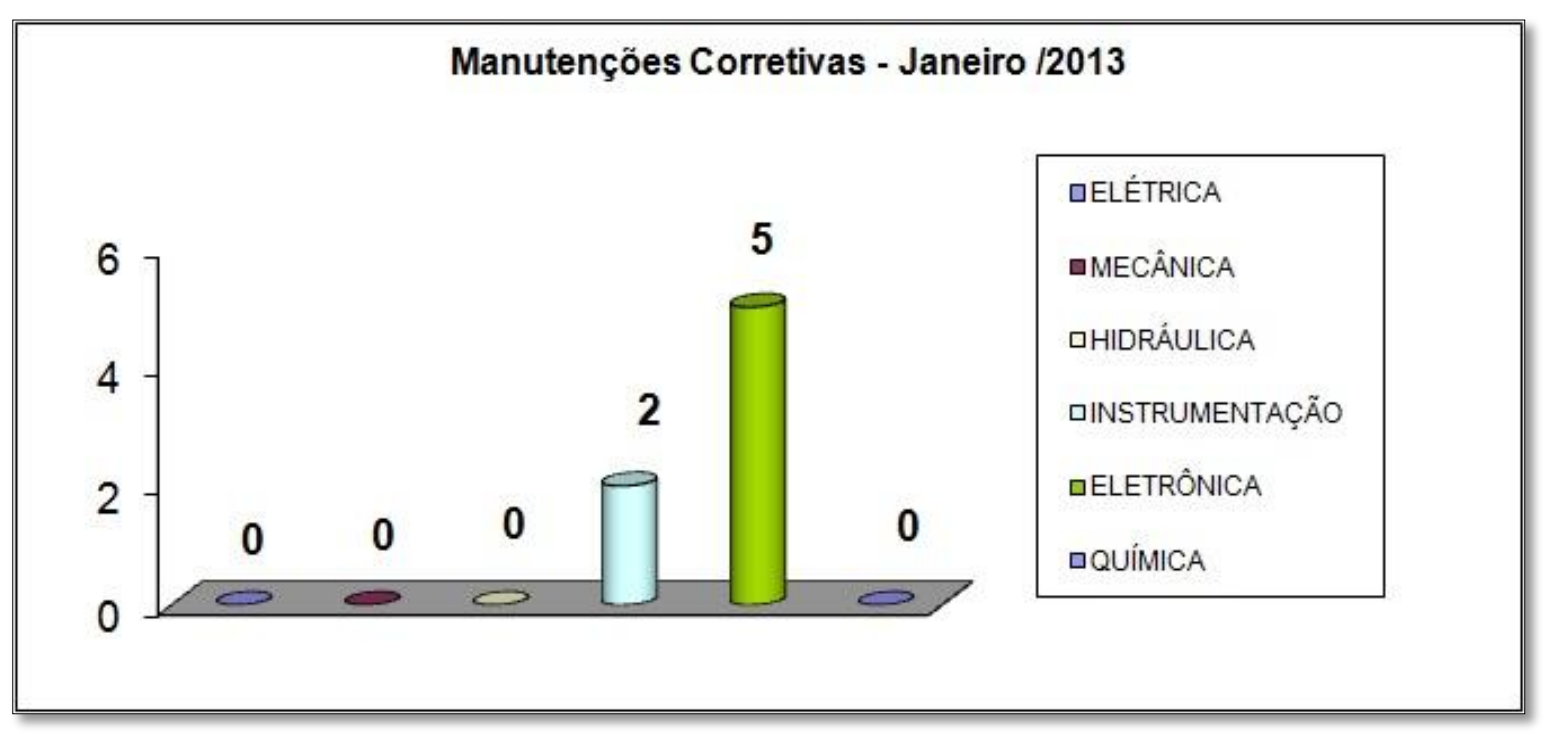

Figura 71 - Número de manutenções corretivas: RMC. 


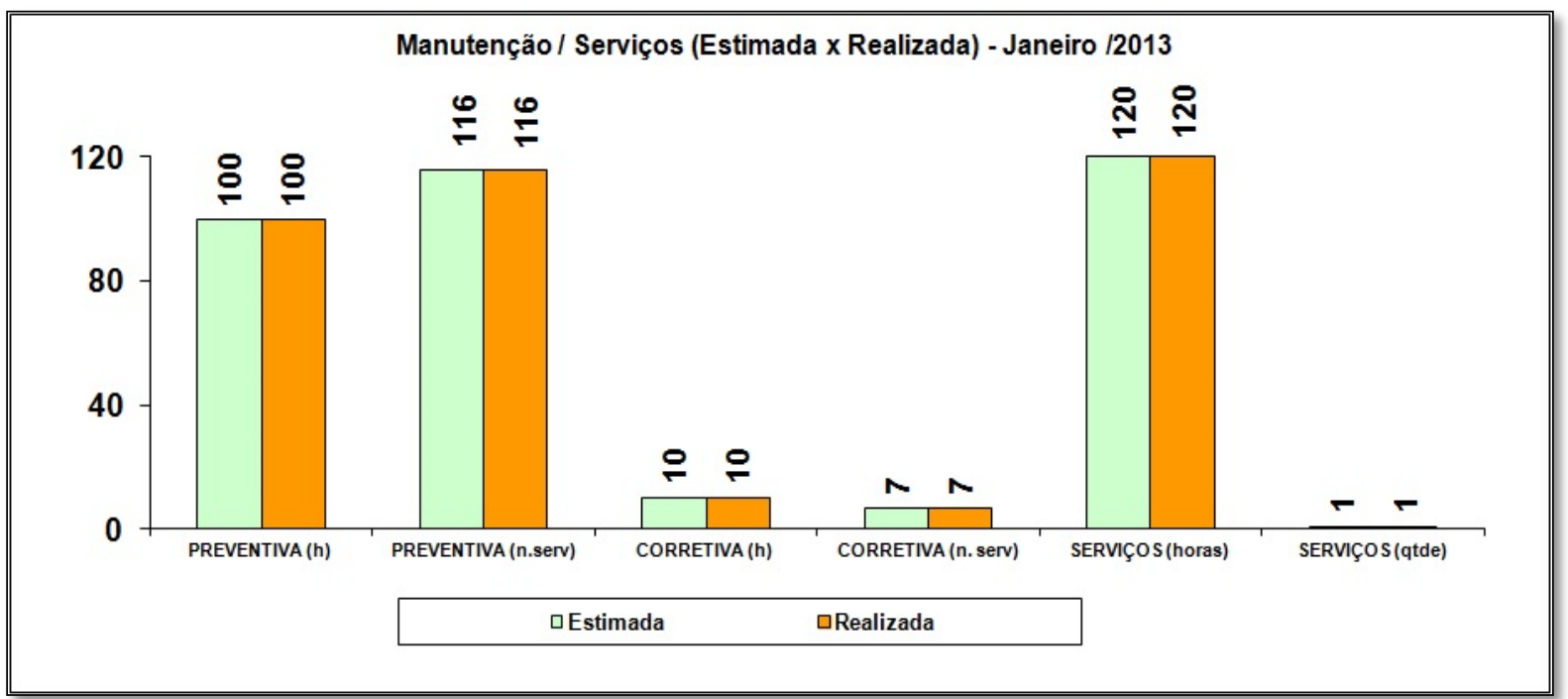

Figura 72 - Relação entre a manutenção preventiva, corretiva e serviço.

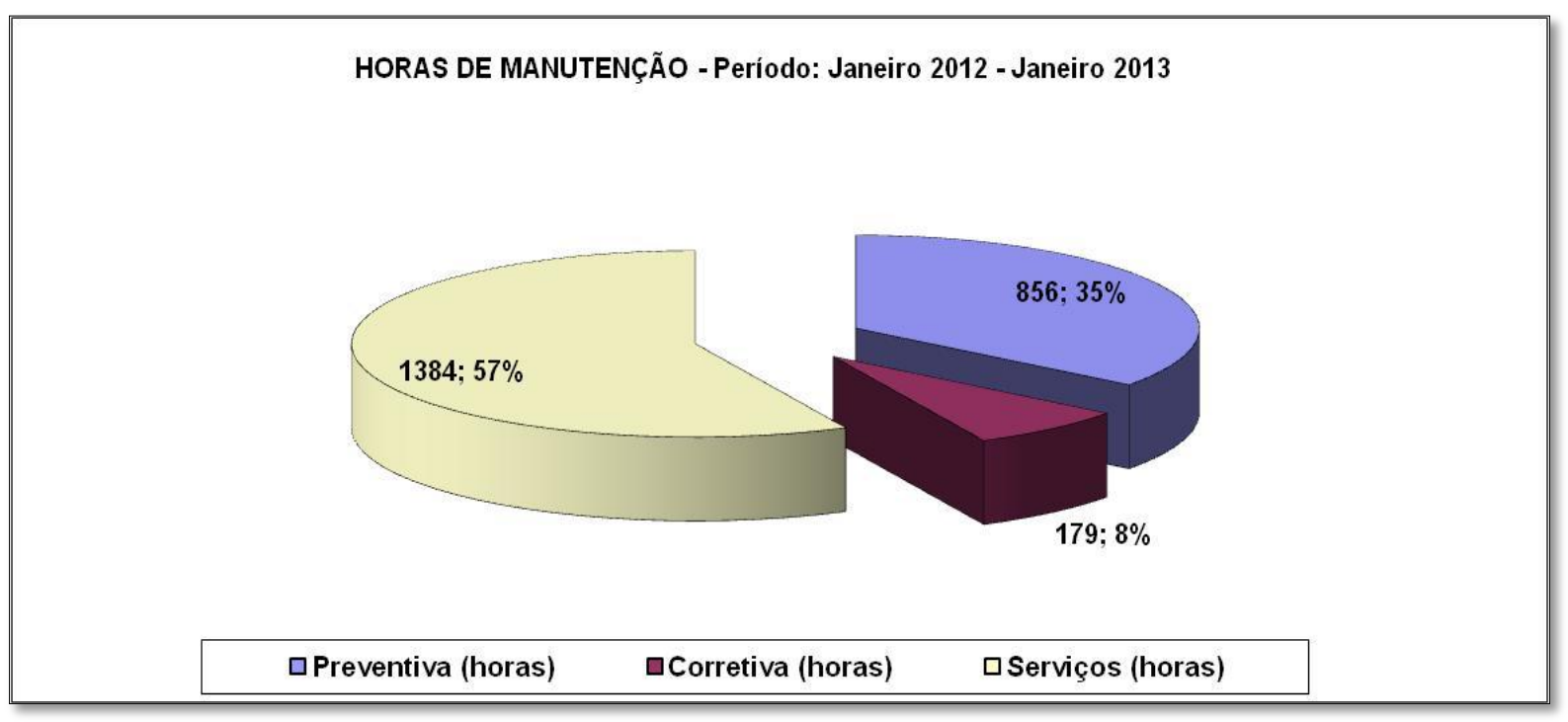

Figura 73 - Total de horas de manutenção.

REGISTROS DE MANUTENÇÃO - Período: Janeiro 2012 - Janeiro 2013

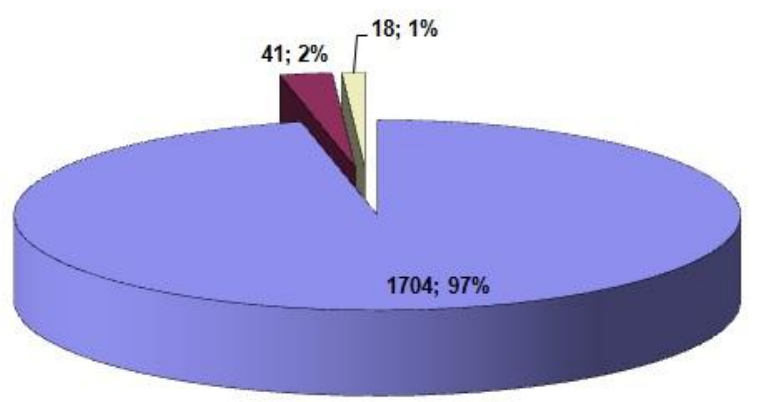

口Preventiva (RMP)

口Corretiva (RMC)

$\square$ Serviços (RMC/S)

Figura 74 - Total de registros de manutenção. 
O relatório mensal é dividido em capítulos, onde cada área do Reator como:

- Manutenção, operação, proteção radiológica;

- Irradiação de amostras, cálculo e simulação;

- Controle químico da água, garantia da qualidade entre outros.

Apresentam suas atividades no período. Neste caso somente os índices de manutenção serão apresentados. As Figuras 75, 76, e 77 apresentam os gráficos elaborados e impressos.

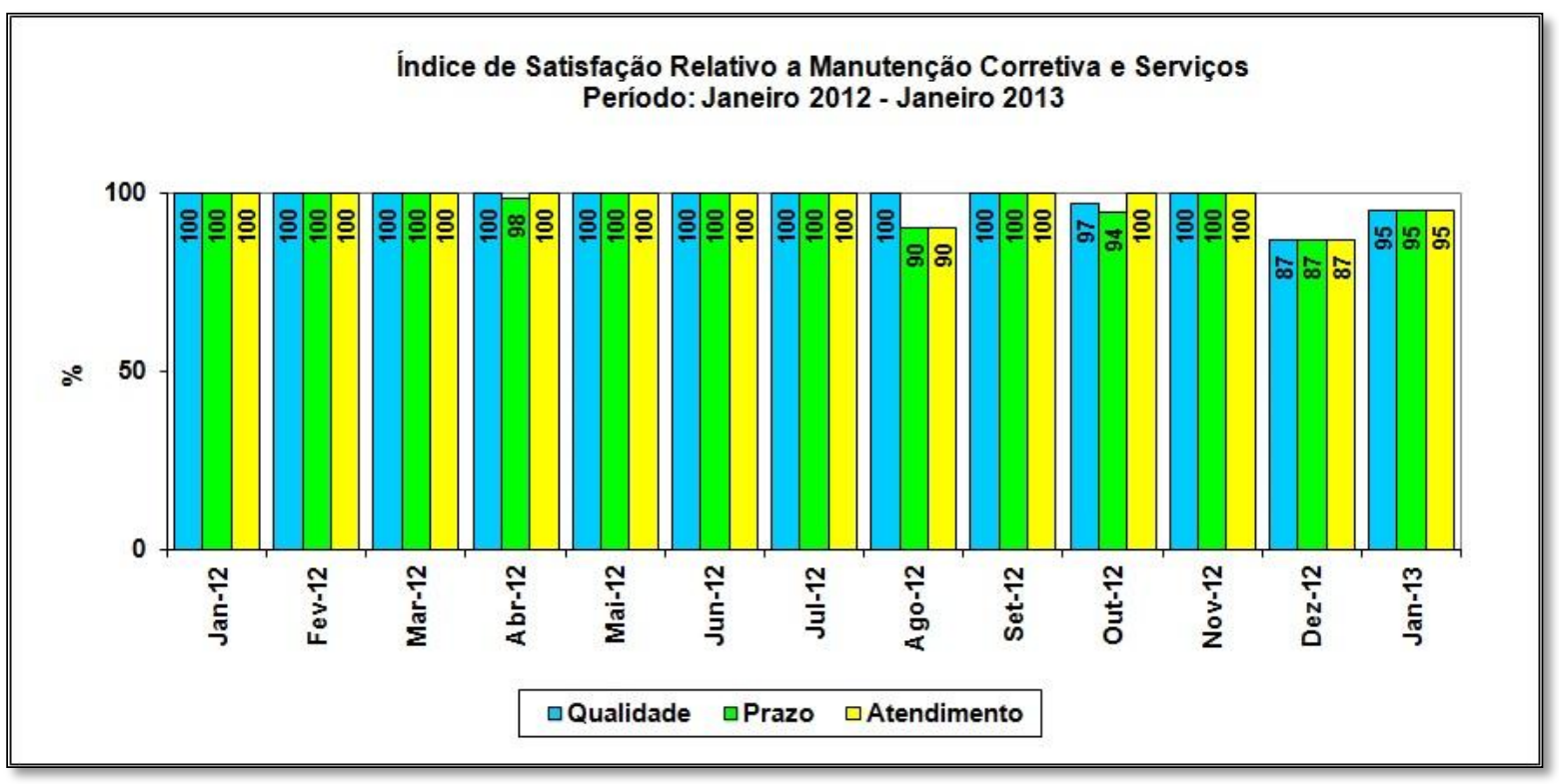

Figura 75 - Índice de satisfação de cliente.

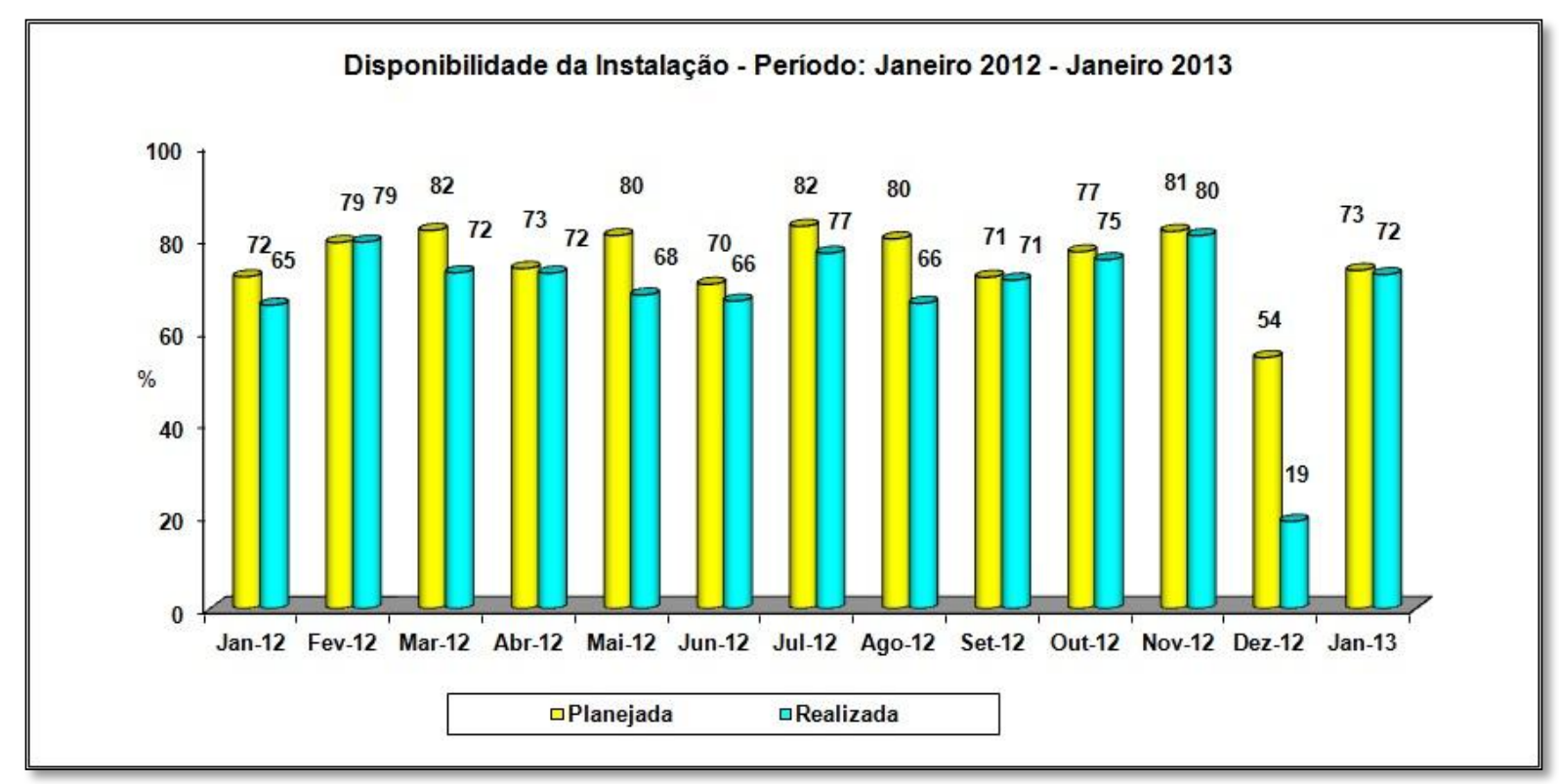

Figura 76 - Disponibilidade do Reator. 


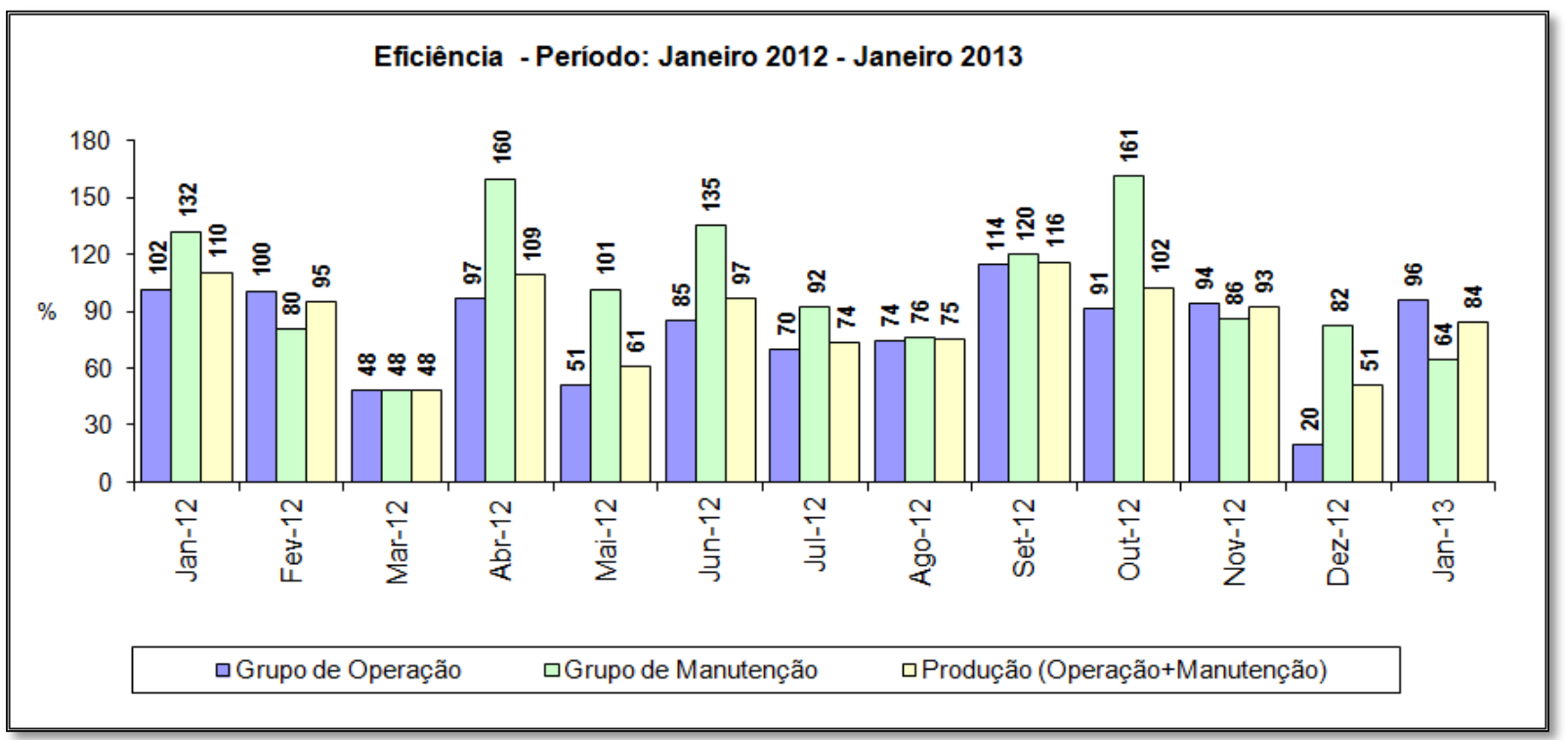

Figura 77 - Eficiência dos grupos de manutenção e operação.

\subsection{4 - Resultados operacionais}

O sistema computacional do Reator IEA-R1 com o seu banco de dados permite, que tenhamos acesso a variáveis importantes para o controle do processo de manutenção, bem como para as tomadas de decisões importantes sobre os equipamentos ou instrumentos utilizados na operação. A seguir são apresentados alguns resultados obtidos até janeiro de 2015.

\subsubsection{1 - Manutenção preventiva}

Total de equipamentos e medidores cadastrados: 1781.

Total de planos de manutenção preventiva: 63 , sendo:

- Planos de equipamentos: 54.

- Planos de instalação: 8.

- Planos de "Ageing" (envelhecimento): 1.

Total de registros de RMP emitidos: 13643.

Mês com mais RMP emitidos no ano: dezembro - média de 210.

Mês com menos RMP emitidos no ano: novembro - média de 100.

\subsubsection{2 - Manutenção corretiva}

Total de RMC emitidos: 1174

Equipamento que teve mais $R M C$ emitido:

- IC-MSC-01 (mesa de controle): 118 
RMC com maior tempo de execução:

- RMC 1079: 960 horas (troca da tubulação do circuito primário).

$R M C$ com o menor tempo de execução:

- RMC 999: 10 minutos (troca de rele térmico).

\subsubsection{3 - Calibração}

Total de instrumentos ou medidores no plano de calibração: 200.

Menor intervalo de calibração: 1 ano.

Maior intervalo de calibração: 5 anos.

Medidor com o maior tempo de execução da calibração:

- IC-SAD-01 (sistema de aquisição de dados) 12 horas, são calibrados 199 sinais de entrada e saída.

Medidor que tem o maior número de calibrações:

- RA-CDO-01, RA-CDO-02 (medidor de condutividade): 13.

Medidor que tem o menor número de calibrações:

- IC-SAD-02 (sistema de aquisição de dados- reserva): 1.

Tipo de medidores com o maior número no plano de calibração:

- Medidores de temperatura: $\mathbf{4 0 .}$ 


\section{6. - CONCLUSÃO}

O objetivo do trabalho foi alcançado uma vez que o sistema computacional desenvolvido no CRPq do IPEN-CNEN/SP para Planejamento e Controle da Manutenção do Reator de pesquisa IEA-R1 está concluído e em operação.

Os relatórios, registros de manutenções preventivas e corretivas, planos, listas de equipamentos, históricos de manutenções preventivas e corretivas, históricos de calibrações gerados pelos módulos são periodicamente auditados pelos órgãos reguladores como a CNEN, ABNT e AIEA [20].

O Sistema Computacional para Planejamento e Controle da Manutenção implementado no Reator IEA-R1 contempla a necessidade dos operadores e auditores que utilizam os seus registros para controlar, salvaguardar e manter integridade fisica do Reator, aumentando assim a vida útil dos equipamentos, contribuindo para que o Reator cumpra o seu papel na sociedade produzindo radioisotopos para medicina, pesquisa e desenvolvimento técnico e acadêmico.

Finalmente, o Sistema Computacional para Planejamento e Controle da Manutenção desenvolvido neste trabalho para o Reator pesquisa IEA-R1 pode ser aplicado em reatores ou instalações semelhantes, tendo em vista sua flexibilidade de utilização. Com uma base de dados sólida e confiável, está sendo utilizado por pesquisadores de outros centros do IPEN-CNEN/SP para pesquisa e trabalhos em áreas como engenharia, segurança e controle de processos.

Trabalho futuros podem, ser incorporados ao Sistema para Planejamento e Controle da Manutenção. Neste sentido, destacamos:

- Manutenção Preditiva;

- Programa de "Ageing" (envelhecimento da instalação do Reator);

- Descomissionamento. 


\section{ANEXO 1}

Tabela 1 - Código e descrição dos sistemas existentes no Reator, utilizados para classificar os equipamentos e medidores no programa computacional.

\begin{tabular}{|c|l|}
\hline Código & Descrição do Sistema \\
\hline AA & Laboratório de Análise por Ativação \\
\hline AC & Ar Comprimido \\
\hline CP & Circuito Primário de Refrigeração \\
\hline CS & Circuito Secundário de Refrigeração \\
\hline DR & Drenagem do Prédio do Reator \\
\hline EE & Distribuição Elétrica Essencial \\
\hline EN & Distribuição Elétrica Normal \\
\hline EV & Distribuição Elétrica Vital \\
\hline IA & Irradiação de Amostras \\
\hline IC & Instrumentação e Controle \\
\hline IE & lluminação de Emergência \\
\hline IN & lluminação Normal \\
\hline IR & Insuflamento e Recirculação \\
\hline ME & Manuseio e Estocagem de Combustível \\
\hline MN & Laboratórios de Metrologia Nuclear \\
\hline OM & Oficina Mecânica e de Apoio a Operaçâo e Manutençâo \\
\hline PI & Proteção e Combate a Incêndio \\
\hline RA & Retratamento de Água \\
\hline RE & Resfriamento de Emergência \\
\hline SI & Sistema de informática \\
\hline SC & Sistema de Movimentação de Carga \\
\hline SM & Sustentação e Movimentação \\
\hline SP & Sistema de Proteção Física \\
\hline SV & Sistema de Vibração \\
\hline TA & Tratamento de Agua \\
\hline TV & Sistema de Circuito Fechado de Televisão \\
\hline XC & Exaustão das Capelas \\
\hline XE & Exaustão de Emergência \\
\hline XN & Exaustão Normal \\
\hline & \\
\hline
\end{tabular}


Tabela 2 - Código e tipo de equipamentos e medidores usados para cadastramento no programa computacional.

\begin{tabular}{|c|l|}
\hline Código & Tipo de Equipamento/Medidor \\
\hline AAM & Auto Amostrador \\
\hline ACC & Acelerômetro \\
\hline ACD & Ar condicionado e Desumidificador \\
\hline AGT & Agitador \\
\hline AMC & Analisador Mono ou Multicanal \\
\hline AMP & Amplificador \\
\hline AME & Amperímetro \\
\hline ANI & Trocador Aniônico \\
\hline ASP & Aspirador de Pó \\
\hline ATD & Abrigo do Tanque de Decaimento \\
\hline BAL & Balança \\
\hline BCG & Bloco de Grafite \\
\hline BEM & Bomba de Engraxar Manual \\
\hline BOM & Bomba \\
\hline BRC & Barra de Controle \\
\hline BRM & Barômetro de Mercúrio \\
\hline BRS & Barra de Segurança \\
\hline CAF & Câmara de Fissão \\
\hline CAP & Coletor de Agua do Prédio do Reator \\
\hline CAT & Trocador Catiônico \\
\hline CAQ & Chapa Aquecedora \\
\hline CBT & Cabine de Alta Tensão \\
\hline CCC & Centro de Comando de CLP \\
\hline CCD & Célula do Condutivímetro \\
\hline CCM & Centro de Comando de Motores \\
\hline CCO & Centro de Comando Operacional \\
\hline CDO & Condutivímetro \\
\hline CDP & Condutivímetro Portátil \\
\hline CET & Controlador Eletrônico de Temperatura \\
\hline CFC & Condicionador 'Fan-Coil' \\
\hline CFL & Cabine de Fluxo Laminar \\
\hline CHA & Chaminé \\
\hline CMN & Canal de Medida Nuclear \\
\hline CMR & Câmera de TV \\
\hline CNB & Conjunto No-Break \\
\hline COL & Colorímetro \\
\hline CPA & Compressor de Ar \\
\hline CPE & Capela \\
\hline CPL & Caixa Plenum \\
\hline CRE & Condensador Remoto \\
\hline CRM & Carro de Ferramenta \\
\hline CSC & Condicionador Self-Contained \\
\hline CTD & Contador \\
\hline
\end{tabular}




\begin{tabular}{|c|l|}
\hline CTF & Centrífuga \\
\hline CTR & Cortadeira \\
\hline CVV & Chave de Vazão \\
\hline CXJ & Caixa de Junção \\
\hline DAE & Distribuidor de Água de Emergência \\
\hline DBR & Dobradeira \\
\hline DET & Detector /Medidor \\
\hline DIG & Disjuntor de Amostra \\
\hline DTA & Destilador de Água \\
\hline DTO & Duto de Ar \\
\hline EAA & Espectrômetro de Absorção Atômica \\
\hline EIF & Elemento de Irradiação de Fios \\
\hline EIG & Elemento de Irradiação com Grafite \\
\hline EIR & Elemento de Irradiação de Amostra \\
\hline EIS & Elemento de Irradição de Silício \\
\hline EIU & Elemento de Irradiacão de Amostra Geociência \\
\hline ELG & Eliminador de Gotas \\
\hline ELM & Eletrômetro \\
\hline ELV & Elevador \\
\hline EMP & Empilhadeira \\
\hline ESA & Estabilizador Analógico \\
\hline ESC & Máquina de Escovação \\
\hline ESM & Moto Esmeril \\
\hline EST & Estabilizador \\
\hline ETM & Estufa /Mufla \\
\hline ETT & Estação Terminal \\
\hline EXN & Extintor \\
\hline EXT & Exaustor \\
\hline FAA & Fonte de Corrente \\
\hline FAB & Filtro Absoluto \\
\hline FAC & Fac-Símile \\
\hline FAT & Fonte de Alta Tensão \\
\hline FBT & Bastidor com Fonte de Tensão \\
\hline FCA & Filtro de Carvão Ativado \\
\hline FAR & Filtro de Areia \\
\hline FCN & Filtro Cuno \\
\hline FFI & Filtro Fino \\
\hline FGR & Filtro Grosso \\
\hline FHE & Filtro HEPA \\
\hline FIS & Sistema de Injeção em Fluxo \\
\hline FNT & Fonte \\
\hline FUR & Furadeira \\
\hline GCR & Garra \\
\hline GDG & Grupo Diesel Gerador \\
\hline GFR & Geladeira, Freezer \\
\hline GPA & Gerador de Porta e Atraso \\
\hline GUH & Guincho Hidráulico \\
\hline GVR & Gravador Elétrico \\
\hline & \\
\hline
\end{tabular}




\begin{tabular}{|c|l|}
\hline HDR & Hidrante \\
\hline HOR & Horímetro \\
\hline HUB & Hube (Roteador) \\
\hline IMP & Impressora \\
\hline IND & Indicador \\
\hline INN & Indicador de Nível \\
\hline INP & Indicador de Posição \\
\hline INV & Indicador de Vazão \\
\hline IRF & Intercomunicador de Radio Freqüência \\
\hline ITF & Interfone \\
\hline LIO & Liofilizador \\
\hline LRM & Leito Misto de Resina \\
\hline LRS & Leito de Resina \\
\hline LRT & Leito de Retratamento \\
\hline MAB & Mecanismo de Acionamento de Barras \\
\hline MCP & Microcomputador \\
\hline MCV & Monitor Central de Vibração \\
\hline MDA & Medidor de Vazão de Ar \\
\hline MDD & Medidor de Depressão \\
\hline MDM & Multímetro \\
\hline MDN & Medidor do N16 \\
\hline MDP & Medidor de Pressão \\
\hline MDS & Medidor de Nível \\
\hline MDT & Monitor de Duto (Radiação) \\
\hline MDV & Medidor de Vazão \\
\hline MET & Metalizadora \\
\hline MFR & Medidor Fixo de Radiação \\
\hline MIC & Microscópio \\
\hline MNV & Monitor de Vibração \\
\hline MOT & Motor \\
\hline MPH & Medidor de pH \\
\hline MPI & Módulo de Potência Ininterrupta \\
\hline MPR & Medidor Portátil de Radiação \\
\hline MQS & Máquina de Solda \\
\hline MRA & Monitor de Radiação \\
\hline MSC & Mesa de Controle \\
\hline MSI & Módulo Soma Invertido \\
\hline MTA & Monitor de Área (Radiação) \\
\hline MTB & Motor da bomba \\
\hline MTD & Termômetro/Termohigrômetro \\
\hline MTP & Monitor Portal \\
\hline MTV & Motor do Ventilador \\
\hline MVA & Medidor de Vácuo \\
\hline OSC & Osciloscópio \\
\hline PAL & Painel de Alarme \\
\hline PAM & Pré-Amplificador \\
\hline PCI & Painel de Controle de Incêndio \\
\hline PCO & Painel de Comando \\
\hline & \\
\hline
\end{tabular}




\begin{tabular}{|c|l|}
\hline PCT & Porta de Coluna Térmica \\
\hline PCV & Painel de Comando de Válvula \\
\hline PFI & Pré-Filtro \\
\hline PHC & Poço/Eletrodo de Mercúrio \\
\hline PIP & Pipetador /Pipeta \\
\hline PLO & Placa de Orif́́cio \\
\hline PLS & Painel Sinótico \\
\hline POT & Potenciostato \\
\hline PRO & Ponte Rolante \\
\hline PRS & Prensa Hidráulica \\
\hline PSI & Processador de Sinal Integrado \\
\hline PSN & Painel de Sinalização \\
\hline PTM & Plataforma Móvel \\
\hline PTN & Plataforma do Núcleo \\
\hline PUA & Purificador de Água, Destilador \\
\hline PUL & Pulsador \\
\hline QCA & Quadro \\
\hline QDF & Quadro de Distribuição de Força \\
\hline QDV & Quadro de Válvulas \\
\hline QFF & Quadro de Força \\
\hline QFL & Quadro de Força e Luz \\
\hline RAQ & Resistência de Aquecimento \\
\hline RAU & Registro Automático \\
\hline RCF & Registro Corta Fogo \\
\hline RCO & Registro de Controle \\
\hline RDD & Registrador de Pena Dupla \\
\hline RDT & Registrador de Temperatura \\
\hline RDV & Registrador de Vazão \\
\hline REP & Registro Estanque com Pistão \\
\hline RGM & Registro de Vazão Manual \\
\hline RMO & Registro Modulante \\
\hline RMT & Registro Motorizado \\
\hline ROT & Rotâmetro \\
\hline RPP & Registro Estanque com Pistão Pneumático \\
\hline RSI & Resistor \\
\hline RSP & Registro de Sobrepressão \\
\hline RVA & Reservatório de Agua \\
\hline RVO & Registro de Volume \\
\hline SAR & Controle do Secador de Ar \\
\hline SEC & Secador de Ar Comprimido \\
\hline SEL & Seladora \\
\hline SEM & Secador Manual de Cabelo \\
\hline SET & Serra Elétrica \\
\hline SHT & Sistema Hidráulico para Movimentar a Coluna Térmica \\
\hline SLS & Skimmer \\
\hline SSC & Sensor de Calor \\
\hline SST & Sensor de Temperatura \\
\hline SUN & Separador de Névoa \\
\hline & \\
\hline
\end{tabular}




\begin{tabular}{|l|l|}
\hline TAC & Conversor de Tempo em Altura de Pulso \\
\hline TBC & Tubo Colimador \\
\hline TBU & Tubulação \\
\hline TCA & Trocador de Calor \\
\hline TDP & Transmissor Diferencial de Pressão \\
\hline TEL & Talha Elétrica \\
\hline TER & Termopar \\
\hline TLF & Telefone \\
\hline TMA & Talha Manual \\
\hline TMP & Timer, Temporizador \\
\hline TMS & Termostato \\
\hline TOM & Torno Mecânico \\
\hline TQD & Tanque de Decaimento \\
\hline TQA & Tanque de Ácido \\
\hline TQR & Tanque de Retenção \\
\hline TQS & Tanque de Salmoura \\
\hline TRE & Torre de Refrigeração \\
\hline TRF & Transformador Elétrico \\
\hline TRP & Transmissor de Pressão \\
\hline TRV & Transformador de Voltagem \\
\hline TVM & Monitor de TV \\
\hline UAB & Unidade de Abrandamento \\
\hline UCD & Unidade de Coincidência \\
\hline URE & Unidade de Retratamento \\
\hline URH & Unidade Recuperadora de Gás Helio \\
\hline VAF & Válvula Sistema de Filtro \\
\hline VAL & Válvula \\
\hline VAP & Vaso de Pressão \\
\hline VAR & Válvula Sistema de Resina \\
\hline VBB & Válvula Tipo Borboleta \\
\hline VBO & Válvula do Tipo Bóia \\
\hline VDG & Acelerador Van Der Graaf \\
\hline VES & Válvula Esfera \\
\hline VEP & Válvula Eletropneumática \\
\hline VGC & Ventilador Centrífugo \\
\hline VGM & Válvula Gaveta Motorizada \\
\hline VGV & Válvula Gaveta Manual \\
\hline VIS & Válvula de Isolamento \\
\hline VOG & Válvula Globo \\
\hline VTL & Ventilador \\
\hline VOL & Voltímetro (Medidor de Tensão) \\
\hline VTR & Válvula de Retenção \\
\hline & \\
\hline
\end{tabular}




\section{REFERÊNCIAS BIBLIOGRÁFICAS}

[1]Tung-Ming $\mathrm{Wu}$ and Sheue-Ling Hwang; Maintenance error reduction strategies in nuclear power plants, using root cause analysis, Applied Ergonomics 1989,20.2,115-121.

[2]Celso M. F. Lapa, Cláudio M. N. A. Pereira, Antônio Carlos de A. $\mathrm{Mol}$, Maximization of a nuclear system availability through maintenance scheduling optimization using a genetic algorithm, Nuclear Engineering and Design 196 (2000) 219-231.

[3]Kardec \& Nascif, Manutenção, Função Estratégica - Qualitymark Editora Ltda, RJ, 1999, 287p.

[4]Lourival A.Tavares, Controle de Manutenção por Computador. JR Editora Técnica, 1987, 214p.

[5]Gil Branco Filho, Planejamento e Controle de Manutenção curso ministrado pela Associação Brasileira de Manutenção, São Paulo, 2003, 62p.

[6]Norma CNEN NN - 1.04 "Licenciamentos de Instalações Nucleares", Resolução CNEN R 16/01-29.11.2001, D.O.U.: 05.01.2002, disponível no site da Comissão Nacional Energia Nuclear (CNEN).

[7]Norma CNEN NN - 1.16 "Garantia da Qualidade para Usinas Nucleoelétricas", Resolução CNEN R 15/99-21.09.1999, D.O.U.: 03.04.2000 disponível no site da Comissão Nacional Energia Nuclear (CNEN).

[8]Norma CNEN NN - 1.21 "Manutenções de Usinas Nucleoelétricas", Resolução CNEN R 03/91, D.O.U.: 28.08.1991, disponível no site da Comissão Nacional Energia Nuclear (CNEN).

[9]IAEA Safety Standards - Safety Guide No. NS-G-4.2 "Maintenance, Periodic Testing and Inspection of Research Reactors", Vienna, November 2006.

[10]Norma ABNT NBR ISO 9001:2008 - "Sistema de Gestão da Qualidade", 28.12.2008, disponível na intranet do Instituto de Pesquisas Energética e Nucleares, ou na Associação Brasileira de Normas Técnicas (ABNT). 
[11]Pressman, Roger. Software Engineering: A Practitioner's Approach, 6ª̣edição, Mc Graw Hill, 2005.

[12]Somera, Guilherme.(2007); Treinamento Profissional em Delphi. Digerati Books, São Paulo, 2007.

[13]De Medeiros, Luciano Frontino.(2006); Redes Neurais em Delphi - 2ª Edição. Visual Books, São Paulo, 2006.

[14]Pauli, Guinther. (2004); Delphi - Programação para Banco de Dados e Web. Neoficio, Rio de Janeiro, 2004

[15]Ramalho, José Antonio (2001); Delphi 5 Teoria e Prática, Série Ramalho, Editora Berkeley, 2a. Edição

[16]Marcelo Medeiros/Pablo Gonçalves, Criando uma Aplicação Comercial Completa em Delphi 5, Advanced Books

[17]Rogério Magela, "Engenharia de Software Aplicada: Princípios vol.1,"Editora Alta Books, 2006, 246p.

[18]Rogério Magela, "Engenharia de Software Aplicada: Princípios vol.2, "Editora Alta Books, 2006, 294p.

[19]Leonardo Molinari, "Gerência de Configuração - Técnicas e Práticas no Desenvolvimento de Software“, Editora Visual Books, 2007, 857502-210-5.

[20]IAEA, "Quality Assurance for Software Important to Safety", Vienna, 2000. 161 p. (Technical Reports - Series, 397).

[21]The Babcock \& Wilcox Co., Open-Pool Research Reactor Instruction Book,1957.

[22] Instituto De Pesquisas Energéticas e Nucleares (IPEN), Relatório de Análise de Segurança do Reator IEA-R1.

[23]Falconi Campos, Vicente - Gerência da Qualidade Total Estratégia para Aumentar a Competitividade da Empresa Brasileira, Bloch Editores, Rio de Janeiro, 1990, 187p. 
[24]IAEA Nuclear Energy Series No. NP-T 5.4 "Optimization of Research Reactor Availability and Reliability: Recommend Pratices", Vienna, November 2008.

[25]INMETRO - "Vocabulário Internacional de Metrologia: Conceitos Fundamentais e Gerais e Termos Associados", Rio de Janeiro, 2012, 94p.

[26]INMETRO - "Vocabulário Internacional de Termos Fundamentais e Gerais de Metrologia", Portaria INMETRO № 029/95, INMETRO,SENAI Departamento Nacional, 5ª Edição, Rio de Janeiro, 2007, 72p.

[27]ABNT, INMETRO, SBM, - "Guia Para a Expressão da Incerteza de Medição", Rio de Janeiro, 1998, 121p.

[28]INMETRO - "Sobre Acreditação de Laboratórios", $<$ http://www.inmetro.gov.br/credenciamento/sobre lab.asp $>$ Acesso em: 14.mar.2014.

[29]Antonio Neris, ASP.NET Aplicações Rápidas e Práticas para Iniciantes" Editora Book Express, 2005,120p.

[30]Robin Dewson, "Microsoft, SQL Server 2008 para Desenvolvedores: Do Iniciante ao Professional“, Editora Alta Books, 2009, $376 p$. 